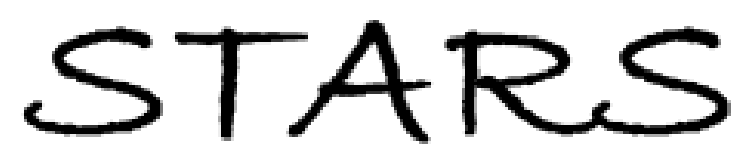

University of Central Florida

STARS

\title{
A Quasi-Experiment Examining Expressive and Receptive Vocabulary Knowledge of Preschool Head Start Children Using Mobile Media Apps
}

Angela Vatalaro

University of Central Florida

Part of the Education Commons

Find similar works at: https://stars.library.ucf.edu/etd

University of Central Florida Libraries http://library.ucf.edu

This Doctoral Dissertation (Open Access) is brought to you for free and open access by STARS. It has been accepted for inclusion in Electronic Theses and Dissertations, 2004-2019 by an authorized administrator of STARS. For more information, please contact STARS@ucf.edu.

\section{STARS Citation}

Vatalaro, Angela, "A Quasi-Experiment Examining Expressive and Receptive Vocabulary Knowledge of Preschool Head Start Children Using Mobile Media Apps" (2015). Electronic Theses and Dissertations, 2004-2019. 728.

https://stars.library.ucf.edu/etd/728

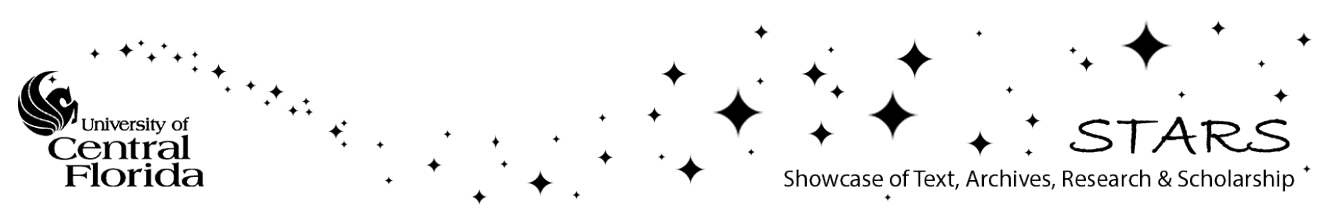


A QUASI-EXPERIMENT EXAMINING EXPRESSIVE AND RECEPTIVE VOCABULARY KNOWLEDGE OF PRESCHOOL HEAD START CHILDREN USING MOBILE MEDIA APPS

ANGELA VATALARO

B.S. University of Central Florida, 2008

M.Ed. University of Central Florida, 2010

A dissertation submitted in partial fulfillment of the requirements

for the degree of Doctor of Philosophy

in the College of Education and Human Performance

at the University of Central Florida

Orlando, Florida

Summer Term

2015

Major Professor: Anne McDonald Culp 
(C) 2015 Angela Vatalaro 


\begin{abstract}
The American Academy of Pediatrics $(1999,2011)$ recommends no screen time for children under two years and limited screen time for three- and four-year-olds. Despite these recommendations, most young children have easy access to various types of screens. In particular, children's use of mobile media, including tablets and other touch screen devices, is increasing (Common Sense Media, 2013). Even though scholars have highlighted positive uses for mobile media (Christakis, 2014; Radesky, Schumacher, \& Zuckerman, 2015) and there are recommendations in place for using mobile media with young children in active, open-ended ways (NAEYC \& Fred Rogers Center, 2012), there has been very limited research conducted on the impact of mobile media on young children's development. What is more, as early childhood professionals are beginning to incorporate mobile media into their classrooms, they are struggling with the ability to use these devices in developmentally appropriate ways (Marklund, 2015; Nuttall, Edwards, Mantilla, Grieshaber, \& Wood, 2015).

The primary purpose of the present study was to examine the efficacy of using different types of mobile media apps to increase the receptive and expressive vocabulary development of preschool children living in economically disadvantaged communities. Children and teachers in four Head Start classrooms participated in the quasiexperimental study, which included an eight-week intervention in which the children interacted with one of two types of apps: one classroom used direct instruction vocabulary apps $(n=16)$ and one classroom used open-ended vocabulary apps $(n=15)$. Two classrooms served as control groups $(n=18 ; n=14)$ which used apps that were
\end{abstract}


chosen by the Head Start program with no specific instructional method. Children's vocabulary was assessed pre- and post-intervention. To assess receptive vocabulary, the PPVT-4 (Dunn \& Dunn, 2007) and an iPad Receptive Vocabulary Assessment (Vatalaro, 2015a) were used. To assess expressive vocabulary, the EVT-2 (Williams, 2007) and an iPad Expressive Vocabulary Assessment (Vatalaro, 2015b) were used. Using a repeated measures analysis of variance with split plot analysis, children who used direct instruction apps performed statistically significantly higher on the PPVT-4 than children who used open-ended apps. Children in the direct instruction app group also performed statistically significantly higher than both control groups on the iPad Receptive Vocabulary Assessment. There were no statistically significant differences between groups for receptive vocabulary as measured by the EVT-2. However, when children were credited for describing a function instead of the iPad vocabulary word, the analysis of the iPad Expressive Vocabulary Assessment revealed that the children using direct instruction apps performed statistically significantly higher than children using openended apps and the children in one of the control groups.

A secondary purpose of the present study was to examine the use of apps in mobile media by Head Start teachers. The teachers in the two intervention classrooms participated in weekly meetings with the primary researcher for support in using mobile media in their classrooms in order to ensure that the child intervention was carried out with fidelity. After analyzing data from teachers' self-report daily logs across the eightweek intervention, it was determined that the children received instruction on the assigned apps in both intervention classrooms. 
Although caution is given to the findings due to some limitations such as the quasi-experimental choice of a research design and the number of participants, the present study contributed to the early childhood research literature with the findings that interactive, animated apps which provide the meanings of vocabulary words in a direct instruction manner may have the ability to increase a child's receptive vocabulary, and to increase a child's descriptive definitions of iPad functions. This information increases the chance that teachers in Head Start will begin using direct instruction apps, in the hope of increasing a child's vocabulary knowledge. 
For Bella 


\section{ACKNOWLEDGMENTS}

I would like to acknowledge and extend my gratitude to the many people who supported me in my doctoral studies. In particular, thank you to my family who always listened to me, even when they did not understand what I was talking about. Thank you to my parents, Ron and Anne Vatalaro, who gave me a rent-free place to live and always called to check up on me on late nights. To my brother Ronny and sister-in-law Samantha, for their encouragement and enthusiasm. To my brother Ryan whose skepticism always kept me on my toes. Finally, to my niece Bella, who let me know which apps were worthy of her "profile" and which apps should be deleted, who would often open the app with the animated planet Uranus just so we could laugh, and who accepted in stride all of the time I spent "at work."

This research could not have been completed without the support of Head Start. Thank you to the district manager for getting the study approved, to the technology program specialist for coordinating the placement of the apps on the iPads, to the center director for opening her site to me, to the education coordinator for making sure I always had everything I needed, and to the four teachers and four teachers' assistants for welcoming me in to their classrooms. In particular, thank you to the children in the Head Start classrooms whose curiosity and welcoming hugs kept me going.

I also had an excellent team of UCF student research assistants who helped me with assessment at the Head Start site. Thank you to Taylor Buongiorno, Sheridan Kushner, Stephanie Propst, Brooke Rusoff, Rachel Sherman, and Cathy Twyman for your professionalism, flexibility, and enthusiasm for assessment. In particular, thank you 
to Amanda Barnes, whose eagerness to learn about research was inspiring and who went above and beyond to ensure the quality of my data.

I am forever grateful to my mentors, committee members, and UCF ECDE family. Thank you to Lap Nguyen, who embarked on this $\mathrm{PhD}$ journey with me and helped me to realize when it was time to take a break. I am grateful to Dr. Judit Szente who encouraged me to enroll in the $\mathrm{PhD}$ program, supported publication efforts, and was always willing to assist me. Thank you to Dr. Judy Levin who believed in me throughout my undergraduate, masters, and doctoral careers and who, despite being the hardest working person I know, was never too busy to listen. Thank you to Dr. Debbie HahsVaughn for her expertise in statistics and always finding time to assist when I needed guidance. Thank you to Dr. Rex Culp for his encouragement and enthusiasm. Thank you to Dr. Laurie Campbell for being a wonderful mentor and support system. I would also like to thank Ms. Jill Goodman for providing expert advice on the apps chosen for this study and guiding me in the development of the iPad assessments and intervention plans. Finally, thank you to my chair, Dr. Anne Culp, who raised the bar for my research, awakened a passion for assessment that I did not know I had, and answered my many emails with much patience. 


\section{TABLE OF CONTENTS}

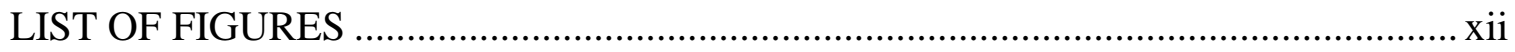

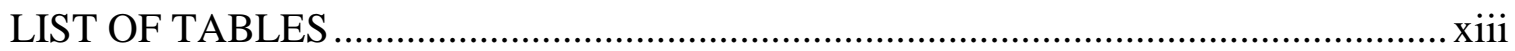

CHAPTER 1 THE PROBLEM AND ITS CLARIFYING COMPONENTS ....................... 1

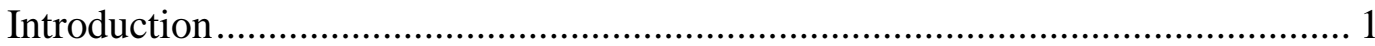

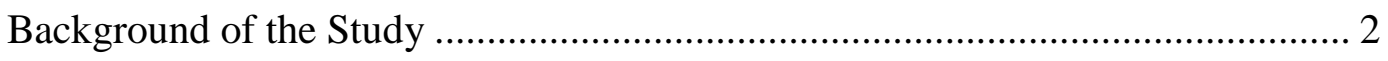

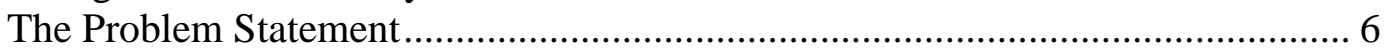

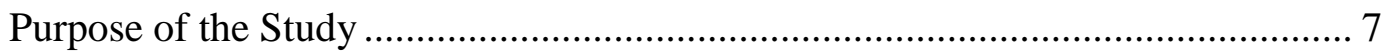

Research Questions ..................................................................................... 7

Limitations and Delimitations........................................................................ 8

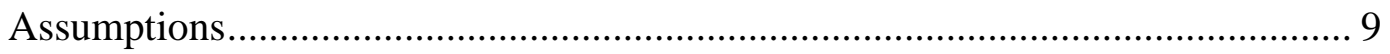

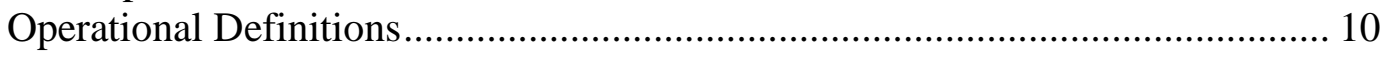

Summary and Organization of the Study .......................................................... 12

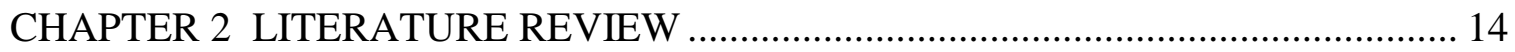

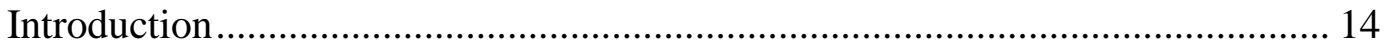

Examining the American Academy of Pediatrics (AAP) Position Statements..... 15

Screen Time: Active Versus Passive ....................................................... 19

Impact of the American Academy of Pediatrics' (AAP) Position

Statements .......................................................................................... 20

Review of Empirical Research on Young Children and Mobile Media ............... 23

Method for Information Retrieval............................................................ 23

Personal Digital Assistants (PDAs) and Handheld Computers ................. 27

Smart Phones and Tablet Devices............................................................ 29

Teacher Perspectives.............................................................................. 35

Summary of the Review of Empirical Research...................................... 39

Vocabulary Development, Young Children, and Technology............................... 40

Interventions in Preschool Classrooms ................................................................... 43

Theoretical Perspectives ................................................................................ 45

Sociocultural Perspective...................................................................... 45

Cognitive Development Perspective ......................................................... 47

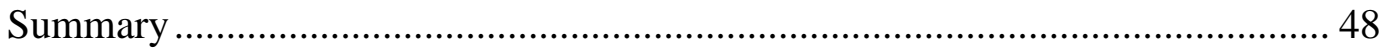

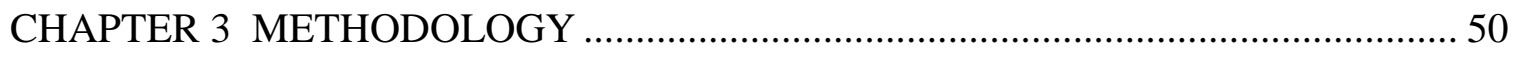

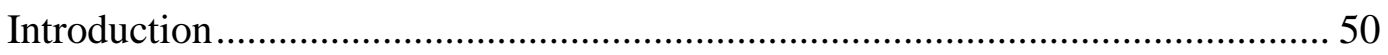

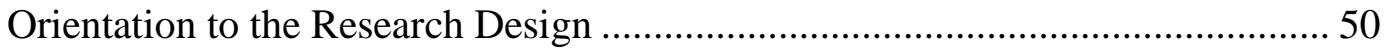

Population and Sample .................................................................................... 50

Power Analysis for Sample Size........................................................ 52

Intervention and Control Groups ................................................................ 52

Intervention Program ……………………………………………..... 52

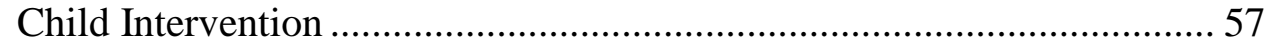

Control Groups....................................................................................... 59 


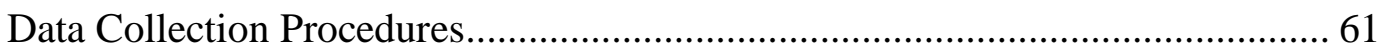

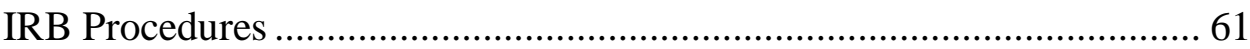

Recruitment of Assessors and Administration of Assessments ................. 62

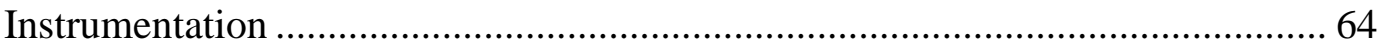

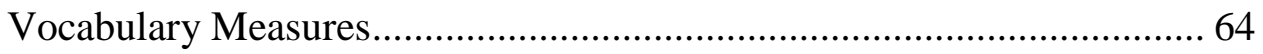

Family Technology Ownership and Use Survey ..................................... 71

Teacher Technology Perception and Use Survey ...................................... 74

Teacher Self-Report and Observation Checklist......................................... 76

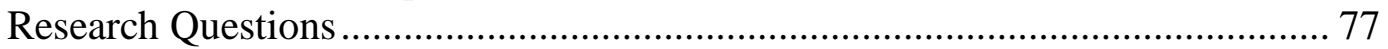

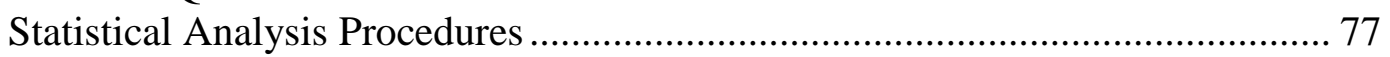

Research Questions 1 and 2 ............................................................. 77

Research Question 3 ...................................................................... 78

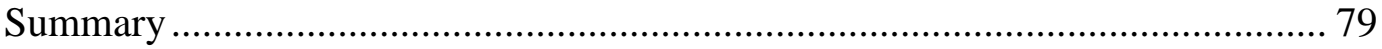

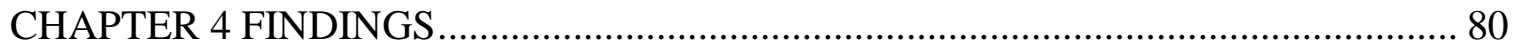

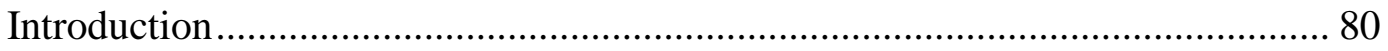

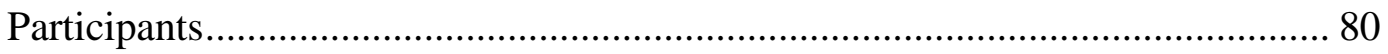

Characteristics of Child Participants ...................................................... 80

Characteristics of Teacher Participants .................................................. 84

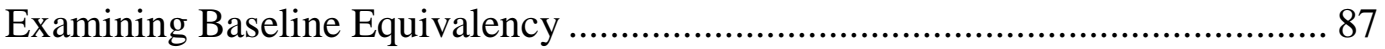

Receptive Vocabulary Measures............................................................ 89

Expressive Vocabulary Measures ............................................................ 91

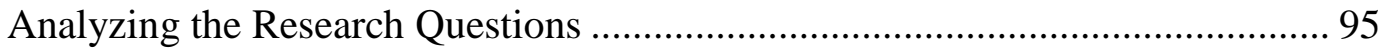

Research Question 1 ......................................................................... 95

Research Question 2 .................................................................... 111

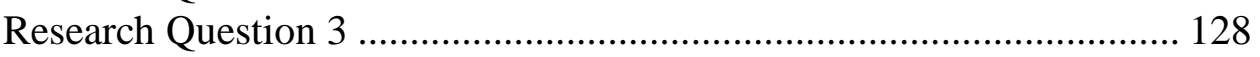

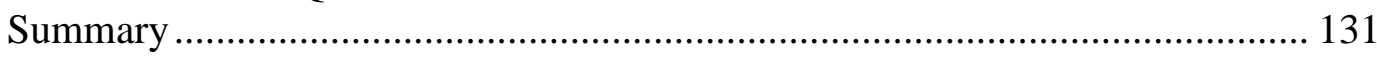

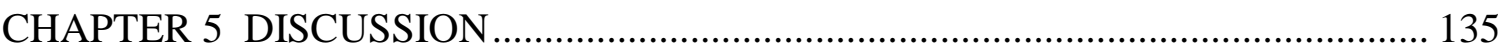

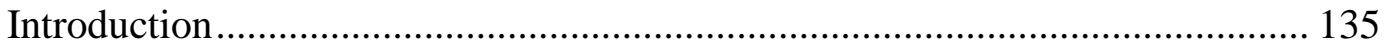

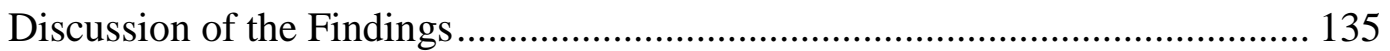

Research Questions 1 and 2 ......................................................... 135

Research Question 3 ....................................................................... 142

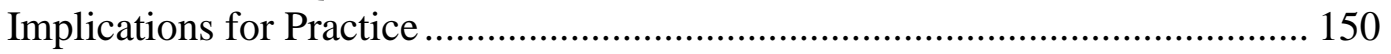

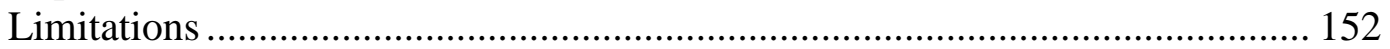

Recommendations for Further Research......................................................... 154

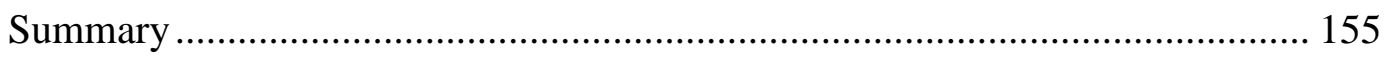

APPENDIX A IRB APPROVAL LETTER ……………...................................... 157

APPENDIX B HEAD START-CHOSEN APPS ……………………...................... 160

APPENDIX C WEEKLY INTERVENTION AGENDAS............................................ 162

APPENDIX D iPAD RECEPTIVE VOCABULARY ASSESSMENT ....................... 173 
APPENDIX E iPAD EXPRESSIVE VOCABULARY ASSESSMENT ................... 186 APPENDIX F ENGLISH FAMILY TECHNOLOGY OWNERSHIP AND USE SURVEY.

APPENDIX G SPANISH FAMILY TECHNOLOGY OWNERSHIP AND USE SURVEY.

APPENDIX H TEACHER TECHNOLOGY PERCEPTION AND USE SURVEY.. 213 APPENDIX I TEACHER SELF-REPORT AND OBSERVATION CHECKLIST ... 221 


\section{LIST OF FIGURES}

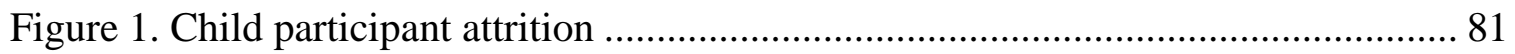

Figure 2. Plot of the within-between subjects interaction effect for the iPad Receptive

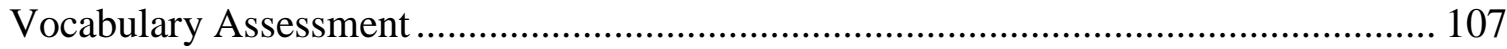

Figure 3. Plot of the within-between subjects interaction effect for the iPad Receptive Vocabulary Assessment with outlier removed ..................................................... 111

Figure 4. Plot of the within-between subjects interaction effect for the EVT-2 GSV scores

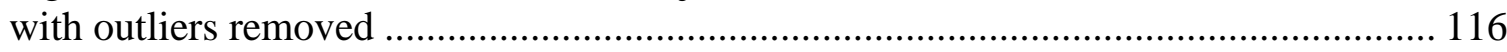

Figure 5. Plot of the within-between subjects interaction effect for the iPad Expressive Vocabulary Correct Word Assessment with outliers removed .................................. 121

Figure 6. Plot of the within-between subjects interaction effect for the iPad Expressive Vocabulary Correct Word or Description Assessment with outliers removed ............... 126 


\section{LIST OF TABLES}

Table 1 Side-by-Side Comparison of Direct Instruction, Open-Ended, and Head StartChosen Apps 56

Table 2 Frequencies for Individual Characteristics of Children by Classroom................ 83

Table 3 Frequencies for Individual Characteristics of Teachers .................................... 86

Table 4 Mean, Standard Deviation, and Range for Individual Characteristics of Teachers

Table 5 One-Way ANOVA Results for Pre-Assessment Baseline Equivalency............ 88

Table 6 Post Hoc Analysis for Pre-Assessment Baseline Equivalency for PPVT-4 GSV

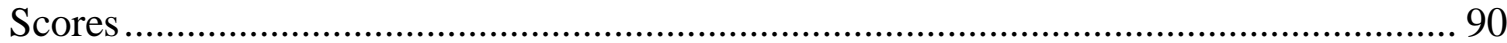

Table 7 Post Hoc Analysis for Pre-Assessment Baseline Equivalency for iPad Expressive Vocabulary Correct Word or Description Scores .............................................................. 94

Table 8 ANOVA Within-Subjects Effects for PPVT-4 GSV Scores ............................... 98

Table 9 ANOVA Within-Subjects Main Effects for PPVT-4 GSV Scores With Outlier

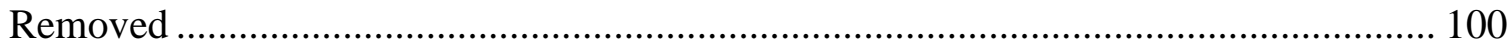

Table 10 ANOVA Between-Subjects Main Effects for PPVT-4 GSV Scores With

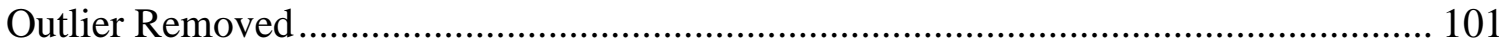

Table 11 Post Hoc Analysis for Between-Subjects Effects for PPVT-4 GSV Scores With Outlier Removed ............................................................................................... 102

Table 12 ANOVA Within-Subjects Effect and Within-Between Subjects Interaction Effect for iPad Receptive Vocabulary ........................................................................... 105

Table 13 ANOVA Between-Subjects Main Effects for iPad Receptive Vocabulary

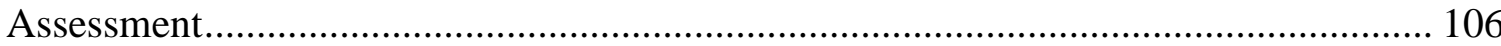

Table 14 Post Hoc Analysis for Between-Subjects Effects for iPad Receptive Vocabulary 108

Table 15 ANOVA Between-Subjects Main Effects for iPad Receptive Vocabulary Assessment With Outlier Removed 109

Table 16 Post Hoc Analysis for Between-Subjects Effects for iPad Receptive Vocabulary Scores With Outlier Removed.. 
Table 17 ANOVA Within-Subjects Effect and Within-Between Subjects Interaction Effect for EVT-2 GSV Scores With Outliers Removed....

Table 18 ANOVA Within-Subjects Effect and Within-Between Subjects Interaction Effect for iPad Expressive Vocabulary Correct Word Assessment With Outliers Removed

Table 19 ANOVA Within-Subjects Effect and Within-Between Subjects Interaction Effect for iPad Expressive Vocabulary Correct Word or Description Assessment With Outliers Removed

Table 20 ANOVA Between-Subjects Main Effects for iPad Expressive Vocabulary Correct Word or Description Assessment With Outliers Removed ............................ 125

Table 21 Post Hoc Analysis for Between-Subjects Effects for iPad Expressive Vocabulary Correct Word or Description Assessment With Outliers Removed.....

Table 22 Frequency of App Use in Intervention Classrooms (in Minutes).....

Table 23 Intervention Teachers' Perceptions of Developmental Appropriateness of App

Use in the Classroom ..... 130 


\section{CHAPTER 1 \\ THE PROBLEM AND ITS CLARIFYING COMPONENTS}

\section{$\underline{\text { Introduction }}$}

Mobile, screen-based technologies are becoming a staple in the lives of young children despite recommendations from the American Academy of Pediatrics (AAP) for strictly limiting the exposure to all screens for children from birth through age eight (American Academy, 1999, 2011). A casual walk through stores selling merchandise for infants and toddlers reveals numerous products which encourage putting mobile, screenbased technologies in children's hands, including iPhone and iPad cases shaped like rattles, inflatable blocks and sports cars with popular children's television characters, and even a potty training seat. Further, the presence of screen-based technologies specifically packaged for children has increased. One such device, the LeapPad ${ }^{\mathrm{TM}}$ Ultra, boasts $1,000+$ "educator approved" applications (apps) and has been marketed to children four to nine years old (LeapFrog Enterprises, 2014). With the proliferation of screen-based technologies in young children's lives, it is time to move beyond the notion of banning or limiting screens; and it is vital to examine the ways in which screen-based technologies can contribute to children's development in appropriate ways.

This chapter provides an overview of the dissertation study which was focused on investigating the efficacy of using apps to increase the receptive and expressive vocabulary knowledge of preschool children living in economically disadvantaged households. The background of the study contains an overview of the role of technology in $21^{\text {st }}$ century learning, the state of the screen time debate in the early childhood field, 
the importance of vocabulary in child development, and the critical need for young children living in economically disadvantaged communities to have rich language experiences and access to mobile media technologies. Also introduced are: (a) the problem statement, (b) the purpose of the present study, (c) research questions, (d) limitations and delimitations, (e) assumptions, and (f) operational definitions. Each area is discussed in detail in subsequent chapters of the dissertation.

\section{Background of the Study}

Information, communication, and technology (ICT) literacy--the ability to use technology to learn, solve problems, share ideas, and communicate with others--is a vital $21^{\text {st }}$ century skill (Partnership for $21^{\text {st }}$ Century Skills, 2011). In order to support ICT literacy, the U.S. Department of Education (2010) formulated a National Educational Technology Plan (NETP) which cast the use of technology as the main component of teaching, learning, and assessment. In fact, numerous technology standards have been adopted, particularly the standards developed by the International Society for Technology Education (ISTE). ISTE includes standards for students (ISTE Standards•S, 2007), teachers (ISTE Standards•T, 2008), and administrators (ISTE Standards•A, 2009), all of which aim to place technology at the forefront of learning.

In addition to ICT literacy becoming a national goal, technology has become a consistent presence in the lives of young children. Children are now continuously exposed to technology (O’Mara \& Laidlaw, 2011) in such a way that if they do not have consistent access to various forms of technology their experiences may be limited 
(Charlton, Panting, \& Hannan, 2002), and they could be excluded from interactions with peers (Leung \& Wei, 1999). In particular, children's use of screen-based technologies-television/DVDS, video games, e-readers, smartphones, tablets, and other mobile devices--has been increasing (Rideout, 2014). Screen-based technologies can be further broken down into two categories: traditional screen media (e.g., television/DVDS, video games, and computers), and mobile media (e.g., smartphones, tablets, and other mobile devices).

Data from Common Sense Media (2013) sheds light on children's experiences with screens. Traditional screen media, especially television, remains the primary screen in children's lives. Yet, children's exposure to mobile media has been increasing. In $2011,10 \%$ of children under the age of two had used a mobile device; in 2013, use of mobile devices by children under two increased to $38 \%$. Additionally, in $2013,17 \%$ of children from zero to eight years old used a mobile device daily, an increase from $8 \%$ in 2011. Furthermore, during a typical day, children from the ages of zero to eight years spent 15 minutes per day using a mobile device in 2013 as compared to five minutes per day in 2011. Children's usage of mobile media will continue to rise as parents have more access to mobile media devices (Common Sense Media, 2013).

The increasing presence of various types of screens in children's lives remains controversial. The AAP recommends a child should not be exposed to any screen before the age of two years. In like manner, screen time for children ages three and four years should be strictly limited to 30 minutes per day (American Academy, 1999, 2011). However, the AAP primarily used research centered on traditional screen media to draw 
its conclusions about the potential harmful consequences of screen time. Traditional screen media is different than mobile media in that traditional screen media often encourages passive, non-interactive consumption of media (Sweetser, Johnson, Ozdowska, \& Wyeth, 2012). A growing number of early childhood scholars and organizations, including the National Association for the Education of Young Children (NAEYC) and the Fred Rogers Center for Early Learning and Children's Media (2012) have differentiated between the passive screen time the AAP position statements were built upon and active screen time. From the active versus passive viewpoint, the quality of screen time is more important than the quantity.

Although there have been conflicting views about young children's exposure to and use of screens, in reality there has been very little research centered on young children and mobile media. Thus, beyond knowledge of the amount of children's exposure to mobile media (Common Sense Media, 2013), the early childhood community has not demonstrated a solid understanding of how mobile media affects child development. The notion that screens reduce social interactions has been presented as one argument for banning and/or limiting screen time (American Academy, 1999, 2011). Therefore, a starting place for research on child development and mobile media can be established by understanding how active screen time using mobile media can impact social development in the form of speech and language development of young children. Vocabulary knowledge is one facet of language development that progresses rapidly in the early childhood years and is a precursor to later academic success (Bloom, 1991; Bochner \& Jones, 2003; Hart \& Risley, 1995). Vocabulary knowledge is also impacted 
by economic status. In their research, Hart and Risley $(1995,2003)$ discovered that children whose families were economically disadvantaged were exposed to 30 million fewer words than children whose families were not economically disadvantaged.

In addition to experiencing disparities in vocabulary knowledge, researchers have found that children from families who are economically disadvantaged do not have consistent access to technology. This is referred to as the digital divide and app gap (Common Sense Media, 2013). In 2013, children with parents earning less than $\$ 30,000$ per year experienced gaps in ownership of both traditional screen media and mobile media devices. Though the ownership of smartphones and tablet devices has increased, mobile media ownership, particularly tablet devices, is lowest for families earning the lowest incomes. Parents in the lower income bracket have also been less likely to download apps that are considered educational for young children.

Because ICT literacy is imperative for $21^{\text {st }}$ century learners (ISTE Standards $\bullet \mathrm{S}$, 2007; Partnership for $21^{\text {st }}$ Century Skills, 2011; U.S. Department of Education, 2010), it is vital for all children to have developmentally appropriate interactions (i.e., active engagement) with mobile media. Mobile media are beginning to be incorporated into early childhood education settings. Despite the creation of developmentally appropriate guidelines for using mobile media with young children (NAEYC \& Fred Rogers Center, 2012), teachers lack in confidence and knowledge in how to incorporate mobile media in classroom settings (Masoumi, 2015; Nuttall, Edwards, Mantilla, Grieshaber, \& Wood, 2015). Thus, research conducted to examine the efficacy of using mobile media as a tool 
in the classroom would require that the researcher give support to the teachers in order to ensure high fidelity in intervention provided to the children.

\section{$\underline{\text { The Problem Statement }}$}

Some scholars believe that a child's exposure to any type of screen (e.g., television/DVDs, video games, computers, smartphones, and tablets) is detrimental to child development (American Academy, 1999, 2011). With vocabulary development being a vital developmental process for young children (Bloom, 1991; Bochner \& Jones, 2003; Hart \& Risley, 1995), there has been concern that extensive exposure to screens can cause additional harm (Levin, 2013). Moreover, children whose families are economically disadvantaged have received less exposure to rich vocabulary experiences than children whose families are economically advantaged (Hart \& Risley, 1995, 2003).

On the other hand, some scholars (NAEYC \& Fred Rogers Center, 2012) have expressed the belief that carefully selected activities involving screens can be a positive addition to children's development because ICT literacy, including mobile media use, is imperative for $21^{\text {st }}$ century learners (Partnership for $21^{\text {st }}$ Century Skills, 2011; U.S. Department of Education, 2010). Yet, early childhood educators, at the time of the present study, lacked the confidence and knowledge needed to use mobile media as a teaching tool in the classroom (Masoumi, 2015; Nuttall et al., 2015). Without a strong body of research, the screen time debate in the early childhood field cannot progress. Therefore, in order to move the field forward, empirical research needed to be conducted on the impact of mobile media in young children's lives. 


\section{Purpose of the Study}

In the present study, the researcher sought to examine several critical issues in the early childhood field: (a) the need to understand if mobile media can offer positive benefits to child development; (b) the need to increase the vocabulary knowledge of children living in economically disadvantaged communities; and (c) the need for ICT literacy in all $21^{\text {st }}$ century learners. Thus, the purpose of this study was to examine the efficacy of using different types of mobile media apps to increase the receptive and expressive vocabulary development of preschool children living in economically disadvantaged communities. A secondary purpose was to examine how much teachers used mobile media apps in their classrooms in order to ensure fidelity of the child intervention.

\section{$\underline{\text { Research Questions }}$}

The research questions that were addressed in this study included the following:

1. Is there a mean difference over time (pre to post) in receptive vocabulary (as measured by PPVT-4, Dunn \& Dunn, 2007; and iPad Receptive Vocabulary Assessment, Vatalaro, 2015a) of preschool Head Start children based on iPad apps in the classroom (open-ended/creative apps versus direct instruction apps versus Head Start-chosen apps)?

2. Is there a mean difference over time (pre to post) in expressive vocabulary (as measured by EVT-2, Williams, 2007; and iPad Expressive Vocabulary Assessment, Vatalaro, 2015b) of preschool Head Start children based on iPad 
apps in the classroom (open-ended/creative apps versus direct instruction apps versus Head Start-chosen apps)?

3. Within the intervention classrooms, what is the frequency of and how do Head Start teachers report using apps in the classroom?

\section{$\underline{\text { Limitations and Delimitations }}$}

As with any research, the present study posed several limitations. First, since 2007, Head Start programs have been required to have a monthly daily attendance average of no less than $85 \%$ (Head Start Act, 2007). Children with excessive absences may be dropped from the Head Start program. Therefore, subject attrition occurred in this study because some children were not consistently present in the classroom during the intervention and others dropped from the Head Start program before post-assessment data were collected.

Second, only four classrooms were examined in the study. The small sample size, along with the fact that a convenience sample of four Head Start classrooms in a large southeastern school district was used, limited the generalizability and power (i.e., increased the likelihood of committing a Type II error of incorrectly failing to reject false null hypotheses). Further, every teacher had a different level of proficiency and an experimental effect could have occurred if a teacher in one of the groups was more skilled than a teacher in the other groups. Next, because of guidelines from Head Start, children in the intervention classrooms also had access to control classroom apps. Other than researcher direct observation, there was not a consistent measure for which apps 
were used and for the duration of use. Finally, the present study was not a true experimental study as there was no random assignment of participants. This, according to Gall, Gall, and Borg (2007), constitutes a limitation.

In order to conduct the research, the present study was delimited in several ways. First, due to time constraints, the researcher only examined four classrooms over an eight-week period. Choosing the Head Start program ensured that the classrooms served children living in economically disadvantaged communities. The specific center was chosen by the district Head Start manager, and the classrooms were chosen by the center director based on her perception of the teachers' willingness to participate in the study.

Furthermore, all pre-test data were collected one week before the intervention began. For children in the intervention classrooms, all post-test data were collected within one week after the intervention ended. For children in the control classrooms, all post-test data were collected within two weeks after the intervention ended. Finally, the teachers in the intervention groups were the only teachers to receive mentoring from the doctoral student researcher in order to ensure program fidelity of the child intervention. The teachers in the control groups did not receive any contact from the researcher other than collecting the pre- and post-test data and conducting periodic observations to determine how apps were being used in their classrooms.

\section{$\underline{\text { Assumptions }}$}

Prior to the beginning of this study, several assumptions were made. First, because the children were enrolled in a Head Start program, it was assumed that they 
were living in economically disadvantaged communities and, as per current research (Common Sense Media, 2013), children in the study would have some access to mobile media apps at home. Second, the teachers in each classroom would have comparable teaching backgrounds (e.g., highest degree earned, teaching experience, use the same curricula). Third, the primary researcher, who had guidance from an app researcher, held a teaching certificate in early childhood education, and had conducted a thorough literature review was qualified to assist the teachers in the intervention groups to ensure children were using mobile media apps as intended by the intervention. Finally, university undergraduate and graduate students, who had been trained in previous coursework, participated in reliability training, and were supervised by the primary researcher, were qualified to administer the assessments.

\section{Operational Definitions}

Application (app): Software that is downloaded on a mobile media device for a specific purpose.

Children living in low-income families; children from economically disadvantaged communities/households/families: Children whose family's total income falls within the U.S. Department of Health and Human Services' 2014 Poverty Guidelines. In 2014 , for a family of two, the poverty guideline was $\$ 15,730$. This amount increased by $\$ 4,060$ for each additional family member (e.g., for a family of three, the guideline was $\$ 19,790$; for a family of four, the guideline was $\$ 23,850$, etc.). A 
child whose family falls within the poverty guidelines qualifies for the Head Start program (Head Start Act, 2007).

Cognitively active screen time: Use of screen media that encourages problem solving and creative thinking (Sweetser et al., 2012).

Expressive language vocabulary: Words that are mentally retrieved and expressed aloud. For the purposes of this study, this was measured by the EVT-2 (Williams, 2007) and iPad Expressive Vocabulary Assessment (Vatalaro, 2015b).

Head Start: A federal education program designed to serve the well-being of children from birth through age five years who are living in economically disadvantaged families (Head Start Act, 2007).

Information, communication, and technology (ICT) literacy: The ability to use technology to learn, solve problems, share ideas, and communicate with others (Partnership for 21st Century Skills, 2011).

iPad: A mobile tablet computer manufactured by Apple, Inc.

iTunes: The platform (i.e., store) used to purchase and download apps on the iPad. Language development: The definition of language will be derived from sociocultural theory (Vygotsky, 1978). Therefore, language will be considered as the connection of inner thought and oral speech to mental cognition that is developed through interactions with a person's social and cultural environment.

Mobile media: Hand-held, portable devices that can be used to access information and perform applications (Simon \& Nemeth, 2012). Includes smartphones, tablets, and other mobile devices. 
Passive screen time: Use of screen media that encourages sedentary, noninteractive responses (Sweetser et al., 2012).

Physically active screen time: Use of screen media that encourages physical activity, including games on platforms that are similar to physical exercise (Sweetser et al., 2012).

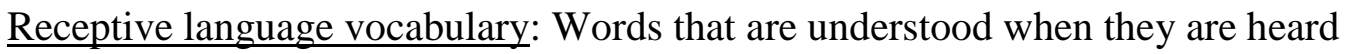
or read. For the purposes of this study, this was measured by the PPVT-4 (Dunn \& Dunn, 2007) and iPad Receptive Vocabulary Assessment (Vatalaro, 2015a).

Screen-based technologies/screen media: Includes television/DVDS, video games, e-readers, smartphones, tablets, and other mobile devices (Rideout, 2014).

Traditional screen media: Includes television/DVDS, video games, and computers.

Young children: Children aged birth through eight years (Bredekamp, 1987).

\section{$\underline{\text { Summary and Organization of the Study }}$}

Discussed in this chapter are the following topics: an overview of factors involved in technology's role in education; differing positions in the early childhood field of technology's role in young children's lives; and the importance of vocabulary development, particularly for children living in economically disadvantaged communities. Also discussed was an overview of the present study designed to address the aforementioned factors. Chapter 2 contains a review of the research on the interaction between screen time, technology, vocabulary development, and teachers' 
perspectives of using technology in the classroom. In Chapter 3, the design and methodology for the study are presented in more detail. In Chapter 4, findings from the quasi-experimental study are presented. Finally, Chapter 5 contains a summary and interpretation of the findings, limitations of the study, implications, and recommendations for future research. 


\section{CHAPTER 2 \\ LITERATURE REVIEW}

\section{$\underline{\text { Introduction }}$}

In this chapter, the rationale is presented for conducting the present study on using applications (apps) to increase receptive and expressive vocabulary of preschool-aged children living in economically disadvantaged communities. The research and scholarship on the impact of screen time on young children's development is reviewed and critiqued. Although there are recommendations from the American Academy of Pediatrics (AAP) that state young children should have extremely limited to no exposure to screens (American Academy, 1999, 2011), the basis of this recommendation does not differentiate between various educational media and ignores mobile media. As such, this literature review provides additional insight into how the research community has applied the AAP recommendations in subsequent research, policy statements, and conceptual publications. The analytic focus on the limitations of the research community's definition of screen media provides another insight. Even though numerous studies have focused on traditional screen media, analytic attention to young children's mobile media usage had just begun at the time of the present study. Thus, this issue is addressed in the literature review by analyzing the limited research base surrounding young children and mobile media. Additional discussion of the vocabulary development of young children, particularly those living in economically disadvantaged communities, is also presented to add further insight into the need to address this issue in the early childhood field. 


\section{Examining the American Academy of Pediatrics (AAP) Position Statements}

Parents and educators do not seem to be adhering to the guidelines outlined by the AAP as children have increasing access to various technologies (Common Sense Media, 2013). It is worth examining the AAP's position statements in order to gain insight into the reasoning behind limiting screen time. The original position statement, Media Education, was published in 1999 by the AAP Committee on Public Education. The majority of the statement focused on negative impacts of media use including exposure to violent programming, sexual content, tobacco, and alcohol. The position also emphasized that media can increase the prevalence of obesity and decrease performance in school. Yet, within the statement, the AAP also recognized the value of media, including “. . . selected educational television programs, to thought-provoking magazine articles, to the creativity and knowledge encouraged through computer use" (p. 341) and called for more responsive media education that teaches children and adolescents to critically analyze media. Within the Recommendations section of the statement, the AAP challenged pediatricians to be knowledgeable of health risks involved in media use and understand how to help parents limit and intentionally choose programs for their children. The statement that ultimately has caused the divide in the early childhood field is as follows:

Pediatricians should urge parents to avoid television viewing for children under the age of 2 years. Although certain television programs may be promoted to this age group, research on early brain development shows that babies and toddlers have a critical need for direct interactions with parents and other significant care 
givers. . . for healthy brain growth and the development of appropriate social, emotional, and cognitive skills. (American Academy, 1999, p. 342)

While the majority of early childhood professionals would agree with the statements regarding early brain growth, it should be noted that no research about early brain development was actually cited in the position statement.

The AAP Council on Communications and Media subsequently updated its position in the 2011 publication, Media Use by Children Younger Than 2 Years. Within the statement, the AAP held the position that the quotation was being misused by media outlets and their intention was to discourage use by children under two, not ban it altogether. Within this second statement, empirical research was cited supporting the reasoning for discouraging media use with children under two. In sum, the AAP stated that research was inconclusive on whether television programming benefited young children's learning and noted that though children develop at different rates, those between 18 and 24 months may not be able to follow the complexities of a television program. Yet, it was also stated that "more research is needed to determine if early television exposure has any long-term effects on learning" (American Academy, 2011, p. 1041). This acknowledged that much was still unknown about children under two and their exposure to television. Equally important, research findings discussed in the statement implied that there could be a correlation between television exposure and negative developmental delays for children under the age of two, but causation between the two could not be proven. For example, it can be said that people who watch a certain number of hours of television per day are obese, but it cannot be said that watching 
television causes obesity. Thus, it is questionable if television is actually causing harm to child development. Nevertheless, within the Recommendations section of this updated policy statement, the AAP reaffirmed that television exposure for children under two was discouraged; and if it is used, parents should intentionally choose the programming and be actively involved while their children are watching television.

It is important to note that this updated 2011 AAP position statement only refers to television viewing and not any other screen media exposure. Christakis (2014), one of the members who drafted the updated AAP position statement, published an opinion piece about rethinking the AAP guidelines for discouraging screen exposure to children under two. He observed that though the position was published in 2011, it was drafted much earlier, notably prior to the iPad becoming available for purchase in 2010. What is more, he explained that mobile, touch screen devices have several of the same benefits as traditional toys, such as being reactive, highly portable, and promote joint attention. Within his explanation, Christakis (2014) also stated that the features of mobile media have additional benefits that traditional toys do not have, including being interactive, tailorable to children's interests and needs, and progressive. The only feature that mobile media do not have that traditional toys do have is that touch screen devices are not threedimensional. With continuing advances in technology, the argument that mobile media do not offer three-dimensional experiences may become invalid as companies such as Tangible Play, Inc. (2014) are creating interfaces where children manipulate tangible objects such as tangrams and word tiles while guided by an iPad app. 
Christakis (2014) also observed that television, the primary screen considered in the 2011 position statement, did not have any of these features and there was simply not enough research on the impact of mobile media on young children's development. Despite writing with a sense of caution, he ultimately concluded, “. . . while many of you wait for us to build an evidence base before this technology is too supplanted by some new one, I believe that judicious use of interactive media is acceptable for children younger than the age of 2 years" (p. E2). In light of this, he stated that children under two years should engage in mobile media use no more than 30 to 60 minutes per day. Following Christakis' (2014) opinion piece, another group of AAP members (Radesky, Schumacher, \& Zuckerman, 2015) added additional commentary about the use of interactive mobile media by young children. In particular, they highlighted the ability of well-designed electronic books (e-books) to boost early literacy skills. Moreover, though they cautioned against using mobile media as a baby sitter or tool to get children to be quiet, they cited instances where devices can be used to distract and entertain children during potentially stressful situations, such as in the hospital prior to surgery. Other potential misuses of mobile media include using devices in place of healthy interactions or gross motor activities. In their guidelines, the authors stated that the most effective use of mobile media occurs when an adult and child have high-quality interactions together and capitalize on teachable moments. Instead of banning or limiting screen time all together, Radesky et al. (2015) suggested that child care providers and clinicians offer parents guidelines for specific content to use and methods for testing an app prior to using it with children. 


\section{Screen Time: Active Versus Passive}

Perhaps because the AAP has continued to defend its original statement of discouraging screen exposure for children under two, it has continued to be touted as a widespread ban on screen time and is used in support of limiting screen time for older children (Levin, 2013). Rideout, in a 2014 survey, indicated that parents are still widely depending on television as a source for educational screen time, which is the type of screen exposure that the AAP has discouraged. Christakis' opinion piece on allowing children under two years to interact with mobile media was published in March 2014, and Radesky et al.'s in January 2015. It will be necessary to track the direction in which the early childhood community follows as a result. Consequently, some relatively current research on active versus passive screen time may provide some insight into how mobile media can be used in developmentally appropriate ways.

In Australia, there was also a recommendation for no screen time for children under two years. Researchers (Sweetser et al., 2012) described a seven-year longitudinal study of 5,107 Australian children aged zero to one year and 4,983 children aged four to five years. This study included interviews, mail-back questionnaires, time-use diaries, and interviewer observations. As with data collected on educational media use in the United States by Rideout (2014), young children in Australia were determined to be exceeding recommended time limits for screen exposure, and the majority of children's screen use involved watching television/DVDs. Sweetser et al. (2012) concluded that television screen time and video game/computer screen time should not be considered in the same screen time category because playing a game involves different responses in the 
brain than watching television. Instead, they recommended categorizing two types of screen time: active and passive. Active screen time can be uniquely divided into two categories: physically active screen time and cognitively active screen time. Physically active screen time includes physical activity with games on platforms that are similar to physical exercise (e.g., XBOX Kinect and Wii Fit). Cognitively active screen time requires the user to solve problems and think creatively. In contrast, "passive screen time involves sedentary screen-based activities and/or passively receiving screen-based information, such as watching TV or a DVD” (Sweetser et al., 2012, p. 96). The researchers argued that this passive screen time is what should be considered for limited or no use at all for young children without putting sanctions on active forms of screen time. Mobile media has the potential to support active screen time, and traditional screen media tends to encourage passive screen time.

Though Sweetser et al. (2012) used statistics garnered from longitudinal data to support their claims about active versus passive screen time, their inferences came from research in related fields. Others have advocated for a differentiation of screen use (NAEYC \& Fred Rogers, 2012), but the reality is very little research has been conducted to support these claims. In order for a consensus to be reached in the screen time debate, more research needs to be conducted in order to support the use of mobile media, particularly those that promote active screen time.

\section{Impact of the American Academy of Pediatrics' (AAP) Position Statements}

Despite researchers beginning to differentiate between passive and active screen time, the AAP has maintained its stance on banning and/or limiting screen time for young 
children. In order to recognize the impact of the AAP position statements, it is important to understand how the research community has responded to the warnings about screen exposure. Using Web of Science and Google Scholar, a search was conducted in April 2014 to find publications that have cited the two AAP position statements (American Academy, 1999, 2011). For the Web of Science database, the reference for each position statement was located and the articles included in the "times cited" lists were reviewed. For the Google Scholar database, the reference for each position statement was located, and the articles included in the "cited by" lists were reviewed.

The 123 articles identified could be uniquely divided into six categories of conceptual articles and empirical research: (a) traditional screen media, 78 articles; (b) mobile media, four articles; (c) traditional and mobile media, 14 articles; (d) quality versus quantity in screen use, two articles; (e) reviews of how pediatricians use policy statements, three articles; and (f) media literacy and education, 16 articles. With the majority of scholars in the field using the AAP position statements to continue to focus on traditional screen media (63\% of the articles identified), it appears as if the research community has not caught up to the increasing trend of mobile media usage among young children. Clearly, banning or limiting screen time has not affected parents' use of screens in the home (Common Sense Media, 2013). Therefore, if the research community continues to examine television in the lives of children, they must determine more realistic ways than imposing screen limitations so that parents can capitalize on young children's interest in television. 
At the same time, it does not seem feasible that the screen time debate will be diminished unless researchers begin to focus on screens other than televisions and computers. In this review, only four publications were found to have cited at least one of the AAP position statements and examined new media technologies (Alessi \& Alessi, 2008; Hoffman \& Paciga, 2014; Tarasuik, Galligan, \& Kaufman, 2011; Teichert \& Anderson, 2014). Although it is somewhat promising that 14 of the reviewed publications focused on both traditional and mobile media, this number is still very small when compared to the 78 publications solely focused on traditional media. As mobile media devices are increasingly being marketed for young children, it is important to understand how these devices affect children's development. Christakis (2014) highlighted the benefits of touch screen devices over television and even, in some cases, traditional toys.

More rigorous examination of the articles citing the AAP position statements (American Academy, 1999, 2011) highlighted gaps in key concepts that need to be addressed and better defined. For example, the term, screen media, remains ambiguous. In review of the literature, many researchers use the term, screen media, but only examine television exposure. Others use the term, information, communication, and technology (ICT), but only examine computers. As technology is enhanced, the term, video games, is now vague. Are games on a tablet such as the iPad considered in this category? Similarly, do tablets fall under the computer category or do researchers define them in their own category? In the research reviewed for the present study, it was not 
specified as to whether mobile media devices are computers. Researchers need to clarify terminology.

Finally, researchers must continue to empirically explore children's use of mobile media devices and their impact on all areas of development in order to strengthen the emerging research base. Many of the publications citing the AAP position statements (American Academy, 1999, 2011) were theoretical or conceptual documents based on a small number of empirical studies. Other studies, such as the 2013 Common Sense Media study, resulted in survey-level data, which provided valuable information about screen use but did not inform the early childhood community of the impact of screens on children's development. For the most part, there needs to be additional quasiexperimental, experimental, and mixed-methods research specifically related to mobile media technologies and child development.

\section{$\underline{\text { Review of Empirical Research on Young Children and Mobile Media }}$}

\section{Method for Information Retrieval}

The use of technology in education is a broad concept. With the adoption of the $21^{\text {st }}$ century skills framework (Partnership for $21^{\text {st }}$ Century Skills, 2011) and the U.S. Department of Education's (2010) National Educational Technology Plan (NETP), the use of technology to support learning has been shown to be increasing. Research examining the efficacy of using technology for learning is so voluminous that a secondorder meta-analysis (i.e., a meta-analysis of multiple meta-analyses) was conducted based on 40 years of research comparing classrooms that used technology to classrooms that 
did not use technology (Tamim, Bernard, Borokhovski, Abrami, \& Schmid, 2011). In an examination of 25 meta-analyses, which included 1,055 primary studies and roughly 109,700 participants, statistically significant small to moderate effect sizes $(E S=0.35, S E$ $=0.04, p<.05)$ indicated better academic performance in classrooms that used technology. Additionally, students in studies where technology was used to support education $(E S=0.42, S E=0.02, p<.05)$ performed statistically significantly better than students where technology was used as a means for direct instruction $(E S=0.31, S E=$ $0.02, p<.05)$. This implies that when technology is used intentionally to support learning, it can increase student achievement. As researchers have shown that technology has a positive impact on learning (Tamim et al., 2011), the current literature review did not reanalyze this area of research.

In the second-order meta-analysis, learners in Kindergarten through Grade 12 were placed in the same category to formulate one analysis. Thus, the research community did not appear to have a solid understanding of the differences in learning through technology for children in the early childhood years (birth through age eight) as compared to older children; nor was there an analysis of the use of technology for learners who were younger than kindergarten age. As technology has become more prevalent in the lives of very young children (Common Sense Media, 2013), it was important to examine how technology influences children's development.

In order to locate empirical research focused on using mobile media with young children, a search was conducted using guidelines for a systematic review of literature (Hammerstrøm, Wade, \& Jørgensen, 2010). The initial search for literature began in 
May 2014 and the final search was run on May 1, 2015. The following procedures were used to locate the reviewed articles. First, the controlled vocabulary for the ERIC database (1966-Current) was examined to determine a set of keywords that would yield results for uses of technology and early childhood. The technology-related keywords included the following: educational technology, information technology, multimedia instruction, and computer uses in education. These keywords were connected with the Boolean operator "OR". The keywords related to early childhood, also connected with the Boolean operator "OR", included: early childhood education; preschool education; primary education; young children; infants; toddlers; Kindergarten; Grade 1; Grade 2; and Grade 3. The technology and early childhood keywords were connected with the Boolean operator "AND". The following databases were selected for the search: (a) Academic Search Premier, (b) Applied Science \& Technology Full Text, (c) Cochrane Database of Systematic Reviews, (d) Education Full Text, (e) Family Studies Abstracts, (f) FRANCIS, (g) General Science Full Text, (h) History of Science, (i) Technology and Medicine Library, (j) Information Science and Technology Abstracts, (k) MEDLINE, (1) Mental Measurements Yearbook, (m) OmniFile Full Text Mega, (n) Primary Search, (o) PscyARTICLES, (p) PscyINFO, (q) Social Sciences Full Text, (r) Urban Studies Abstracts, and (s) Teacher Reference Center. For the initial search, all documents, including peer-reviewed journal articles, periodicals, and government documents were included. This initial search yielded 2,513 original publications.

Once the initial set of publications was reviewed, a list of mobile technology related words was drafted. An additional search was run with the following keywords: 
personal digital assistant, handheld computer, handheld device, iPod, iTouch, iPhone, iPad, touchscreen, tablet, Palm Pilot, Nintendo, Game Boy, and DS connected by the Boolean operator "OR" and the previously mentioned early childhood keywords. This search yielded 68 additional publications. All results were downloaded into EndNote software, which stored abstracts and .pdf full text files for each of the results. Ultimately, only studies in peer-reviewed journals were included in the review.

The abstracts were examined, and the full text of relevant articles were read based on the following inclusion criteria for each publication: (a) an empirical study was conducted; (b) children in the study were between zero and eight years old; (c) the focus of the study was early language or literacy development; and (d) mobile technology was used. Exclusion criteria for each publication included: (a) a conceptual or theoretical piece with no new empirical research, (b) children in the study were over eight years old, (c) a technology other than mobile technology was used (e.g., robotics, interactive white boards, blogs, podcasts), and (d) the study was reported in a news article or blog and had not yet been published in a peer-reviewed journal. Once the inclusion and exclusion criteria were applied, 26 empirical research studies were chosen to represent the current research and scholarship in this field. The 23 studies identified were divided into three categories: (a) personal digital assistants and handheld computers, (b) smart phones and tablet devices, and (c) teacher perspectives. The studies are discussed in the following sections. 


\section{Personal Digital Assistants (PDAs) and Handheld Computers}

Scholars first started researching the impact of mobile media on young children's development when personal digital assistants (PDAs) were introduced into the market. PDAs were mobile devices with touch screens that could run apps ranging from note taking to educational games, and typically ran on a PC-based operating system. In the context of educational research, PDAs were often placed in the "handheld computer" category, which included other mobile media such as the Nintendo Game Boy (Margolis, Nussbaum, Rodriguez, \& Rosas, 2006) and robot-like toys (Magagna-McBee, 2010). Nine empirical research studies examining the impact of handheld computers on young children's learning were chosen to represent the scholarship in this area. Of note, after provided with adult guidance, children were able to independently use handheld computers to plan what they were going to do, perform specific functions, navigate to different screens, and write letters (Chang, Mullen, \& Stuve, 2005; Kuhlman, Danielson, Campbell, \& Topp, 2005) as well as increase collaborative learning, motivation, and engagement (Fritz, 2005; Zurita \& Nussbaum, 2004). An additional benefit was discovered for the self-monitoring and increased on-task behavior of a child with emotional and behavioral disorders (Gulchak, 2008). Handheld computers were also found to be tools that can be used to meet content area and technology standards (Fritz, 2005).

In examining the use of handheld computers to increase academic achievement, the results were mixed. Results from a quantitative study $(N=758$ in the experimental group) using the Game Boy to increase mathematics and reading abilities of first- and 
second-grade students in Chile indicated statistically significant differences in mathematics and spelling scores, but no statistically significant increases in reading scores (Margolis et al., 2006). An additional study with Chilean seven-year-olds $(N=12)$ showed that a specific program targeting syllabic knowledge resulted in statistically significant higher scores in word construction (Zurita \& Nussbaum, 2004). In contrast, a mixed-methods study examining the potential of the Bee-Bot robotic toy for kindergarteners $(N=92)$ indicated no statistically significant increase in phonemic awareness scores on the Dynamic Indicators of Basic Early Literacy Skills (DIBELS) assessment (Magagna-McBee, 2010). Therefore, overall, early examinations of handheld computers in classrooms with young children demonstrated benefits in student motivation and engagement, but no definitive conclusions could be made as to their impact on academic achievement.

The early studies of handheld computers did have practical significance for the field. First, it was concluded that appropriate uses for young children included activities in which children guide their learning and construct their own knowledge (Chang et al., 2005; Kuhlman et al., 2005; Lan, Sung, \& Chang, 2007). Furthermore, in many cases, researchers placed emphasis on the importance of teachers becoming experts in using the technology in order to effectively implement the use of handheld computers in the classroom (Chang et al., 2005; Fritz, 2005; Kuhlman et al., 2005). Just as important, in the Bee-Bot study, teachers concluded that handheld computers are best served for enrichment activities and not as a replacement for other learning activities (MagagnaMcBee, 2010). Finally, a cost analysis was suggested for use in determining if 
educational technology should be adopted (Margolis et al., 2006). The cost analysis required decision makers to weigh the costs of educational technology against the potential benefits and determine the feasibility of incorporating it into schools. If, according to the authors, the costs outweighed the benefits and it was difficult to begin a new program with handheld computers, planners were not encouraged to invest in the technology. Thus, the early research into handheld devices, particularly PDAs, offered insight into how educational technology can be maximized to support young children's development in appropriate ways.

\section{Smart Phones and Tablet Devices}

Once "smart" devices, including phones and tablets, were introduced into the market, the use of PDAs and the term, handheld computers, declined. Smart devices have the same capabilities as PDAs; and with advances in technology and their increased usage, smart devices have surpassed the functions of the PDA. Ten empirical research studies conducted to examine the impact of smart devices on young children's development were chosen to represent the scholarship in this field. Similar to the previously reviewed research on handheld computers, research on young children's use of smart devices indicated an easy-to-use interface and increased motivation, engagement, and collaborative learning (Beschorner \& Hutchison, 2013; Couse \& Chen, 2010; Cubelic \& Larwin, 2014), as well as enhancement of inquiry projects (Geist, 2012). Detailed relevant findings are discussed in the following paragraphs.

Much of the information available for review on young children's use of technology is survey-level data (Common Sense Media, 2013). Plowman and Stevenson 
(2012) posited that previous survey-based studies examining screen time only help understand the duration in which a child is exposed to a screen. However, survey data is surface level data that does not always inform about the impact of screens on the child's development. Deeper examinations can provide insight into what else is happening in the home or classroom while children are exposed to screens. To offer a more in-depth examination of how children were using mobile media at home, ethnographic case studies of 14 children who were three years old at the start of the study were conducted over an 18-month period. Based on their findings, the authors suggested that technology can support learning through four categories: acquiring operational skills; extending knowledge and understanding of the world; developing dispositions to learn; and understanding the role of technology in everyday life. Rather than continuing to use survey-level data about the frequency of screen time to provide warnings about limiting use, educators and the research community can focus on the four identified areas in order to maximize children's time with screens in developmentally appropriate ways (Plowman \& Stevenson, 2012).

Another qualitative study (Beschorner \& Hutchison, 2013) concerning iPad use involved 35 four- and five-year-olds in two preschool classrooms. Each week, for seven weeks, the classrooms were given two or three new apps to use. Data were collected through classroom observations, digital work samples, and teacher interviews. The researchers concluded that the chosen apps supported digital print awareness, including locating a specific app on the iPad, recognizing print from other media formats (such as the PBS logo), and moving from one screen or one app to another. Emergent writing was 
supported through digital writing apps that allowed children to draw, type text, add photographs, and manipulate letters to spell words. Additionally, the iPad allowed children to connect reading, writing, listening, and speaking in ways that could not be accomplished using traditional learning formats. The iPad also promoted social interactions among children and allowed them to collaboratively problem solve. Finally, the iPad was specifically beneficial because it allowed children to carry it around with them as they spelled words from the physical environment, and provided a means for teachers to quickly share children's work with parents via email (Beschorner \& Hutchison, 2013). The researchers indicated that intentionally chosen apps on tablets could support and transform learning in ways that traditional educational tools could not.

Researchers conducting quantitative analyses also indicated benefits of mobile media in the classroom. In a quasi-experimental study, researchers examined 281 Kindergarten students' use of apps that support early literacy skills that were to be assessed on the DIBELS assessment (Cubelic \& Larwin, 2014). Teachers in the treatment group were provided with iPads, on-going professional development, and a budget for specific apps to use to target required knowledge assessed with the DIBELS. The control group received no iPads or professional development. The assessment was administered at the middle and end of the school year. At the middle of the school year, the control group was performing statistically significantly higher on letter naming fluency and first sound fluency. The researchers attributed these differences to students' pre-existing kindergarten readiness levels. At the end of the year, the treatment group performed statistically significantly higher on phoneme segmentation fluency and 
nonsense word fluency. Despite not all areas of phonemic awareness increasing for the treatment group, the researchers concluded that, when used intentionally, mobile media can have a positive impact on students' standardized assessment performance (Cubelic \& Larwin, 2014).

Falloon (2014) conducted a study with 18 five-year-olds (11 female, 7 male) in New Zealand. The classroom was provided with nine iPads. The teacher was tasked, after thoroughly researching and practicing with apps, with choosing 45 apps for use in the classroom. The apps were arranged in five folders on the iPads, designed for one folder to be used for each day of the week, and rotating which apps were used on which days. Each day, children worked in pairs and used the apps for 30 to 40 minutes of instructional time. A device which recorded video and audio of the children was attached to the iPads. The device ran for six months, yielding 24 hours of data and interactions of 40 combinations of paired students. A sample of seven student pairs was used for the final data analysis which focused on interactions with literacy, numeracy, and problemsolving/decision-making apps.

Three broad themes emerged: the features of the apps, including design, content, and structure; students' knowledge, including ability to operate the device and follow the tasks required by the apps; and the cognitive strategies the students displayed during app use. Falloon (2014) concluded that, of the apps selected, there were not many opportunities for learning to be scaffolded and that, even if children seemed motivated and engaged in app use, they were rarely learning anything new. Equally important, even though the apps were carefully selected, it did not become apparent that the apps would 
not support learning until they were used with students in a classroom. Design flaws in the apps included the following:

no, poor or inaccessible instructions, unstated or obscure learning purpose, lack of options other than difficult text for instruction or content delivery, inadequate structure guiding student interaction, overemphasis on games of limited learning value, and limited or no built-in learning scaffolds or formative feedback systems. (Falloon, 2014, p. 333)

Falloon (2014) concluded that prior to use apps need to be evaluated to determine how they will fit into learning objectives and to ensure that children are able to use them independently. He did indicate that the children were participating in complex social interactions and were highly engaged and motivated. Albeit not considered by the researcher, in early childhood settings where play is encouraged, perhaps apps with content specific learning objectives should be balanced with apps that children can play to simply engage in fun, non-threatening activities with peers.

In examining the potential for audio-books to increase vocabulary development, Boeglin-Quintana and Donovan (2013) introduced an iPod Shuffle into a kindergarten class' silent reading time. Using random assignment, nine students were assigned to the iPod shuffle group and 17 students were assigned to the non-iPod group. Vocabulary knowledge using the PPVT-4 (Dunn \& Dunn, 2007) was measured before and after a sixweek intervention. During the intervention, the children in the iPod group listened to 30 stories (one per school day) while children in the non-iPod group read physical books silently to themselves. For the iPod group, motivation to complete the whole story, 
engagement, comprehension, and interest increased. However, for both the iPod and non-iPod groups, there was no significant increase in vocabulary knowledge. The short time frame of the study could have contributed to the iPod group not preforming better than the non-iPod group. Though not included in the study's limitations, considering the developmental inappropriateness of a "silent reading time" for kindergarten-aged children, the fact that the children listening to the books on the iPod showed increases in motivation and comprehension could be viewed as a positive method for including more appropriate story engagement for young children.

A mixed-methods examination of 41 three- to six-year-olds added deeper insight into children's ability to use mobile media and their capacity to be creative during use (Couse \& Chen, 2010). Even though the type of mobile media tablet was not specified, it was noted that the children used Microsoft Word software. First, children were taken to a quiet space next to their classroom and sat at a table next to one another with individual devices. They were introduced to the devices by the researchers. Through several sessions, the researchers determined when children were "warmed up" to the devices and, when they were, instructed the children to draw a self-portrait. Next, children participated in semi-structured interviews to determine if they preferred drawing on the tablet to drawing with traditional tools such as crayons and paper. Finally, teachers were interviewed in a focus group to compare children's drawings on the tablet versus traditional tools. It was discovered that children adapted to the functions of the tablet quickly and were able to easily use it for learning. Additionally, children's drawings on the tablet were comparable to their drawings using traditional tools. Uniquely, younger 
children (under 53 months) demonstrated less persistence than older children. Though not specifically mentioned by the researchers (Couse \& Chen, 2010), it seems younger children will naturally move on to other activities once their mental capacity for usage is reached.

Research findings concerning mobile devices and young children with special needs have been promising. Cardon (2012) found that caregivers of four young children between the ages of 24 and 50 months who were diagnosed with autism could create videos on an iPad to increase the children's imitation of desired behaviors. In another study, Chai, Vail, and Ayers (2015) examined the use of an iPad app to increase the literacy development of two children in kindergarten and one child in second grade with developmental delays to support initial and final phoneme identification. After 80 tenminute sessions with the app, the children were assessed at four and seven weeks postintervention. All children showed increases in their accuracy in identifying initial phonemes, but only one child showed progress with identification of final phonemes. Finally, Lorah and Parnell (2014) found that a handwriting iPod app could assist children with developmental disabilities in producing the proper letter formation when skills learned on the app were transferred to paper and pencil. Based on the findings of these small-scale studies, it seems optimistic that mobile devices can transform assistive technologies for children with disabilities.

\section{Teacher Perspectives}

The findings discussed in the studies reviewed indicate that mobile media use can increase children's motivation, engagement, and, in some cases, academic achievement. 
Nevertheless, when any type of technology is used in an early childhood classroom setting, technology is simply a tool that teachers can use along with a wide array of other tools. The majority of studies that were located during the review of literature focused on teacher perspectives for using technology in the classroom. Thus, the impact of mobile media on children appeared to be directly related to teachers' perceptions and knowledge of using devices in the classroom (Hylén, 2015; Sang, Valcke, van Braak, \& Tondeur, 2010). Although there were numerous studies examining teacher perception and knowledge, a majority of researchers arrived at the same conclusions. Therefore, a representative four studies were chosen for review.

In one study, Marklund (2015) examined preschool teachers' questions and information shared about tablets on online social networks. Data were collected from two popular Swedish discussion groups and included contributions by preschool teachers using tablets in the classroom. Because data were collected from an online, public forum, demographics of the participants were unknown. Instead, the number of posts (240 for Group A and 225 for Group B) over a timespan of a little less than two years, were analyzed

Examining the types of questions the teachers asked, Marklund (2015) concluded that preschool teachers needed mentoring in the following three areas: technological knowledge (how to use the device and its software); technological content knowledge (how to integrate technology into specific academic subjects); and technological pedagogical knowledge (concerns about the developmental appropriateness of technology). Next, Marklund observed that teachers may seek the informal use of 
discussion postings rather than formal mentoring or professional development because discussion boards have the potential to better meet their specific needs than what may be provided by the school system, and they are a forum in which teachers may be more willing to share experiences. Teachers in this study indicated a willingness to seek information about using tablets in the classroom as well as provided information about what teachers need to know and be able to do in order to effectively use mobile media with young children.

Other researchers (Nuttall et al., 2015) examined teachers' beliefs about the developmental appropriateness of mobile media use in the classroom. Three suburban kindergarten teachers in Australia viewed video recordings of six boys and one girl at play. During the play, children were recorded first playing with traditional toys, then with toys including characters from popular television shows, and finally with iPad apps including the characters of the shows. The video recordings were shown to each child's teacher, and a semi-structured interview was conducted as the teachers were viewing. Questions were centered on what the teachers thought was and was not play and then transcripts of the interviews were shown to an additional focus group of teachers.

Based on the original teachers' responses, the teachers in the focus group were invited to share their thoughts about what teachers should know regarding contemporary children's play (Nuttall et al., 2015). Common themes in responses included curriculum, teacher knowledge, and contemporary play. The researchers concluded that the teachers already understood that mobile media can be valuable teaching tools, but they did not yet know how to fully engage children in the use of the technology. Thus, according to 
Nuttall et al. (2015), early childhood teacher mentoring should include ways to assist in transforming traditional knowledge about children and play to incorporate mobile media into play-based learning.

In an attempt to add deeper insight into technology use in preschools, Masoumi (2015) conducted a case study of teachers' beliefs and experiences. Six Swedish teachers at three preschools were interviewed after the researcher conducted observations in their classrooms across three weeks. Five main themes emerged. First, teachers used technology to enhance current content and teaching practices. Second, technology was used to help children who were immigrants stay connected to their culture, connect all children to other cultures, encourage non-native speakers to engage in literacy activities, and support children in talking to one another in complex ways. Third, technology was used to "keep children busy" (Masoumi, 2015, p. 12). Fourth, technology was used as a tool to document children's learning through creating multi-media (e.g., pictures, videos, drawings) portfolios. Finally, some teachers believed that technology was not important for use and was encroaching on traditional forms of play in preschool. Thus, while many teachers found multiple types of technology to be useful tools for teaching, some teachers were resistant to their use in the classroom. These findings were similar to those of the previously summarized study (Nuttall et al., 2015) where teachers had not yet conceptualized the intersection of developmentally appropriate practices in a play-based program with the incorporation of technology.

Ciampa \& Gallagher (2013) conducted a case study of 14 kindergarten through eighth-grade teachers and their principal as they integrated the iPod Touch into 
classrooms. In this study, the researchers facilitated eight workshops over a four-month period. Data were gathered from a pre-intervention needs assessment, a questionnaire about teacher experiences and attitudes related to technology, and teacher and principal interviews about their mentoring experiences. The teachers were also given time and guidance to explore the functions and capabilities of the iPods prior to using them in the classroom. In summarizing results from the pre-intervention needs assessment, Ciampa and Gallagher indicated that the teachers had little familiarity and minimal confidence in using the iPods. Through the interviews, it was discovered that, although the teachers appreciated the time spent understanding the functions of the iPods, a "one-size-fits-all" approach to mentoring was not sufficient for teachers to feel confident in using the iPods. Instead, the teachers desired mentoring that was related to specific experiences in their classrooms and allowed them to have the iPods in their hands to observe real-time models of apps being downloaded and demonstrated during workshops. Finally, the teachers found it beneficial to be able to co-plan and co-teach with the researchers in order to gain an understanding of how to differentiate the technology use in their own classroom.

\section{Summary of the Review of Empirical Research}

Although the findings from the empirical studies reviewed indicated the statistical and practical significance of mobile media on young children's development, the literature base was too narrow to reach conclusions or to suggest changes in practice. It is clear that young children have access to and are able to use mobile technology for a variety of purposes (Common Sense Media, 2013). Yet, there are very few empirical studies examining usage, especially related to language and literacy development and 
academic achievement. Therefore, researchers need to rigorously examine the impact of mobile media on various aspects of young children's development in order to move the field forward.

Furthermore, though there has been extensive research conducted on the attitudes, perceptions, and perceived competence of teachers using mobile media in the classroom, it does not seem as if the practice of 21 st century teachers has caught up to the research. This could perhaps be due to principals receiving limited guidance when it comes to technology (Dawson \& Rakes, 2003). Within the studies reviewed, Ciampa \& Gallagher's (2013) seemed to propose the most efficient method for researchers to mentor teachers in implementing mobile media interventions with children in order to ensure the program fidelity of the interventions. An additional element to include for program fidelity would be mentoring early childhood teachers in understanding how technology fits into a developmentally appropriate, play-based program (Marklund, 2015; Nuttall et al., 2015).

\section{Vocabulary Development, Young Children, and Technology}

Vocabulary development is multi-faceted. It is not just limited to spoken words but also includes visual communication, written signs and symbols, and non-verbal cues (Bloom, 2000). In the early childhood years, vocabulary development is particularly important because young children develop rapidly and, without the proper support, can miss developmental milestones quickly. Beginning at 12 months, children who are regularly exposed to new words have the capacity to learn an average of 10 words per 
day (Bloom, 2000). Vocabulary development is particularly critical for children from two to three years old, when vocabulary progresses at the fastest rate (Bloom, 1991; Bochner \& Jones, 2003). Typically developing three-year-old children have a 200 to 300 word vocabulary which increases daily. At three years old, children are also using vocabulary to express their emotions and can get easily frustrated if they are not understood (Bloom, 1991).

Vocabulary knowledge is an important precursor to later literacy development. For example, if a child has a limited vocabulary, sounding out words while reading and spelling, predicting what will happen in a text, and comprehension are all negatively impacted (Snow \& Tabors, 1993). The primary method by which children learn new words is through interacting with adults and peers during daily routines, familiar situations, stories, songs, nursery rhymes, and play (Bochner \& Jones, 2003; Snow \& Tabors, 1993). A solid foundation for vocabulary is needed for children to achieve in various other developmental domains: cognitive, social, behavioral, and emotional. Additionally, the quality of children's language experiences from birth to three years old can predict later social development (Fillmore \& Snow, 2000; Rice, Huston, Truglio, \& Wright, 1990) and academic success (Hart \& Risley, 1995). Thus, it is important to support the vocabulary development of young children.

Added examination revealed the impact of economic status on young children's vocabulary development (Hart \& Risley, 1995, 2003). Children whose families live on welfare are exposed to drastically fewer words (616 per hour) than children from working class (1,251 words per hour) and professional (2,153 words per hour) families. By three 
years old, children from welfare families have a 13-million word vocabulary, compared to 26 million words in children from working class families and 45 million words in children from professional families. The "30 million word gap" (Hart \& Risley, 2003) children from welfare families experience highlights the crucial need to support the vocabulary development of young children living in economically disadvantaged families before they enter Prekindergarten at four years old. Hart and Risley's word gap study continues to impact policy and practice. In October 2014, President Obama announced federal initiatives designed to reduce the word gap, including incentivizing programs that produce technologies that can assist parents in sustaining interactions that will support vocabulary development (Administration for Children \& Families, 2014). Thus, determining ways to increase young children's vocabulary knowledge continues to be a prevalent issue in the early childhood research community.

Research on technology use in classrooms indicates that computers, when coupled with non-computer activities, can be used to promote vocabulary knowledge. Technology can be used to help children learn and can also facilitate social interactions among young children (Clements, 1998). In particular, Muller and Perlmutter (1985) found that children were nine times more likely to talk to one another while using a computer than when using puzzles. Children can also use technology as a vehicle for play (Yelland, 1999). Wohlwend (2009) found that the more exposure children have to technology the more likely they are to incorporate it into their pretend play. For example, children in Wohlwend's study were observed pretending a piece of paper was a cell phone and engaged in a "conversation" using their pretend phones. More recent studies 
also confirmed that, when used intentionally, mobile media can encourage collaboration, communication, and connections among children in a classroom as well as foster creativity and curiosity (Falloon, 2015; Hsu \& Geist, 2012; Lan et al., 2007). Further, according to Neumann (2014), three- to five-year-old children who have access to mobile media in their homes have more letter sound and name writing skills than children who do not have access to mobile media.

Yet, parents, educators, and researchers are trying to determine the full potential of mobile media to support vocabulary and, ultimately, literacy development. Because vocabulary development is particularly critical for children living in economically disadvantaged families, an examination of mobile media's influence on the language development of young children in this population would be particularly beneficial to the early childhood field. In order to experimentally study the potential impact of mobile media on young children's vocabulary development, appropriate interventions for preschool-aged children need to be examined.

\section{$\underline{\text { Interventions in Preschool Classrooms }}$}

Researchers (Camilli, Vargas, Ryan, \& Barnett, 2010) conducted a meta-analysis on early childhood interventions and young children's cognitive development from 19602000. The analysis included center-based early childhood programs in which experimental treatment-control group interventions focusing on United States children's cognitive development and language development were carried out for at least 10 hours per week for two months. A total of 123 studies were located and were categorized as 
follows: treatment-control (T/C) interventions $(n=76)$, treatment-alternative treatment (T/A) interventions $(n=17)$, and both T/C and T/A interventions $(n=30)$. Results indicated that direct instruction $(E S=.211, p<.01)$ and individualized instruction $(E S=$ $.161, p<.05)$ T/A interventions in which concepts were explicitly taught by the teacher had higher effect sizes than open-ended, hands-on, inquiry-based instruction. At the same time, Camilli et al. (2010) interpreted these findings with caution, stating that the majority of direct instruction studies occurred in the 1980s, prior to Bredekamp's (1987) notion of developmentally appropriate practice through inquiry and play-based instruction. Studies occurring in the 1990s had fewer direct instruction interventions. Those that did, albeit not of high quality, resulted in findings that children in play-based classrooms performed better than children in direct instruction classrooms. Therefore, though direct instruction may have produced higher effect sizes, it was not conclusive that direct instruction was more effective overall than developmentally appropriate, openended instruction.

Researchers have concluded that the most appropriate uses of technology occur in the support of instruction within open-ended, inquiry-based instruction (Chang et al., 2005; Kuhlman et al., 2005; Lan, et al., 2007; Tamim et al., 2011) and that vocabulary is developed in play-based settings (Bochner \& Jones, 2003; Snow \& Tabors, 1993). Of the quantitative studies located for the literature review, one experimental versus control group study (Margolis et al., 2006) yielded a finding that mobile media had the potential to increase mathematics and spelling scores. In another experimental/control group study, it was indicated that intervention participants produced higher results in specific 
areas of phoneme segmentation fluency and nonsense word fluency on a standardized assessment (Cubelic \& Larwin, 2014). Further examination of specific app use in the classroom by Falloon (2014) indicated that the software on mobile devices (i.e., apps) can increase social interactions, motivation, and engagement, but may not always have content-specific educational value.

None of the studies reviewed included a design in which direct instruction apps were compared to open-ended apps. In order to design such a study, information about the ways in which mobile technology aligns with theoretical perspectives of children's language development needs to be explored.

\section{Theoretical Perspectives}

\section{Sociocultural Perspective}

In the early childhood development and education (ECDE) field, it is important to find a balance for supporting different developmental domains. Vygotsky's (1978) sociocultural theory is most directly related to the present study, as it provides a combination of social learning theory and cognitive development. Sociocultural theory (Vygotsky, 1978) posits that learning is a social process that is influenced by a child's interactions with his or her environment, culture, family, and peers. Therefore, cognition, being a social process, is dependent on a child's ability to think verbally (i.e., vocabulary knowledge). Vygotsky argued that humans are distinct from primates and other animals in that they use "tools" to change oneself and society. The tools that are available to a child are dependent on the child's culture and society. In the United States and many 
other countries, computers are tools that can assist in the development of thought and language (Miller, 2011).

Vygotsky (1978) also believed that a child's abilities fall on a continuum. First, there is the actual developmental level, which is what a child is expected to know and be able to do based on a previously established standard criteria. Vygotsky argued that the actual developmental level typically measures a task or mental function that a child already knows how to do and, thus, offers limited information about the child's development. Next on the continuum is the zone of proximal development, which "is the distance between the actual developmental level as determined by independent problem solving and the level of potential development as determined through problem solving under adult guidance or in collaboration with more capable peers" (Vygotsky, 1978, p. 86). If a child does not have the ability to do something on his or her own, but can do so when given guidance, that task falls within the child's zone of proximal development. Eventually, the guidance will no longer be needed, and the child will be able to perform the task independently. Vygotsky argued that two children who have the same actual developmental level would indeed be at different levels developmentally when the zone of proximal development is taken into consideration. The term, scaffolding, is usually defined as the support that is given within a child's zone of proximal development. Vygotsky posited that it was important to allow each child to explore a concept within his or her own zone of proximal development and use the tools within the child's culture to master the concept. 
The present study draws from sociocultural theory. Because language and cognition go hand-in-hand, it is important to make sure that young children, particularly children who live in in economically disadvantaged communities, have a strong foundation for vocabulary development (Bloom, 2000; Cartmill et al., 2013; Hart \& Risley, 1995). It is also necessary to look at the tools that society offers and use those in the development of language and cognition. Because technology plays an important role in children's lives (Charlton et al., 2002; Common Sense Media, 2013; Leung \& Wei, 1999; O'Mara \& Laidlaw, 2011), it is a tool that has great potential to support vocabulary and language development.

\section{Cognitive Development Perspective}

The second theory in ECDE that relates to the present research is Piaget's theory of cognitive development. Both Vygotsky (1978) and Piaget (1977) created theories of children's cognitive development. Even though Piaget did not consider social forces such as culture and peer interactions that can influence a child's cognition, his stages of cognitive development offered additional insight into children's development that guided the present study.

Piaget suggested children go through four stages as they develop cognitively. Children in the present study were in the second stage, the preoperational stage, which spans from about two to seven years old. During the preoperational stage, children cannot think logically, mentally perform tasks, or understand the world beyond their own perspective (i.e., egocentrism). However, children in the preoperational stage are able to complete external, physical tasks and have a greater ability to think imaginatively. 
Within the preoperational stage, children think externally, rather than internally. Therefore, it is important to provide many different types of hands-on activities to allow children to concretely learn new concepts. The apps in the present study offered one method of hands-on learning. Piaget (1977) also believed that all children do not move through each stage at the same pace, and it is important to offer experiences that allow children to work within their individual abilities. Carefully chosen apps can range in difficulty, so different levels of vocabulary knowledge were considered.

Additionally, there was an element where children needed to think internally about the choices they made while using the apps. Some children were able to do this, and others were not. Early in the preoperational stage, it was expected that a majority of children would need to externally express their thoughts. The intervention teachers in the present study were mentored to set up experiences where children were able to talk aloud as they processed information while working individually or collaboratively with peers.

\section{$\underline{\text { Summary }}$}

The presence of screen use and mobile media in young children's lives remains controversial (American Academy, 1999, 2011). However, researchers have discovered positive ways in which mobile media can be incorporated in the home and classroom (Christakis, 2014; Radesky et al., 2015; Sweetser et al., 2012). As vocabulary knowledge of children living in economically disadvantaged communities remains a critical concern in the early childhood field (Cartmill et al., 2013; Hart \& Risley, 1995, 2003), examinations into the potential of mobile media to facilitate early literacy have begun 
(Beschorner \& Hutchison, 2013; Chang et al., 2005; Couse \& Chen, 2010; Cubelic \& Larwin, 2014). Results from these studies indicate potential for positive impacts on mobile media and early literacy.

Yet, the ability of the specific software used on mobile media to target specific content areas remains in question (Falloon, 2014). None of the studies reviewed employed an experimental or quasi-experimental design that examined different types of apps within an intervention.

In particular, with debates on the use of direct instruction versus developmentally appropriate open-ended instruction in early childhood programs (Camilli et al., 2010), it is worthwhile to employ an intervention with apps that focus on each of these areas. Additionally, mobile media in the classroom are a tool that teachers need to understand how to use in order for child interventions to be effective. Areas to focus on for teacher mentoring in order to ensure program fidelity of child interventions include how to use the device itself, how to integrate apps into specific content areas, and how to balance developmentally appropriate practices and mobile media use, particularly in the area of play (Marklund, 2015; Nuttall et al., 2015).

Thus, the researcher in the present study adopted Piaget's (1977) perspective that children progress through specific stages of cognitive development and that cognition is a process that can be scaffolded with social tools (Vygotsky, 1978). The researcher sought to compare the impact of an intervention using direct instruction vocabulary apps versus an intervention using open-ended vocabulary apps with children who were economically disadvantaged. 


\section{CHAPTER 3 METHODOLOGY}

\section{$\underline{\text { Introduction }}$}

The purpose of this study was to examine the efficacy of using iPads and intentionally chosen applications (apps) to increase the receptive and expressive vocabulary of preschool children who were economically disadvantaged and enrolled in a Head Start program. A secondary purpose was to examine the usage of mobile media apps by Head Start teachers. The methodology to answer the research questions is presented in this chapter which has been organized into the following sections: (a) orientation to the research design, (b) population and sample, (c) intervention and control groups, (d) data collection procedures, (e) instrumentation, (f) research questions, (g) statistical analysis procedures, and (h) chapter summary.

\section{Orientation to the Research Design}

This quasi-experimental research study employed a nonequivalent control-group design. This consisted of four classrooms of children who served as two intervention groups and two control groups. The design did not include random assignment of individual participants (Gall et al., 2007) due to stipulations made by the Head Start director.

\section{$\underline{\text { Population and Sample }}$}

The population of children included Head Start preschool classrooms within a large, southeastern school district. There were 20 individual Head Start centers within 
the school district and 85 classrooms across the centers. The total enrollment for each classroom across the district was capped at 20 children.

The county Head Start program had recently purchased iPads to be used in 68 of the 85 classrooms with one iPad Air and one iPad Mini in each classroom. From the population of centers that had iPads, the primary researcher was given permission by the Head Start district manager to be within one center which had iPads, and four Head Start preschool classrooms were selected by the director of the center. One classroom served as an intervention classroom where children interacted with direct instruction apps, one classroom served as an intervention classroom where children interacted with open-ended apps, and two classrooms served as control groups.

After the center was chosen by the county Head Start manager, the researcher met with the center's director who identified the classrooms to be included in the study. Due to the primary researcher's interest in three-year-olds, the center director identified the four classrooms that included the most three-year-olds at the beginning of the school year. The center director then chose which classrooms served as the intervention groups and which classrooms served as the control groups based primarily on the director's perception of which teachers would be most willing to work with the primary researcher's child intervention plan. Despite the study beginning in the middle of the school year (January 2015), the teachers did not receive the iPads to use in their classrooms until November 2014. Thus, they had limited experience with the iPads at the beginning of the study. 


\section{Power Analysis for Sample Size}

Using G*Power 3.1 (Faul, Erdfelder, Lang, \& Buchner, 2007), an a priori power analysis was conducted to determine an appropriate sample size to detect a withinbetween interaction in a repeated measures ANOVA. With four groups of 12 participants and two measurements, a total of 48 participants was acceptable for identifying a moderate effect size (as defined by Cohen, $1988 ; f=.25$ ) with $80 \%$ power at a .05 significance level (correlation among repeated measures $=0.5$; nonsphericity correction $\mathcal{E}$ =1). Four classrooms were identified by the center director that had at least 17 children in each classroom at the beginning of the study. Although some children dropped from the Head Start program, the total number of participants at the end of the study remained above the minimum total and the proposed power was maintained.

\section{$\underline{\text { Intervention and Control Groups }}$}

The following section provides a detailed description of the intervention and control groups. Details of the intervention program for the children are also presented.

\section{Intervention Program}

After reviewing potential apps with Ms. Jill Goodman, a nationally recognized app reviewer, it was discovered that apps which focus on vocabulary knowledge tended to fall into two categories: (a) those that allow for vocabulary to be developed in an open-ended way, such as drawing apps that encourage children to use the mobile device's microphone to narrate their pictures; and (b) those that allow for vocabulary to be developed with direct instruction, such as apps that, somewhat like a flashcard, show a 
picture and then define what is in the picture through audio narration and visual effects. The open-ended apps were more likely to support expressive vocabulary, and the direct instruction apps were more likely to support receptive vocabulary. NAEYC and the Fred Rogers Center (2012) have encouraged open-ended, active engagement in play with technology, though these guidelines were not necessarily for vocabulary growth. This has been supported through meta-analysis on all types of technology in Kindergarten through Grade 12 classrooms (Tamim et al., 2011). However, discussion has continued about the benefits of direct instruction interventions in early childhood classrooms (Camilli et al., 2010). Thus, an examination of open-ended versus direct instruction apps used to target children's vocabulary knowledge was viewed as worthwhile. Specific apps chosen for the intervention on the children are described in the next section. Due to stipulations set by the Head Start district, the intervention apps were added to the iPads in addition to the Head Start-chosen apps which are detailed in the Control Group section of this chapter. All apps were purchased and downloaded onto the iPads by Head Start's district technology office.

\section{Intervention--Direct Instruction (I-DI)}

One classroom was chosen by the center director to be the intervention group that received direct instruction apps. After consulting with the app reviewer, four direct instruction apps were chosen for the Intervention--Direct Instruction (I-DI) classroom. The app names, appropriate age ranges, and iTunes categories for each of the four apps are displayed in Table 1. Also included are ratings from the iTunes app store, Common 
Sense Media, AppoLearning, and Children's Technology Review which were used to judge the appropriateness and quality of each app.

Overall, three of the direct instruction apps were appropriate for children from two to five years old. The Noodle Words HD--Action Set 1 app was appropriate for children from three to six years old. All direct instruction apps were included in the education category in iTunes. The four apps were rated by at least three of the four organizations; and the Endless Alphabet app was rated by all four organizations. Despite the varying rating scale for each organization, the ratings for each app were fairly consistent, except for the Endless Alphabet app, which was given a lower rating ( 3 out of 5) from Common Sense Media than from the other organizations.

\section{Intervention--Open-Ended (I-OE)}

One classroom was chosen by the center director to be the intervention group which received open-ended apps. After consulting with the app reviewer, four openended apps were chosen for the Intervention--Open-Ended (I-OE) classroom. The app names, appropriate age ranges, and iTunes categories for each of the four apps are displayed in Table 1. Also included are ratings from the iTunes app store, Common Sense Media, AppoLearning, and Children's Technology Review which were used to judge the appropriateness and quality of each app.

Overall, all four of the open-ended apps were appropriate for children under five years old. The designated category for each app in iTunes varied: Beck and Bo was listed under games, Draw and Tell HD and Alien Assignment were listed under 
education, and Don't Let the Pigeon Run This App! was listed under books. The four apps were rated by at least three of the four organizations; and the Alien Assignment app was rated by all four organizations. Despite the varying rating scale for each, the ratings for each app were fairly consistent, except for the Draw and Tell HD app, which was given a lower rating ( 3 of 5) from Common Sense Media than from the other organizations. 
Table 1

Side-by-Side Comparison of Direct Instruction, Open-Ended, and Head Start-Chosen Apps

\begin{tabular}{|c|c|c|c|c|c|c|c|}
\hline Apps & App Name & Ages & $\begin{array}{l}\text { Category in } \\
\text { iTunes }\end{array}$ & $\begin{array}{l}\text { iTunes Store } \\
\text { Rating (1-5) }\end{array}$ & $\begin{array}{c}\text { Common } \\
\text { Sense Media } \\
\text { Learning } \\
\text { Rating }(1-5)\end{array}$ & $\begin{array}{c}\text { AppoLearning } \\
\text { Rating } \\
(1-10)\end{array}$ & $\begin{array}{c}\text { Children's } \\
\text { Technology } \\
\text { Review Rating } \\
(1-100)\end{array}$ \\
\hline \multirow{4}{*}{$\begin{array}{l}\text { Direct } \\
\text { Instruction } \\
\text { Apps }\end{array}$} & Endless Alphabet & $\geq 5$ & Education & 5 & 3 & 8.9 & 96 \\
\hline & $\begin{array}{l}\text { Noodle Words HD - } \\
\text { Action Set } 1\end{array}$ & $3-6$ & Education & 4.5 & 4 & Not Rated & 94 \\
\hline & Goodnight ABC & $2+$ & Education & 4 & Not Rated & 9 & 86 \\
\hline & ABC Go & $\geq 5$ & Education & 4 & 4 & Not Rated & 90 \\
\hline \multirow{4}{*}{$\begin{array}{l}\text { Open-Ended } \\
\text { Apps }\end{array}$} & Beck and Bo & $\geq 5$ & Games & 4.5 & 4 & 9.6 & Not Rated \\
\hline & Draw and Tell HD & $\geq 5$ & Education & Not Rated & 3 & 8.8 & 94 \\
\hline & $\begin{array}{l}\text { Don't Let the Pigeon } \\
\text { Run This App! }\end{array}$ & $\geq 5$ & Books & 4 & $\begin{array}{l}\text { Not rated on } \\
\text { learning }\end{array}$ & 8.3 & 90 \\
\hline & Alien Assignment & $\geq 5$ & Education & 4.5 & 4 & 9 & 82 \\
\hline \multirow{5}{*}{$\begin{array}{l}\text { Head Start- } \\
\text { Chosen Apps }\end{array}$} & Letter School & $\geq 5$ & Education & 4.5 & 4 & 9.6 & 96 \\
\hline & Gazzili Science & $\geq 5$ & Education & 3.5 & Not Rated & 8.7 & Not Rated \\
\hline & $\begin{array}{l}\text { Yumiloo Rainbow } \\
\text { Power }\end{array}$ & $\geq 5$ & Education & 4 & Not Rated & Not Rated & Not Rated \\
\hline & Faces iMake ABC & $\geq 5$ & Education & 5 & 3 & Not Rated & 82 \\
\hline & Counting Bear & $4+$ & Education & 4 & Not Rated & 8.3 & Not Rated \\
\hline
\end{tabular}




\section{Child Intervention}

The specific apps were chosen to target the vocabulary knowledge of the children and served as the child intervention. In order to ensure program fidelity, the teachers in the I-DI and I-OE classrooms were required to attend weekly meetings with the doctoral student, who was the primary researcher. At the beginning of the study, the teachers were already using the iPads in the classrooms, and the first week the children came back from winter break, the primary researcher observed the morning block in the intervention and control classrooms to determine a baseline for how the teachers were using the iPads. During that week, the primary researcher brainstormed ideas for mentoring the intervention teachers during the weekly meetings. At the end of the week, initial thoughts were shared with the intervention teachers to help form an overall plan for the child intervention based on the needs of the classroom. The following week, the preassessments were conducted on the children. After the pre-assessments were completed, the teachers taught the children for eight weeks using their assigned apps. The children were allowed to use the apps throughout the day in addition to the time the teacher specifically taught the apps to the children.

Eight weeks was chosen for the intervention period because it was a similar duration to interventions in previous studies (Beschorner \& Hutchison, 2013; Couse \& Chen, 2010) conducted to examine the impact of mobile media and apps on young children's early literacy development. Additionally, after baseline observations and preassessments, there was a nine-week uninterrupted block of time prior to the children 
going on spring break. An eight-week intervention allowed for a week of postassessment to occur before the spring break.

The primary researcher met with the teachers in the intervention classrooms each week for approximately 30 minutes in order to ensure the program fidelity of the child intervention. The agendas for the weekly meetings in which the primary researcher mentored the teachers were based on developmentally appropriate practices for using interactive technology in early childhood settings, as outlined by NAEYC and the Fred Rogers Center (2012). Because the teachers were required to meet state mandated childteacher ratios (15:1 in three-year-old classrooms), meetings with the intervention teachers were held separately. This also allowed for differentiation of the child intervention for the different teachers based on their individual classroom needs. For each meeting, the teachers received a one-page meeting agenda (Appendix C) with suggestions from practitioner-based books (Puerling, 2012; Simon \& Nemeth, 2012) which were also summarized verbally during the meeting. The teachers' assistants were given a copy of the meeting agendas, but they did not take part in the meetings because the teachers' assistants could not leave the classroom to take part in the meetings without violating the 15:1 ratio mandate. Furthermore, the primary researcher observed at least once a week in the classrooms; notes and suggestions from observations were included on the weekly meeting agenda. The majority of the time children interacted with apps occurred during free choice centers in the classroom. The children had access to all of the apps at once. 
The following is an overall summary of the areas that were explored by the primary researcher with the two intervention teachers in order to ensure program fidelity of the child intervention:

1. The teachers allowed more than one child to use the same iPad at the same time.

2. Intentional teaching of iPad vocabulary and the functions of the apps were built into lesson plans so that children could use the devices and software more independently.

3. Children were moved from sitting in chairs at a table to a carpeted area to facilitate sharing during app use.

4. The teachers began to use apps during learning experiences other than free choice center time (e.g., small group and whole group).

5. The cameras were enabled on the iPads; the teachers used them to document children's learning and create digital portfolios.

6. The teachers created a "clean up" procedure so that the iPad center had the same accountability as all other centers.

7. The teachers attempted to discover systems so that the same children were not using the iPads every day, but still allowed for some degree of free choice in the centers.

\section{Control Groups}

Two classrooms within the same center as the intervention classrooms were

chosen by the center director to serve as control groups. After determining the four 
classrooms in the center which had the most three-year-olds at the beginning of the school year, the director chose the two intervention group classrooms based on her perception of the teachers' willingness to adhere to the child intervention. The control classrooms were the remaining two classrooms which had the most three-year-olds at the beginning of the school year. The classrooms had iPads with apps chosen by Head Start. The teachers received no weekly mentoring meetings. The primary researcher observed the teachers and children in the control groups at least once a week to determine how often the teachers were using the iPads and apps. All of the app use occurred during free choice center time.

Included in Table 1 are the app names, appropriate age ranges, and iTunes categories for the four Head Start-chosen apps that children in the control groups were most commonly observed using. A complete list of the 13 Head Start-chosen apps is included in Appendix B. Head Start did not examine the ratings prior to purchasing the apps; nevertheless, the ratings from the iTunes app store, Common Sense Media, AppoLearning, and Children's Technology Review are included to evaluate the appropriateness and quality of each app. Of the 13 apps chosen by Head Start, only the Letter School app was rated by all organizations. The majority of the apps were not rated by any of the organizations other than users in the iTunes app store, indicating that the Head Start-chosen apps were not on the radar of the early childhood technology community. 


\section{$\underline{\text { Data Collection Procedures }}$}

Once the study was approved by the researcher's dissertation committee, the manager of the Head Start program in a large, southeastern school district was contacted. At an initial meeting in August 2014, it was discovered that iPads were already purchased for the classrooms and the Head Start manager provided initial contact with a specific center within the county. The center was chosen based on recommendation from the manager. With nine classrooms, it was one of the largest centers in the county and afforded more classrooms to choose for the study. After the site was selected and the study was approved by the Head Start manager, University of Central Florida (UCF) Institutional Review Board (IRB) approval was obtained (Appendix A).

\section{IRB Procedures}

As per IRB protocol, no data were collected on any child who did not have an informed consent signed by a legal guardian. Participation was voluntary and, as described on the consent form, the legal guardian was given the option to withdraw his or her child from the data collection at any time. All data were coded, and codes were stored separately from identifying information so that children, teachers, and the specific Head Start county and site would remain anonymous in the data analysis. No incentives were offered to the site, teachers, children, or parents for participation in the study. Nevertheless, at the end of the study, the teachers were given a gift card to a local school supply store as a token gift.

In late October 2014, a meeting was held with the center director and the teachers in each classroom to discuss a strategy for collecting informed consent. As per 
recommendation of the director, teachers were provided with the informed consent forms, and they collected signatures from legal guardians. Signatures were obtained for every child in the four classrooms except for one child, whose parent declined consent. No assessment data or biographical information were collected for this child.

Additionally, prior to the administration of each assessment, every child provided assent. In order to obtain child assent, the assessor was trained to say, "Will you play a game with me?" If the child verbally said, "Yes," or nodded his/her head up and down, the assessment was conducted. There were no instances where a child declined assent.

At the end of the study, the primary researcher offered to meet with the teachers in the control classrooms to discuss developmentally appropriate practices for using technology in the classroom. The teachers declined, but the primary researcher provided a phone number and email address to the teachers. The Head Start manager requested a meeting once the final report was completed and that meeting was tentatively scheduled for August 2015.

\section{Recruitment of Assessors and Administration of Assessments}

During December 2014, a team of seven UCF undergraduate and graduate students were recruited via email to help administer the assessments to the children. Four of the assessors took the UCF Early Childhood Development and Education (ECDE) undergraduate course EEC 3613 Observation and Assessment of Young Children or EEC 4207 Assessment and Evaluation of Young Children and used the PPVT-4 (Dunn \& Dunn, 2007) and EVT-2 (Williams, 2007) as part of their coursework. The students were chosen based on recommendations from the professor of the courses who also served as 
dissertation chair. The remaining three assessors were recruited after they emailed a UCF ECDE faculty member about their interest in gaining research experience. The assessors did not receive an incentive for assisting in the study. However, the assessors valued the experience of working on a research project.

The primary researcher, who had experience training UCF students in administering these assessments to children, held an information session at the Head Start site to review the assessments. All assessors participated in reliability training, wherein they observed the primary researcher assessing Head Start children not included in the study and scored the children at the same time. Then, the primary researcher scored along with each of the assessors as they administered the assessments to non-study Head Start children. After each practice assessment, scores were compared, and discrepancies were discussed. After discussion, there was $100 \%$ agreement for each item on each assessment.

The administration of the assessments took place in an empty classroom at the Head Start site, which was converted into a space for children to receive therapy services. Each assessor was seated at a table in the space which was arranged so that the primary researcher could oversee the administration of all assessments at once. The assessments each took approximately 15 minutes to administer (the expected time for the assessments chosen) and the assessments were administered between 9 a.m. and 11:30 a.m. each day of the assessment period. So as not to overwhelm the children with all assessments at once, the assessments were administered on alternating days. For example, one child may have been assessed on the PPVT- 4 on a Monday, the EVT-2 on a Tuesday, and then 
the iPad Receptive and Expressive Vocabulary Assessments (Vatalaro, 2015a, 2015b) on a Wednesday. The PPVT-4, EVT-2, and iPad Receptive and Expressive Vocabulary assessments were administered within one week prior to the beginning of the intervention. Due to absences, some assessment occurred during the first week of the intervention. To immediately assess the effect of the intervention, the post-assessments were administered within one week after the intervention ended for the children in the intervention classrooms. The post-assessments for the children in the control classrooms were administered when the children returned to school immediately after their spring break.

\section{$\underline{\text { Instrumentation }}$}

\section{Vocabulary Measures}

The study sought to examine the receptive and expressive vocabulary knowledge of preschool children in Head Start classrooms. In order to do so, data were collected using two standardized assessments that assess receptive and expressive vocabulary. The first assessment was the Peabody Picture Vocabulary Test, fourth edition (PPVT-4), which assesses receptive vocabulary (Dunn \& Dunn, 2007). The second assessment is the Expressive Vocabulary Test, second edition (EVT-2), which assesses expressive vocabulary (Williams, 2007). Because the two assessments correlate highly with one another (average $r=.82$ ), they are often used together to gain a comprehensive picture of a child's vocabulary knowledge (Dunn \& Dunn, 2007; Williams, 2007). 
Scores from the PPVT-4 and the EVT-2 include standard scores and growth scale values (GSV). The purpose of the GSV is to measure absolute value of children's performance and their changes in scores over time. The standard score measures one child's performance against the performance of similar-aged children. Thus, children's standard scores should remain constant if their vocabulary is increasing at the same rate of same-aged peers. It is possible for children's GSVs to increase but the standard scores to decrease, because even though the children's vocabulary may be increasing, it may not be doing so at the average rate for their age. The GSV is the more accurate measure of individual child performance across time and is a better measure when examining scores across a short time span (Dunn \& Dunn, 2007; Williams, 2007). Thus, for the purposes of this study, the GSVs were analyzed.

\section{$\underline{\text { Psychometrics for the Peabody Picture Vocabulary Test (PPVT-4) }}$}

The PPVT-4 is a norm-referenced, 228 item standardized assessment that measures receptive vocabulary of Standard American English. Not all children in the classrooms of the present study spoke English as a first language; nevertheless, all apps except for one Head Start-chosen app, Feed Me! 3.0 Mexican Spanish, used Standard American English. Thus, exposure to English-language apps could potentially increase scores from pre- to post-assessment. The assessment is appropriate for ages 2 years, 6 months through $90+$ years. The assessment provides standard scores by age and by grade level (Kindergarten through Grade 3). The assessment includes pages of four color pictures. Participants are asked to point to one specific picture on each page until the 
child reaches the ceiling level. It takes approximately 10 to 20 minutes to administer the assessment. There are parallel forms of the assessment (Form A and Form B) so that preand post-test data can be collected without the pre-test influencing responses on the posttest. The reliability of the items was computed across all ages and grade levels; and differences in gender, ethnicity, parental education, and geographical region were accounted for. Reliability and validity data for the PPVT-4 was reported based on the age norm as the current study examined children who were not of school age.

Data from the PPVT-4 indicate reliability. Internal consistency reliability determined by coefficient alpha is high with a mean alpha of .97 for Form A and .96 for Form B $(N=3,540)$. Alternate-form reliability is high with a mean adjusted $r$ of .89 for all ages $(N=508)$. Test-retest reliability is high with a mean adjusted $r$ of .93 for all ages $(N=340)$. The three forms of reliability indicate that measurement error will have little effect on a participants' scores, regardless of which form is administered (Dunn \& Dunn, 2007).

Data from the PPVT-4 also indicate validity. In order to ensure content validity of the vocabulary assessed on the PPVT-4, the 2003 edition of the Merriam-Webster's Collegiate Dictionary and the 1953, 1967, and 1981 editions of the Webster's New Collegiate Dictionary were consulted to create a pool of words from 20 content areas. The number of items for each content area is comparable for Forms A and B. Construct validity was determined by correlating the PPVT-4 with five other measures of vocabulary development: the Comprehensive Assessment of Spoken Language (CASL); the Clinical Evaluation of Language Fundamentals, fourth edition (CELF-4); the Group 
Reading Assessment and Diagnostic Evaluation (GRADE); the EVT-2; and the PPVTIII. For the PPVT-4 comparison to the CASL for children ages three to five years $(N=$ $68)$, three areas were correlated: basic concepts $(r=.50)$; antonyms $(r=.41)$; and sentence completion $(r=.54)$. For the PPVT-4 comparison to the CELF-4 for children ages five to eight years $(N=55)$, three areas were examined: core language $(r=.73)$; receptive language $(r=.67)$; and expressive language $(r=.72)$. For the PPVT-4 comparison to the GRADE, grade level was used for kindergarteners in the fall $(N=50 ; r$ $=.71)$. For the PPVT-4 comparison to the EVT-2, the average $r$ was $.82(N=3,540)$. Finally, for the PPVT-4 comparison to the PPVT-III, the average $r$ was $.84(N=322)$. This data indicates that the PPVT-4 has moderate to high correlations with other valid vocabulary measures. The lower correlations for the CASL are most likely because the PPVT-4 assesses receptive language and the CASL examines different areas of language development such as sentence completion (Dunn \& Dunn, 2007).

\section{$\underline{\text { Psychometrics for the EVT-2 }}$}

The EVT-2 is a norm-referenced, 190 item standardized assessment that measures expressive vocabulary of Standard American English. The assessment is appropriate for ages 2 years, 6 months through $90+$ years. The assessment provides standard scores by age and by grade level (Kindergarten through Grade 3). The assessment includes sets of one color picture. For each picture, the examiner is provided with a stimulus question such as: "What is she doing?"; "Tell me another word for "; and "What do you see?" The participants are expected to verbally provide a response. For each item, there 
is a list of correct and incorrect responses, and the child's score for each item is based on the list of these responses. It takes approximately 10 to 20 minutes to administer the assessment. There are parallel forms of the assessment (Form A and Form B) so that preand post-test data can be collected without the pre-test influencing responses on the posttest. The reliability of the items was computed across all ages and grade levels; and differences in gender, ethnicity, parental education, and geographical region were accounted for. Reliability and validity data for the EVT-2 was reported based on the age norm, as the current study was conducted to examine children who were not of school age.

Data from the EVT-2 indicate reliability. Internal consistency reliability determined by coefficient alpha is high with a mean alpha of .96 for Forms $\mathrm{A}$ and $\mathrm{B}(N=$ 3,540). Alternate-form reliability is high with a mean adjusted $r$ of .87 for all ages $(N=$ 507). Test-retest reliability is high with a mean adjusted $r$ of .95 for all ages $(N=348)$. The three forms of reliability indicate that measurement error will have little effect on participants' scores, regardless of which form is administered (Williams, 2007).

Data from the EVT-2 indicate validity. In order to ensure content validity of the vocabulary assessed on the EVT-2, nine published reference works were consulted to create a pool of words from 20 content areas. The number of items for each content area is comparable for Form A and Form B. Construct validity was determined by correlating the EVT-2 with five other measures of vocabulary development: the CASL, the CELF-4, the GRADE, the PPVT-4, and the EVT. For the EVT-2 comparison to the CASL for children ages three to five years $(N=68)$, three areas were examined: basic concepts $(r=$ 
$.59)$; antonyms $(r=.67)$; and sentence completion $(r=.51)$. For the EVT-2 comparison to the CELF-4 for children ages five to eight years $(N=55)$, three areas were examined: core language $(r=.80)$; receptive language $(r=.68)$; and expressive language $(r=.79)$. For the EVT-2 comparison to the GRADE, grade level was used for kindergarteners in the Fall $(N=50 ; r=.76)$. For the EVT-2 comparison to the PPVT-4, the average $r$ was $.82(N=3,540)$. Finally, for the EVT-2 comparison to the EVT, the average $r$ was $.81(N$ =377). This data indicate that the EVT-2 has moderate to high correlations with other valid vocabulary measures (Williams, 2007).

\section{$\underline{\text { iPad Receptive Vocabulary Assessment }}$}

The primary researcher (Vatalaro, 2015a) created an iPad Receptive Vocabulary Assessment (Appendix D). The iPad Receptive Vocabulary Assessment was designed to measure the receptive vocabulary of nine components and functions of the iPad, including: iPad; screen; swipe; home button; apps; dock port; lock screen; volume control; and camera. Modeled from the PPVT-4, for each vocabulary word, children were shown sets of four color pictures at a time and were asked to point to the targeted vocabulary word. Each picture was numbered for the assessor to mark the child's response on the scoresheet. Like the PPVT-4, the correct answer on the scoresheet was indicated in red. Each item was worth one point and the highest score that could be obtained was 9 .

The iPad Receptive Vocabulary Assessment was created by the primary researcher for the present study and there was no previous evidence of reliability or 
validity. In order to ensure reliability, children at the Head Start center in which the study was conducted, but not included in the study, were given the assessment by an assessor while the primary researcher scored the children at the same time. Answers were compared and 100\% agreement on each item was achieved. The primary researcher also observed while the children in the study were being assessed to further ensure the reliability of the results.

\section{$\underline{\text { iPad Expressive Vocabulary Assessment }}$}

The primary researcher (Vatalaro, 2015b) created an iPad Expressive Vocabulary Assessment (Appendix E). The iPad Expressive Vocabulary Assessment was designed to measure the expressive vocabulary of nine components and functions of the iPad, including: iPad; screen; swipe; home button; apps; dock port; lock screen; volume control; and camera. Modeled from the EVT-2, for each vocabulary word, children were shown sets of one color picture at a time and were asked a stimulus question (e.g., "What is this?") to prompt a verbal response from the children. For the picture of the iPad, children could receive two points if the word iPad was stated, and one point if the word tablet was stated. For the picture of the dock port, children could receive two points if the word dock port was stated, and one point if the word charger was stated. For all other items, children could receive one point for verbally stating the correct vocabulary word. The highest score that could be obtained was 11. The iPad Expressive Vocabulary Assessment was administered prior to the iPad Receptive Vocabulary Assessment so that 
expressive vocabulary responses were not influenced by first hearing the correct terms for receptive vocabulary responses.

During the post-assessment period, the primary researcher noticed that, while many children were not using the correct technical vocabulary word, they were correctly describing the function. For example, when shown a picture of the lock screen, one child in the I-OE classroom responded, "turn it and do passcode." Similarly, when shown a picture of the volume control, another child in the I-OE classroom responded, "buttons to turn the sound up." Therefore, the iPad Expressive Vocabulary data were analyzed twice: iPad Expressive Vocabulary Correct Word and iPad Expressive Vocabulary Correct Word or Description.

The iPad Expressive Vocabulary Assessment was created by the primary researcher for the present study and there was no previous evidence of reliability or validity. In order to ensure reliability, children at the Head Start center in which the study was conducted, but not included in the study, were given the assessment by an assessor while the primary researcher scored the children at the same time. Answers were compared and $100 \%$ agreement on each item was achieved. The primary researcher also observed while the children in the study were being assessed to further ensure the reliability of the results.

\section{Family Technology Ownership and Use Survey}

A Family Technology Ownership and Use Survey, which included selected and modified questions from previous survey research in the field (Common Sense Media, 2013) was given to a legal guardian for each child in the study. The survey had no 
reliability or validity evidence from previous research, but the survey offered helpful guidelines on how to phrase simple questions about screen media usage in the home. The survey included questions about all types of screen media in the home (e.g., TV/DVDs, computers, video games, and tablets). Because the focus of the present study was specific to mobile media, questions were modified so that parents were only reporting on mobile media use in the home, rather than all types of screen media. Information from the survey included demographic data and children's access and exposure to mobile media in the home.

Questions 1 through 7 on the Family Technology Ownership and Use Survey were demographic questions created by the primary researcher. Questions 15 and 16 were open response and were also created by the primary researcher to allow parents to add information that may not have been considered in the survey. For the present study, questions 8 through 14 on the Family Technology Ownership and Use Survey pertaining to mobile media usage were selected from the Common Sense Media (2013) survey.

The original Common Sense Media (2013) survey included 27 items. Item scales varied and included: yes or no questions about which screen media are included in the home, frequency of use for specific types of screen media, and varying five-point Likert scales (e.g., from "all of them" to "none"; from "always" to "never"). Perceptions about screen media were also measured through guided responses. For example, a question about media use in the home included the following choices: "(a) media cause us to spend more time with other family members; (b) media cause us to spend less time with 
family members; [and] (c) media don't make much difference in how much time we spend with other family members" (p. 33).

For the present study, question responses were modified so that the lowest level of the Likert scale (e.g., "none") consistently appeared as the first choice and the highest level (e.g., "all”) appeared as the final choice. An additional point was added to the Likert scale ("only a few") to make it a six-point scale and allow parents to have a response between "none" and "less than half". For questions 12 and 13 on the Family Technology Ownership and Use Survey, the activities were modified to reflect only mobile media use. For example, the original item on the Common Sense Media survey (2013) stated, "play video games on a console player like an X-box, PlayStation, or Wii" (p. 35) and the modified item stated, "play games on a handheld video game player (like a Gameboy, PSP, or Nintendo DS). The activity "listen to music" on question 12 was added by the primary researcher.

The Family Technology Ownership and Use Survey was piloted with parents at a local early childhood center which served an economically disadvantaged community. Six parents returned the pilot survey. In reviewing the completed surveys, two of the parents marked more than one choice for question 15 ("When your child uses a mobile device, how does your child primarily use the device"). In order to ensure that parents in the present study would answer the question as intended, "Please mark one choice" was added to the question. All other questions were answered as intended by the primary researcher. 
The Family Technology Ownership and Use Survey was given to the teachers in the present study to collect from parents in January 2015, and all completed surveys were collected by March 2015. The teachers primarily had the parents complete the surveys when they dropped off their children in the morning or picked them up in the afternoon. For parents of children who attended an extended day program where the teacher did not encounter the parents during typical drop off and pick up times, the surveys were sent home in the child's backpack for the parent to return. The teachers gave the primary researcher completed surveys at the end of every week. Surveys were offered to the parents in both English (Appendix F) and Spanish (Appendix G).

\section{Teacher Technology Perception and Use Survey}

A Teacher Technology Perception and Use Survey, which included selected and modified questions from previous survey research in the field (Blackwell, Lauricella, \& Wartella, 2014) was given to all teachers and all teachers' assistants pre- and post-child intervention. This survey had no reliability or validity evidence from previous research, but the survey offered helpful guidelines on how to phrase simple questions about screen media usage in the classroom. The survey included questions about all types of screen media that may be found in the classroom (e.g., TV/DVDs, computers, video games, and tablets). Because the focus of the present study was specific to mobile media, questions were modified so that teachers were only reporting on mobile media use in the classroom, rather than all types of screen media. Survey data included demographic information, the ways the teachers were using mobile media in the classroom with children, and perceptions about mobile media use in the classroom (Appendix $\mathrm{H}$ ). 
Questions 1 through 4 on the Teacher Technology Perception and Use Survey included demographic questions and were created by the primary researcher. Questions 13 and 14 were created by the primary researcher to gather more information about teacher professional development than what was on the original survey. Question 19 was open response and was also created by the primary researcher to allow teachers to add information that may not have been considered in the survey. For the present study, questions 5 through 12 and 15 through 18 on the Teacher Technology Perception and Use Survey pertaining to mobile media usage were selected from Blackwell et al.’s survey (2014).

The original survey (Blackwell et al., 2014) included 48 items. Item scales varied and included: yes or no questions about which screen media are used in the classroom, scales for frequency of use (e.g., from "never" to "daily"), and varying five-point Likert scale (e.g., from "not confident at all" to "very confident"; from "strongly disagree" to "strongly agree"). Perceptions about screen media were also measured through guided responses. For example, the question posed by Blackwell and colleagues (included as question 11 on the Teacher Technology Perception and Use Survey) was, "What is the earliest age you think is appropriate to introduce children to technology in an early childhood classroom/program?” (p. 6). Responses for this item included narrow age ranges for children from birth through age eight (e.g., "0-2 years old; "3-4 years old", etc.). Original questions were modified to only reflect mobile media usage. For example, the original items on the survey (Blackwell et al., 2014) began with "technology 
can help. .." (p. 6). This was modified on the Teacher Technology Perception and Use Survey to state, "mobile device apps can help. . ."

\section{Teacher Self-Report and Observation Checklist}

In order to get a sense of how frequently teachers and children in the intervention groups were using the iPads and apps on a daily basis, the lead teachers in these classrooms were asked to complete self-report daily logs (Appendix I). The log was created after the baseline observation was completed and was based on developmentally appropriate guidelines for using technology in the classroom (Harms, Clifford, \& Cryer, 2005; NAEYC \& Fred Rogers Center, 2012). The logs were also used by the primary researcher as a guided observation tool for weekly observations in the intervention and control classrooms.

There were eight items on the log. The first item included all areas on the teachers' daily schedule to help determine the frequency of app use for each school day. Items 2 through 6 included a three-point Likert scale (e.g., "very", "somewhat", and "not at all") to indicate the degree to which the person completing the form believed that apps use adhered to developmentally appropriate guidelines. These guidelines included the degree to which app use: supported children's learning, encouraged children to be actively involved in their learning, encouraged children to be creative, supported daily classroom themes and activities, and encouraged children to collaborate with one another. Item 7 was intended to track which apps were used on the iPad Air and iPad Mini in each classroom. Finally, item 8 was an open response item added for the intervention 
classroom teachers to include any additional insights not answered by the previous questions.

\section{$\underline{\text { Research Questions }}$}

The research questions that were addressed in the study included the following:

1. Is there a mean difference over time (pre to post) in receptive vocabulary (as measured by PPVT-4, Dunn \& Dunn, 2007; and iPad Receptive Vocabulary Assessment, Vatalaro, 2015a) of preschool Head Start children based on iPad apps in the classroom (open-ended/creative apps versus direct instruction apps versus Head Start-chosen apps)?

2. Is there a mean difference over time (pre to post) in expressive vocabulary (as measured by EVT-2, Williams, 2007; and iPad Expressive Vocabulary Assessment, Vatalaro, 2015b) of preschool Head Start children based on iPad apps in the classroom (open-ended/creative apps versus direct instruction apps versus Head Start-chosen apps)?

3. Within the intervention groups, what is the frequency of and how do Head Start teachers report using apps in the classroom?

\section{$\underline{\text { Statistical Analysis Procedures }}$}

\section{Research Questions 1 and 2}

For Research Questions 1 and 2, data were inputted and analyzed using SPSS version 22. A repeated measures analysis of variance (ANOVA) with a two-factor split- 
plot design (Lomax \& Hahs-Vaughn, 2012) was conducted to determine if the mean preand post-test PPVT-4 and EVT-2 GSVs, as well iPad Receptive Vocabulary Assessment and iPad Expressive Vocabulary Assessment scores differed between the intervention and control groups. The repeated measures ANOVA with between group interactions (splitplot) was selected because the dependent variables (expressive and receptive vocabulary) consisted of interval, continuous data, and the difference and interaction of more than two related groups were measured more than one time. The split-plot was used because there was more than one independent group being analyzed. The categorical between-subjects factor was group (intervention or control). The categorical within-subjects factors was time (pre- and post-test). The continuous, dependent variables were the PPVT-4, EVT-2, iPad Receptive Vocabulary Assessment and iPad Expressive Vocabulary Assessment scores.

Prior to running the repeated measures ANOVA with split-plot, the following assumptions were tested, as suggested by Lomax and Hahs-Vaughn (2012), so that the results were valid: (a) data will be controlled for outliers; (b) the data will be normally distributed; (c) there will be homogeneity of variances; and (d) there will be spherecity. Any violations of the assumptions were addressed in the analysis.

\section{Research Question 3}

For Research Question 3, data from the intervention group teachers' daily selfreport logs was inputted into SPSS version 22. Data were expressed as descriptive statistics, with frequencies for each area on the log presented. 


\section{Summary}

This chapter contains an outline of the research methodology for conducting the present study. A quasi-experimental research design with nonequivalent control-group design was used to answer the research questions. The chapter included a discussion of the population of Head Start classrooms and how the convenience sample of four classrooms was identified. Data collection procedures, including ethical considerations as outlined by UCF IRB protocol, were presented. A detailed description of the eightweek child intervention was provided. Finally, the data analysis plan was described. Chapter 4 presents the analysis of the data using the procedures described in this chapter. 


\section{CHAPTER 4}

\section{FINDINGS}

\section{$\underline{\text { Introduction }}$}

The primary purpose of this study was to examine if different types of apps could increase the receptive and expressive vocabulary scores of Head Start preschool children. A secondary purpose was to examine the frequency and use of apps by the teachers in the Head Start intervention classrooms. This chapter presents the characteristics of the participants and the findings from the three research questions which were used to guide the study.

\section{$\underline{\text { Participants }}$}

\section{Characteristics of Child Participants}

Child participants were children aged three, four, and five years old from four Head Start preschool classrooms at the same center in a large southeastern school district. As shown in Figure 1, at the beginning of the study, there were a total of 73 child participants. At the end of the study, six children had left the Head Start Center, and four children had very low attendance. Thus, a total of 63 children were included in the final data analysis, 31 in the intervention classrooms and 32 in the control classrooms [Intervention--Direction Instruction $(\mathrm{I}-\mathrm{DI})=16$; Intervention--Open-Ended $(\mathrm{I}-\mathrm{OE})=15$; Control $1(\mathrm{C}-1)=18 ;$ Control $2(\mathrm{C}-2)=14]$. 


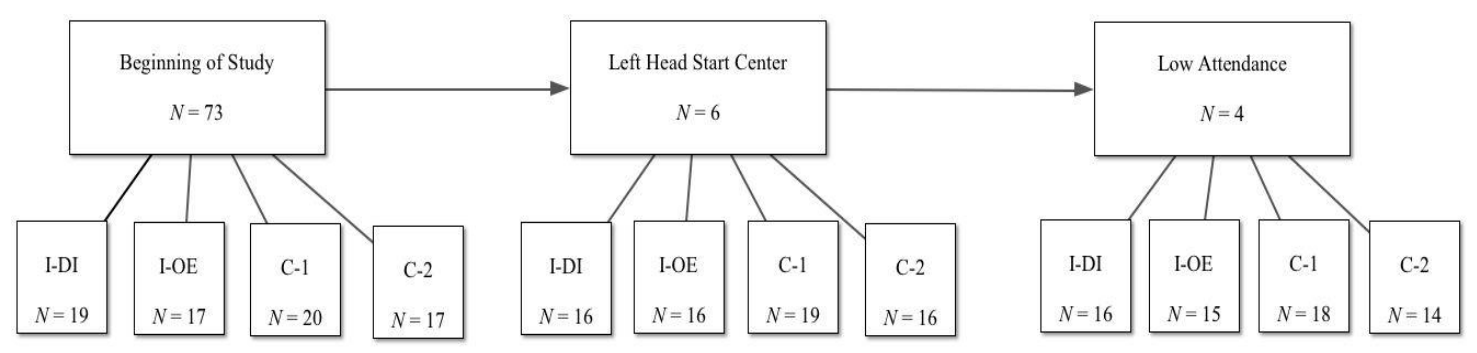

Figure 1. Child participant attrition

Head Start center staff members provided the age and gender for each child. Other demographic data and information about mobile device use in the home were collected through the English and Spanish Family Technology Ownership and Use Surveys (Appendices F and G). Of the 63 child participants, two parents did not return the survey (96.8\% response rate). For the two children with no completed parent survey, the child's teacher was asked to confirm ethnicity and primary language spoken at home; information about mobile device use in the home was not received for these two children.

Individual characteristics of the children are included in Table 2. Of note, $77.8 \%$ of children in the study were Hispanic. Children who were Hispanic comprised $68.8 \%$ of the I-DI classroom, $80.0 \%$ of the I-OE classroom, $94.4 \%$ of the C-1 classroom, and $64.3 \%$ of the C-2 classroom. For primary language spoken at home, overall, $85.8 \%$ of the children were exposed to a language other than English. For each group, $93.8 \%$ of the I-DI classroom, $86.6 \%$ of the I-OE classroom, $83.3 \%$ of the C- 1 classroom, and $78.5 \%$ of the C-2 classroom were exposed to a language other than English in the home. Of the entire sample, $14.3 \%$ of the children heard a non-English language only at home. Children who were exposed to only a non-English language encompassed $12.5 \%$ of the I- 
DI classroom, $13.3 \%$ of the I-OE classroom, $22.2 \%$ of the C-1 classroom, and $7.1 \%$ of the $\mathrm{C}-2$ classroom.

All children who returned a survey had exposure to at least one mobile device at home with a mean of 2.23 devices in each home $(S D=1.039$, range $=4)$. The majority of children in the I-DI classroom $(56.3 \%)$ had access to three mobile devices in the home. The majority of children in the I-OE classroom (40.0\%) and the C-1 classroom (44.4\%) had access to two mobile devices in the home. Finally, the majority of children in the C2 classroom $(28.6 \%)$ had access to one mobile device in the home. 
Table 2

Frequencies for Individual Characteristics of Children by Classroom

\begin{tabular}{|c|c|c|c|c|}
\hline Characteristic & $\begin{array}{c}\text { Intervention } \\
\text { Direct Instruction } \\
\text { (I-DI) }\end{array}$ & $\begin{array}{c}\text { Intervention } \\
\text { Open-Ended } \\
\text { (I-OE) }\end{array}$ & Control 1 (C-1) & Control 2 (C-2) \\
\hline \multicolumn{5}{|l|}{$\begin{array}{l}\text { Age at beginning } \\
\text { of study }\end{array}$} \\
\hline 3 years & $3(18.8 \%)$ & $6(40.0 \%)$ & $6(33.3 \%)$ & $3(21.4 \%)$ \\
\hline 4 years & $9(56.3 \%)$ & $8(53.3 \%)$ & $6(33.3 \%)$ & $6(42.9 \%)$ \\
\hline 5 years & $4(25.0 \%)$ & $1(6.7 \%)$ & $6(33.3 \%)$ & $5(35.7 \%)$ \\
\hline \multicolumn{5}{|l|}{ Gender } \\
\hline Male & $10(62.5 \%)$ & $853.3 \%)$ & $9(50.0 \%)$ & $6(42.9 \%)$ \\
\hline Female & $6(37.5 \%)$ & $7(46.7 \%)$ & $9(50.0 \%)$ & $8(57.1 \%)$ \\
\hline \multicolumn{5}{|l|}{ Ethnicity } \\
\hline $\begin{array}{l}\text { African } \\
\text { American }\end{array}$ & $1(6.3 \%)$ & $1(6.7 \%)$ & $1(5.6 \%)$ & $1(7.1 \%)$ \\
\hline Hispanic & $11(68.8 \%)$ & $12(80.0 \%)$ & $17(94.4 \%)$ & $9(64.3 \%)$ \\
\hline Mixed & $2(12.5 \%)$ & $0(0 \%)$ & $0(0 \%)$ & $2(14.3 \%)$ \\
\hline Other & $2(12.5 \%)$ & $2(13.3 \%)$ & $0(0 \%)$ & $2(14.3 \%)$ \\
\hline \multicolumn{5}{|l|}{$\begin{array}{l}\text { Primary language } \\
\text { spoken at home }\end{array}$} \\
\hline Only English & $1(6.3 \%)$ & $2(13.3 \%)$ & $3(16.7 \%)$ & $3(21.4 \%)$ \\
\hline $\begin{array}{l}\text { Mainly English, } \\
\text { but also some } \\
\text { other } \\
\text { language(s) }\end{array}$ & $11(68.8 \%)$ & $4(26.7 \%)$ & $3(16.7 \%)$ & $8(57.1 \%)$ \\
\hline $\begin{array}{l}\text { Mainly other } \\
\text { language(s), but } \\
\text { also English }\end{array}$ & $2(12.5 \%)$ & $7(46.7 \%)$ & $8(44.4 \%)$ & $2(14.3 \%)$ \\
\hline $\begin{array}{l}\text { A non-English } \\
\text { language only }\end{array}$ & $2(12.5 \%)$ & $2(13.3 \%)$ & $4(22.2 \%)$ & $1(7.1 \%)$ \\
\hline \multicolumn{5}{|l|}{$\begin{array}{l}\text { Number of } \\
\text { mobile devices } \\
\text { child had access } \\
\text { to at home }\end{array}$} \\
\hline 1 & $4(25.0 \%)$ & $4(26.7 \%)$ & $6(33.3 \%)$ & $4(28.6 \%)$ \\
\hline 2 & $2(12.5 \%)$ & $6(40.0 \%)$ & $8(44.4 \%)$ & $3(21.4 \%)$ \\
\hline 3 & $9(56.3 \%)$ & $2(13.3 \%)$ & $3(16.7 \%)$ & $3(21.4 \%)$ \\
\hline 4 & $0(0 \%)$ & $3(20.0 \%)$ & $1(5.6 \%)$ & $2(14.3 \%)$ \\
\hline 5 & $0(0 \%)$ & $0(0 \%)$ & $0(0 \%)$ & $1(7.1 \%)$ \\
\hline Missing & $1(6.3 \%)$ & $0(0 \%)$ & $0(0 \%)$ & $1(7.1 \%)$ \\
\hline
\end{tabular}




\section{Characteristics of Teacher Participants}

Four teachers and their assistants participated in the study. Direct instruction and open-ended apps were used for the child intervention and did not necessarily reflect each teacher's specific teaching style. Nevertheless, for clarity, the teachers and assistants are described as I-DI teacher and assistant and I-OE teacher and assistant. All eight teachers and assistants were female. Individual characteristics of the teachers and assistants are included in Tables 3 and 4 . Of note, the mean age of the teachers in the intervention groups was $44.5(S D=7.778$, range $=11)$. The mean age of the intervention teachers' assistants was $36.5(S D=.707$, range $=1)$. The mean age of the teachers in the control groups was $50.0(S D=1.414$, range $=2)$. The mean age of the teachers' assistants in the control groups was $36.5(S D=21.920$, range $=31)$.

The majority of teachers and assistants were Hispanic. The teachers and assistants in the C-1 and I-DI classrooms held a bachelor's degree in ECDE. The teacher and assistant in the C-2 classroom had some coursework in ECDE, but no degree. The IOE teacher had a graduate degree in special education.

The mean number of years in the teaching profession for the teachers in the intervention groups was $12.0(S D=11.314$, range $=16)$ and their mean number of years teaching in Head Start was $4.0(S D=4.243$, range $=6)$. The mean number of years in the teaching profession for the teachers' assistants in the intervention groups was 10.5 $(S D=4.950$, range $=7)$, which was the same as their mean number of years teaching in Head Start. The mean number of years in the teaching profession for the teachers in the control groups was $16.5(S D=2.121$, range $=3)$ and their mean number of years 
teaching in Head Start was $13.5(S D=2.121$, range $=3)$. The mean number of years in the teaching profession for the teachers' assistants in the control groups was $12.5(S D=$ 10.607, range $=15)$ and their mean number of years teaching in Head Start was $7.79(S D$ $=10.196$, range $=14)$. 
Table 3

Frequencies for Individual Characteristics of Teachers

\begin{tabular}{|c|c|c|c|c|c|c|c|c|}
\hline \multicolumn{5}{|c|}{ Intervention } & \multicolumn{4}{|c|}{ Control } \\
\hline Characteristic & $\begin{array}{l}\text { Teacher } \\
\text { I-DI }\end{array}$ & $\begin{array}{l}\text { Assistant } \\
\text { I-DI }\end{array}$ & $\begin{array}{l}\text { Teacher } \\
\text { I-OE }\end{array}$ & $\begin{array}{l}\text { Assistant } \\
\text { I-OE }\end{array}$ & $\begin{array}{l}\text { Teacher } \\
\text { C-1 }\end{array}$ & $\begin{array}{l}\text { Assistant } \\
\text { C-1 }\end{array}$ & $\begin{array}{c}\text { Teacher } \\
\text { C-2 }\end{array}$ & $\begin{array}{l}\text { Assistant } \\
\text { C-2 }\end{array}$ \\
\hline Age & 50 & 36 & 39 & 37 & 49 & 52 & 51 & 21 \\
\hline $\begin{array}{l}\text { Number of years } \\
\text { teaching at head } \\
\text { start }\end{array}$ & 7 & 14 & 1 & 7 & 15 & 15 & 12 & $<1$ \\
\hline Ethnicity & & & & & & & & \\
\hline African American & & & $X$ & & & & & \\
\hline Hispanic & & $X$ & & $X$ & $X$ & $X$ & $X$ & $X$ \\
\hline $\begin{array}{l}\text { Asian/Pacific } \\
\text { Islander } \\
\text { Type of ECDE } \\
\text { preparation }\end{array}$ & X & & & & & & & \\
\hline $\begin{array}{l}\text { Some ECDE } \\
\text { course work, but } \\
\text { no degree }\end{array}$ & & & & & & & $\mathrm{X}$ & $X$ \\
\hline $\begin{array}{l}\text { Child development } \\
\text { Associate (CDA) } \\
\text { credential }\end{array}$ & & & & $X$ & & $X$ & $\mathrm{X}$ & $X$ \\
\hline $\begin{array}{l}\text { Associate's degree } \\
\text { in ECDE }\end{array}$ & & & & & & & & $X$ \\
\hline $\begin{array}{l}\text { Bachelor's degree } \\
\text { in ECDE }\end{array}$ & $X$ & $X$ & & & $X$ & $X$ & & \\
\hline $\begin{array}{l}\text { Graduate work in } \\
\text { ECDE, but no } \\
\text { degree }\end{array}$ & $X$ & & & & & & & \\
\hline $\begin{array}{r}\text { Graduate degree in } \\
\text { special education }\end{array}$ & & & $X$ & & & & & \\
\hline
\end{tabular}


Table 4

Mean, Standard Deviation, and Range for Individual Characteristics of Teachers

\begin{tabular}{|c|c|c|c|c|}
\hline & \multicolumn{2}{|c|}{ Intervention } & \multicolumn{2}{|c|}{ Control } \\
\hline & Teachers & Assistants & Teachers & Assistants \\
\hline \multicolumn{5}{|l|}{ Characteristic } \\
\hline \multicolumn{5}{|l|}{ Age } \\
\hline Mean & 44.5 & 36.5 & 50.0 & 36.5 \\
\hline $\begin{array}{l}\text { Standard } \\
\text { deviation }\end{array}$ & 7.778 & .707 & 1.414 & 21.920 \\
\hline Range & 11 & 1 & 2 & 31 \\
\hline \multicolumn{5}{|l|}{$\begin{array}{l}\text { Number of } \\
\text { years in } \\
\text { teaching } \\
\text { profession }\end{array}$} \\
\hline Mean & 12.0 & 10.5 & 16.5 & 12.5 \\
\hline $\begin{array}{l}\text { Standard } \\
\text { deviation }\end{array}$ & 11.314 & 4.950 & 2.121 & 10.607 \\
\hline Range & 16 & 7 & 3 & 15 \\
\hline \multicolumn{5}{|l|}{$\begin{array}{l}\text { Number of } \\
\text { years teaching } \\
\text { in the Head } \\
\text { Start Program }\end{array}$} \\
\hline Mean & 4.0 & 10.5 & 13.5 & 7.79 \\
\hline $\begin{array}{l}\text { Standard } \\
\text { deviation }\end{array}$ & 4.243 & 4.950 & 2.121 & 10.196 \\
\hline Range & 6 & 7 & 3 & 14 \\
\hline
\end{tabular}

\section{Examining Baseline Equivalency}

Because there was not random assignment of participants in the present study, the baseline equivalency was tested in order to determine if there were any significant differences between groups at the pre-test. Five one-way analysis of variance (ANOVA) were generated, one for each of pre-assessment continuous, dependent variable: PPVT-4 
Growth Scale Value, EVT-2 Growth Scale Value, iPad Receptive Vocabulary

Assessment, iPad Expressive Vocabulary Correct Word Assessment, and iPad Expressive Vocabulary Correct Word or Description Assessment. The independent variable was group status (four groups). Templates from Lomax and Hahs-Vaughn (2012) were used to write the following analyses. The results of the one-way ANOVAs for all groups are shown in Table 5 and are discussed in the following sections.

Table 5

One-Way ANOVA Results for Pre-Assessment Baseline Equivalency

\begin{tabular}{|c|c|c|c|c|c|}
\hline Descriptor & PPVT-4 & $\begin{array}{l}\text { iPad Receptive } \\
\text { Vocabulary }\end{array}$ & EVT-2 & $\begin{array}{l}\text { iPad Expressive } \\
\text { Vocabulary } \\
\text { Correct Word }\end{array}$ & $\begin{array}{c}\text { iPad } \\
\text { Expressive } \\
\text { Vocabulary } \\
\text { Correct } \\
\text { Word or } \\
\text { Description }\end{array}$ \\
\hline$F$ statistic & 3.25 & 2.38 & 2.68 & 1.59 & 3.29 \\
\hline $\begin{array}{l}\text { Degrees of } \\
\text { freedom }\end{array}$ & 3 & 3 & 3 & 3 & 3 \\
\hline $\begin{array}{l}\text { Significance } \\
\text { value }\end{array}$ & .028 & .079 & .055 & .202 & .027 \\
\hline $\begin{array}{l}\text { I-DI mean } \\
\text { (standard } \\
\text { deviation) }\end{array}$ & $\begin{array}{l}115.81 \\
(17.39)\end{array}$ & $\begin{array}{c}3.81 \\
(1.80)\end{array}$ & $\begin{array}{l}119.88 \\
(23.85)\end{array}$ & $\begin{array}{c}1.50 \\
(1.37)\end{array}$ & $\begin{array}{r}2.81 \\
(1.97)\end{array}$ \\
\hline $\begin{array}{l}\text { I-OE mean } \\
\text { (standard } \\
\text { deviation) }\end{array}$ & $\begin{array}{c}98.40 \\
(18.96)\end{array}$ & $\begin{array}{c}2.47 \\
(1.41)\end{array}$ & $\begin{array}{l}109.27 \\
(29.25)\end{array}$ & $\begin{array}{r}.67 \\
(.72)\end{array}$ & $\begin{array}{l}1.27 \\
(.80)\end{array}$ \\
\hline $\begin{array}{l}\text { C-1 mean } \\
\text { (standard } \\
\text { deviation) }\end{array}$ & $\begin{array}{l}109.22 \\
(16.39)\end{array}$ & $\begin{array}{c}3.11 \\
(1.18)\end{array}$ & $\begin{array}{l}125.44 \\
(12.75)\end{array}$ & $\begin{array}{r}1.22 \\
(1.00)\end{array}$ & $\begin{array}{c}2.44 \\
(1.34)\end{array}$ \\
\hline $\begin{array}{l}\text { C-2 mean } \\
\text { (standard } \\
\text { deviation) }\end{array}$ & $\begin{array}{l}114.71 \\
(15.71)\end{array}$ & $\begin{array}{c}3.50 \\
(1.02)\end{array}$ & $\begin{array}{l}127.21 \\
(9.82)\end{array}$ & $\begin{array}{c}1.50 \\
(1.61)\end{array}$ & $\begin{array}{c}2.64 \\
(1.65)\end{array}$ \\
\hline
\end{tabular}




\section{Receptive Vocabulary Measures}

\section{Baseline Equivalency for Pre-Assessment PPVT-4 Growth Scale Values}

The results of the one-way ANOVA to establish baseline equivalence for the PPVT-4 GSVs indicated there were statistically significant differences between groups ( $F$ $=3.252, d f=3, p=.028)$. The means and standard deviations of the PPVT-4 GSV scores for each group of the independent variables were as follows: $115.8125(S D=17.3943)$ for the I-DI group, $98.40(S D=18.9616)$ for the I-OE group, $109.2222(S D=16.3871)$ for the $\mathrm{C}-1$ group, and $114.7143(S D=15.7061)$ for the $\mathrm{C}-2$ group. Because there was statistical significance, Tukey's post hoc test was reviewed. As shown in Table 6, there was a statistically significant difference between the I-DI and I-OE groups $(p=0.32, S E$ $=6.1620$ ). There were no statistically significant differences between the other groups. This indicated that the I-DI group was performing significantly higher than the I-OE group on the PPVT-4 GSV pre-assessment. Therefore, this may have suggested that any significant differences between the I-DI and I-OE groups from pre- to post-assessment on the PPVT-4 were conservative, given than the I-OE group started with a lower mean score. 
Table 6

Post Hoc Analysis for Pre-Assessment Baseline Equivalency for PPVT-4 GSV Scores

Tukey HSD

(I) Group

(J) Group

Mean Std. Sig. $\quad 95 \%$ Confidence

Difference Error Interval

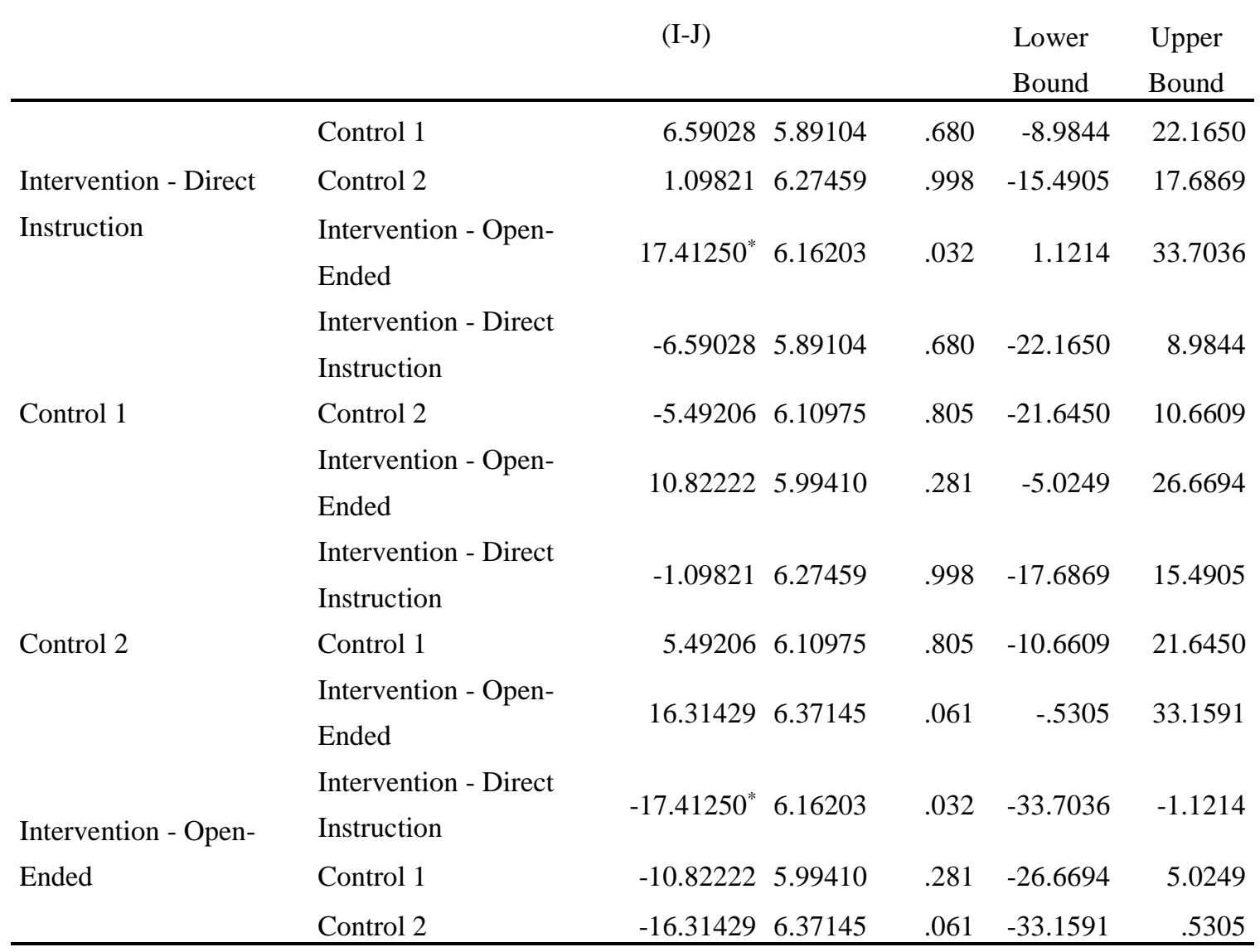

Note. *. The mean difference is significant at the 0.05 level.

$\underline{\text { Baseline Equivalency for Pre-Assessment iPad Receptive Vocabulary Scores }}$

The results of the one-way ANOVA to establish baseline equivalence for the iPad Receptive Vocabulary Assessment indicated there were no statistically significant differences between groups $(F=2.677, d f=3, p=.055)$. The means and standard 
deviations of the iPad Receptive Vocabulary scores for each group of the independent variables were as follows: $3.81(S D=1.797)$ for the I-DI group, $2.47(S D=1.407)$ for the I-OE group, $3.11(S D=1.183)$ for the $\mathrm{C}-1$ group, and $3.50(S D=1.019)$ for the $\mathrm{C}-2$ group. Because there was not statistical significance, this may have suggested that the groups were similar on iPad Receptive Vocabulary at pre-test even though there was not random assignment to groups.

\section{Expressive Vocabulary Measures}

Baseline Equivalency for Pre-Assessment EVT-2 Growth Scale Values

The results of the one-way ANOVA to establish baseline equivalence for the EVT-2 GSVs indicated there were no statistically significant differences between groups $(F=2.381, d f=3, p=.079)$. The means and standard deviations of the EVT-2 GSV scores for each group of the independent variables were as follows: $119.8750(S D=$ 23.8548) for the I-DI group, $109.2667(S D=29.2464)$ for the I-OE group, 125.4444 ( $S D$ $=12.7520)$ for the $\mathrm{C}-1$ group, and $127.2143(S D=9.8229)$ for the $\mathrm{C}-2$ group. Because there was not statistical significance, this may have suggested that the groups were similar on expressive vocabulary measured by the EVT-2 at pre-test even though there was not random assignment to groups. 
$\underline{\text { Baseline Equivalency for Pre-Assessment iPad Expressive Vocabulary Correct Word }}$ $\underline{\text { Scores }}$

The results of the one-way ANOVA to establish baseline equivalence for the iPad Expressive Vocabulary Correct Word Assessment indicated there were no statistically significant differences between groups $(F=1.589, d f=3, p=.202)$. The means and standard deviations of the iPad Expressive Vocabulary Correct Word scores for each group of the independent variables were as follows: $1.50(S D=1.366)$ for the I-DI group, $.67(S D=.724)$ for the I-OE group, $1.22(S D=1.003)$ for the $\mathrm{C}-1$ group, and $1.50(S D=$ 1.605) for the C-2 group. Because there was not statistical significance, this may have suggested that the groups were similar on iPad Expressive Vocabulary Correct Word at pre-test even though there was not random assignment to groups.

Baseline Equivalency for Pre-Assessment iPad Expressive Vocabulary Correct Word or $\underline{\text { Description Scores }}$

The results of the one-way ANOVA to establish baseline equivalence for the iPad Expressive Vocabulary Correct Word or Description Assessment indicated there were statistically significant differences between groups $(F=3.288, d f=3, p=.027)$. The means and standard deviations of the iPad Expressive Vocabulary Correct Word or Description scores for each group of the independent variables were as follows: 2.81 (SD $=1.974)$ for the I-DI group, $1.27(S D=.799)$ for the I-OE group, $2.44(S D=1.338)$ for the $\mathrm{C}-1$ group, and $2.64(S D=1.646)$ for the $\mathrm{C}-2$ group. Because there was statistical 
significance, Tukey's post hoc test was reviewed. As shown in Table 7, there was a statistically significant difference between the I-DI and I-OE groups $(p=.029, S E=$ .540). There were no statistically significant differences between the other groups. This indicated that the I-DI group was performing significantly higher than the I-OE group on the iPad Expressive Vocabulary Correct Word or Description Assessment at preassessment. Therefore, this may have suggested that any significant differences between the I-DI and I-OE groups from pre- to post-assessment on the iPad Expressive Vocabulary Correct Word or Description Assessment were conservative, given than the IOE group started with a lower mean score. 
Table 7

Post Hoc Analysis for Pre-Assessment Baseline Equivalency for iPad Expressive Vocabulary Correct Word or Description Scores

\begin{tabular}{|c|c|c|c|c|c|c|}
\hline \multirow[b]{2}{*}{$\begin{array}{l}\text { Tukey HSD } \\
\text { (I) Group }\end{array}$} & \multirow[b]{2}{*}{ (J) Group } & \multirow{2}{*}{$\begin{array}{c}\text { Mean } \\
\text { Difference } \\
(\mathrm{I}-\mathrm{J}) \\
\end{array}$} & \multirow[b]{2}{*}{$\begin{array}{l}\text { Std. } \\
\text { Error }\end{array}$} & \multirow[b]{2}{*}{ Sig. } & \multicolumn{2}{|c|}{$\begin{array}{l}\text { 95\% Confidence } \\
\text { Interval }\end{array}$} \\
\hline & & & & & $\begin{array}{l}\text { Lower } \\
\text { Bound } \\
\end{array}$ & $\begin{array}{l}\text { Upper } \\
\text { Bound } \\
\end{array}$ \\
\hline \multirow{3}{*}{$\begin{array}{l}\text { Intervention - Direct } \\
\text { Instruction }\end{array}$} & Control 1 & .368 & .516 & .891 & -1.00 & 1.73 \\
\hline & Control 2 & .170 & .550 & .990 & -1.28 & 1.62 \\
\hline & $\begin{array}{l}\text { Intervention - Open- } \\
\text { Ended }\end{array}$ & $1.546^{*}$ & .540 & .029 & .12 & 2.97 \\
\hline \multirow{3}{*}{ Control 1} & $\begin{array}{l}\text { Intervention - Direct } \\
\text { Instruction }\end{array}$ & -.368 & .516 & .891 & -1.73 & 1.00 \\
\hline & Control 2 & -.198 & .535 & .982 & -1.61 & 1.22 \\
\hline & $\begin{array}{l}\text { Intervention - Open- } \\
\text { Ended }\end{array}$ & 1.178 & .525 & .124 & -.21 & 2.57 \\
\hline \multirow{3}{*}{ Control 2} & $\begin{array}{l}\text { Intervention - Direct } \\
\text { Instruction }\end{array}$ & -.170 & .550 & .990 & -1.62 & 1.28 \\
\hline & Control 1 & .198 & .535 & .982 & -1.22 & 1.61 \\
\hline & $\begin{array}{l}\text { Intervention - Open- } \\
\text { Ended }\end{array}$ & 1.376 & .558 & .076 & -.10 & 2.85 \\
\hline \multirow{3}{*}{$\begin{array}{l}\text { Intervention - Open- } \\
\text { Ended }\end{array}$} & $\begin{array}{l}\text { Intervention - Direct } \\
\text { Instruction }\end{array}$ & $-1.546^{*}$ & .540 & .029 & -2.97 & -.12 \\
\hline & Control 1 & -1.178 & .525 & .124 & -2.57 & .21 \\
\hline & Control 2 & -1.376 & .558 & .076 & -2.85 & .10 \\
\hline
\end{tabular}

Note. *. The mean difference is significant at the 0.05 level. 


\section{Analyzing the Research Questions}

\section{Research Question 1}

Is there a mean difference over time (pre to post) in receptive vocabulary (as measured by PPVT-4, Dunn \& Dunn, 2007; and iPad Receptive Vocabulary Assessment, Vatalaro, 2015a) of preschool Head Start children based on iPad apps in the classroom (open-ended/creative apps versus direct instruction apps versus Head Start-chosen apps)?

Two repeated measures analysis of variance (ANOVA) with a two-factor splitplot design (Lomax \& Hahs-Vaughn, 2012) were generated, one for each of the continuous, dependent variables: PPVT-4 Growth Scale Value and iPad Receptive Vocabulary Assessment. The categorical between-subjects factor was group (intervention or control). The categorical, continuous within-subjects factor was time (pre- and post-test). Templates from Lomax and Hahs-Vaughn (2012) were used to write the following analyses.

\section{PPVT-4 Growth Scale Value Results}

\section{Testing for Assumptions}

A two-factor split-plot ANOVA was conducted. The within-subjects factor was Pre- and Post-PPVT Growth Scale Value (GSV), and the between-subjects factor was group status (four groups). There were no missing data and no univariate outliers. Because there were only two levels of repeated measures, the assumption of sphericity was met. The assumption of homogeneity of variance was met for the Pre- and Post- 
PPVT GSV (PPVT Pre-GSV, $F_{3,59}=.433, p=.730$; and PPVT Post-GSV, $F_{3,59}=1.076$ $p=.366)$.

The assumption of normality was tested via examination of the residuals. Review of the Shapiro-Wilk test of normality $\left(S W_{P P V T P r e-G S V}=.980, d f=63, p=.377 ; S W_{P P V T P o s t}\right.$ $G S V=.966, d f=63, p=.077)$, and skewness (PPVT Pre-GSV $=-.037$; PPVT Post-GSV $=$ -.532), and kurtosis (PPVT Pre-GSV = -.687; PPVT Post-GSV = .685) suggested that normality was a reasonable assumption. The boxplot of the residuals for the PPVT PreGSV suggested a relatively normal distributional shape with no outliers. The boxplot of the residuals for the PPVT Post-GSV suggested nonnormality with one outlier. The Q-Q plots suggested normality was reasonable for the residuals for the PPVT Pre-GSV, but suggested nonnormality for the PPVT Post-GSV. Although there was one outlier, all other normality indices suggested a relatively normal distribution. Therefore, the analysis was continued without excluding the outlier.

A scatterplot of residuals against the levels of the between-subjects factors was reviewed. A relatively random display of points around 0 provided evidence that the assumption of independence was met.

Results of the ANOVA

As shown in Table 8, there was a statistically significant within-subjects main effect for PPVT GSV across the time $\operatorname{span}\left(F_{1,59}=6.857, p=.011\right)$. PPVT Post-GSV scores $(M=113.1587, S D=17.4413)$ were significantly higher than PPVT Pre-GSV scores $(M=109.5397, S D=18.0553)$. Approximately $10.4 \%$ of the variance in score can 
be attributed to change in scores across the time span. Power to detect this difference was .731.

There was not a statistically significant between-subjects main effect between the groups $\left(F_{3,59}=2.621, p=.059\right)(\mathrm{I}-\mathrm{DI}, M=118.156, S E=4.057 ; \mathrm{C}-1, M=110.111, S E=$ 3.825; C-2, $M=114.571, S E=4.337 ; \mathrm{I}-\mathrm{OE}, M=102.567, S E=4.190)$. Approximately $11.8 \%$ of the variance in score was attributed to group. Power to detect this difference was .614.

There was not a statistically significant within-between subjects interaction effect between PPVT GSV and group status $\left(F_{3,59}=1.741, p=.169\right)$. Interaction between PPVT GSV and group status accounted for $8.1 \%$ of the variance in score. Power to detect this effect was .432 . 
Table 8

ANOVA Within-Subjects Effects for PPVT-4 GSV Scores

\begin{tabular}{|c|c|c|c|c|c|c|c|c|c|}
\hline \multicolumn{2}{|c|}{ Source } & $\begin{array}{c}\text { Type III Sum } \\
\text { of Squares }\end{array}$ & df & $\begin{array}{l}\text { Mean } \\
\text { Square }\end{array}$ & $\mathrm{F}$ & Sig. & $\begin{array}{c}\text { Partial Eta } \\
\text { Squared }\end{array}$ & $\begin{array}{l}\text { Noncent. } \\
\text { Parameter }\end{array}$ & $\begin{array}{c}\text { Observed } \\
\text { Power }^{\mathrm{a}}\end{array}$ \\
\hline \multirow{4}{*}{ PPVTGSV } & $\begin{array}{l}\text { Sphericity } \\
\text { Assumed }\end{array}$ & 411.133 & 1 & 411.133 & 6.857 & .011 & .104 & 6.857 & .731 \\
\hline & $\begin{array}{l}\text { Greenhouse- } \\
\text { Geisser }\end{array}$ & 411.133 & 1.000 & 411.133 & 6.857 & .011 & .104 & 6.857 & .731 \\
\hline & Huynh-Feldt & 411.133 & 1.000 & 411.133 & 6.857 & .011 & .104 & 6.857 & .731 \\
\hline & Lower-bound & 411.133 & 1.000 & 411.133 & 6.857 & .011 & .104 & 6.857 & .731 \\
\hline \multirow{4}{*}{ PPVTGSV * Group } & $\begin{array}{l}\text { Sphericity } \\
\text { Assumed }\end{array}$ & 313.059 & 3 & 104.353 & 1.741 & .169 & .081 & 5.222 & .432 \\
\hline & $\begin{array}{l}\text { Greenhouse- } \\
\text { Geisser }\end{array}$ & 313.059 & 3.000 & 104.353 & 1.741 & .169 & .081 & 5.222 & .432 \\
\hline & Huynh-Feldt & 313.059 & 3.000 & 104.353 & 1.741 & .169 & .081 & 5.222 & .432 \\
\hline & Lower-bound & 313.059 & 3.000 & 104.353 & 1.741 & .169 & .081 & 5.222 & .432 \\
\hline \multirow{4}{*}{ Error(PPVTGSV) } & $\begin{array}{l}\text { Sphericity } \\
\text { Assumed }\end{array}$ & 3537.370 & 59 & 59.955 & & & & & \\
\hline & $\begin{array}{l}\text { Greenhouse- } \\
\text { Geisser }\end{array}$ & 3537.370 & 59.000 & 59.955 & & & & & \\
\hline & Huynh-Feldt & 3537.370 & 59.000 & 59.955 & & & & & \\
\hline & Lower-bound & 3537.370 & 59.000 & 59.955 & & & & & \\
\hline
\end{tabular}

Note. ${ }^{\mathrm{a} C o m p u t e d ~ u s i n g ~ a l p h a ~}=.05$ 
Removal of Outlier

After results from the initial repeated measures ANOVA were analyzed, the ANOVA was run again with the one outlier removed as shown in Table 9. PPVT PostGSV scores $(M=113.9355, S D=16.4485)$ were still significantly higher than PPVT PreGSV scores $(M=109.6290, S D=18.1887)$. With the outlier removed, the significance of the within-subjects main effect increased $\left(F_{1,58}=12.419, p=.001\right)$, with approximately $17.6 \%$ variance in score, and a power of .934 
Table 9

ANOVA Within-Subjects Main Effects for PPVT-4 GSV Scores With Outlier Removed

\begin{tabular}{|c|c|c|c|c|c|c|c|c|c|}
\hline Source & & $\begin{array}{c}\text { Type III Sum } \\
\text { of Squares }\end{array}$ & df & $\begin{array}{l}\text { Mean } \\
\text { Square }\end{array}$ & $\mathrm{F}$ & Sig. & $\begin{array}{c}\text { Partial Eta } \\
\text { Squared }\end{array}$ & $\begin{array}{l}\text { Noncent. } \\
\text { Parameter }\end{array}$ & $\begin{array}{c}\text { Observed } \\
\text { Power }^{\mathrm{a}}\end{array}$ \\
\hline \multirow{3}{*}{ PPVTGSVScores } & $\begin{array}{l}\text { Sphericity } \\
\text { Assumed }\end{array}$ & 584.632 & 1 & 584.632 & 12.419 & .001 & .176 & 12.419 & .934 \\
\hline & $\begin{array}{l}\text { Greenhouse- } \\
\text { Geisser }\end{array}$ & 584.632 & 1.000 & 584.632 & 12.419 & .001 & .176 & 12.419 & .934 \\
\hline & Lower-bound & 584.632 & 1.000 & 584.632 & 12.419 & .001 & .176 & 12.419 & .934 \\
\hline \multirow{3}{*}{$\begin{array}{l}\text { PPVTGSVScores * } \\
\text { Group }\end{array}$} & $\begin{array}{l}\text { Sphericity } \\
\text { Assumed }\end{array}$ & 197.263 & 3 & 65.754 & 1.397 & .253 & .067 & 4.190 & .352 \\
\hline & $\begin{array}{l}\text { Greenhouse- } \\
\text { Geisser }\end{array}$ & 197.263 & 3.000 & 65.754 & 1.397 & .253 & .067 & 4.190 & .352 \\
\hline & Lower-bound & 197.263 & 3.000 & 65.754 & 1.397 & .253 & .067 & 4.190 & .352 \\
\hline \multirow{4}{*}{ Error(PPVTGSVScores) } & $\begin{array}{l}\text { Sphericity } \\
\text { Assumed }\end{array}$ & 2730.326 & 58 & 47.075 & & & & & \\
\hline & $\begin{array}{l}\text { Greenhouse- } \\
\text { Geisser }\end{array}$ & 2730.326 & 58.000 & 47.075 & & & & & \\
\hline & Huynh-Feldt & 2730.326 & 58.000 & 47.075 & & & & & \\
\hline & Lower-bound & 2730.326 & 58.000 & 47.075 & & & & & \\
\hline
\end{tabular}

Note. ${ }^{\mathrm{a} C o m p u t e d ~ u s i n g ~ a l p h a ~}=.05$ 
Additionally, as shown in Table 10, there was a statistically significant betweensubjects main effect between the groups $\left(F_{3,58}=3.070, p=.035\right)(\mathrm{I}-\mathrm{DI}, M=118.156, S E$ $=3.962 ; \mathrm{C}-1, M=110.111, S E=3.735 ; \mathrm{C}-2, M=116.885, S E=4.395 ; \mathrm{I}-\mathrm{OE}, M=$ $102.567, S E=4.092$ ). Approximately $13.7 \%$ of the variance in score was able to be attributed to group. Power to detect this difference was .690.

Table 10

ANOVA Between-Subjects Main Effects for PPVT-4 GSV Scores With Outlier Removed

\begin{tabular}{lrrrrrrrrr}
\hline Source & $\begin{array}{c}\text { Type III } \\
\text { Sum of }\end{array}$ & df & $\begin{array}{c}\text { Mean } \\
\text { Square }\end{array}$ & F & Sig. & $\begin{array}{c}\text { Partial Eta } \\
\text { Squared }\end{array}$ & $\begin{array}{c}\text { Noncent. } \\
\text { Parameter }\end{array}$ & $\begin{array}{c}\text { Observed } \\
\text { Power }^{\mathrm{a}}\end{array}$ \\
& \multicolumn{1}{c}{ Squares } & & & & & & & \\
\hline Intercept & 1532242.193 & 1 & 1532242.193 & 3050.673 & .000 & .981 & 3050.673 & 1.000 \\
Group & 4625.326 & 3 & 1541.775 & 3.070 & .035 & .137 & 9.209 & .690 \\
Error & 29131.295 & 58 & 502.264 & & & & & \\
\hline
\end{tabular}

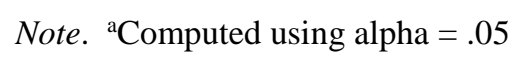

Because of the presence of a between-subjects effect, Tukey's post hoc test was reviewed. As shown in Table 11, there was a statistically significant difference between the I-DI and I-OE groups $(p=0.40, S E=5.69542)$. There were no statistically significant differences between the other groups. With the outlier removed, there was still no different main effect for the within-between subjects interaction $\left(F_{3,58}=1.397, p=\right.$ $.253)$. 
Table 11

Post Hoc Analysis for Between-Subjects Effects for PPVT-4 GSV Scores With Outlier Removed

\begin{tabular}{|c|c|c|c|c|c|c|c|}
\hline \multirow{2}{*}{$\begin{array}{l}\text { Tukey } \\
\text { HSD }\end{array}$} & \multirow[b]{2}{*}{ (I) Group } & \multirow[b]{2}{*}{ (J) Group } & \multirow{2}{*}{$\begin{array}{c}\text { Mean } \\
\text { Difference } \\
(\mathrm{I}-\mathrm{J}) \\
\end{array}$} & \multirow[b]{2}{*}{$\begin{array}{l}\text { Std. } \\
\text { Error }\end{array}$} & \multirow[b]{2}{*}{ Sig. } & \multicolumn{2}{|c|}{$\begin{array}{l}\text { 95\% Confidence } \\
\text { Interval }\end{array}$} \\
\hline & & & & & & $\begin{array}{l}\text { Lower } \\
\text { Bound }\end{array}$ & $\begin{array}{l}\text { Upper } \\
\text { Bound }\end{array}$ \\
\hline & Intervention - Direct & Control 1 & 8.0451 & 5.44495 & .457 & -6.3574 & 22.4476 \\
\hline & \multirow[t]{2}{*}{ Instruction } & Control 2 & 1.2716 & 5.91723 & .996 & -14.3801 & 16.9233 \\
\hline & & $\begin{array}{l}\text { Intervention - } \\
\text { Open-Ended }\end{array}$ & $15.5896^{*}$ & 5.69542 & .040 & .5246 & 30.6546 \\
\hline & \multirow[t]{3}{*}{ Control 1} & $\begin{array}{l}\text { Intervention - } \\
\text { Direct Instruction }\end{array}$ & -8.0451 & 5.44495 & .457 & -22.4476 & 6.3574 \\
\hline & & Control 2 & -6.7735 & 5.76798 & .645 & -22.0304 & 8.4834 \\
\hline & & $\begin{array}{l}\text { Intervention - } \\
\text { Open-Ended }\end{array}$ & 7.5444 & 5.54021 & .528 & -7.1100 & 22.1989 \\
\hline & \multirow[t]{3}{*}{ Control 2} & $\begin{array}{l}\text { Intervention - } \\
\text { Direct Instruction }\end{array}$ & -1.2716 & 5.91723 & .996 & -16.9233 & 14.3801 \\
\hline & & Control 1 & 6.7735 & 5.76798 & .645 & -8.4834 & 22.0304 \\
\hline & & $\begin{array}{l}\text { Intervention - } \\
\text { Open-Ended }\end{array}$ & 14.3179 & 6.00499 & .091 & -1.5659 & 30.2018 \\
\hline & \multirow[t]{3}{*}{$\begin{array}{l}\text { Intervention - Open- } \\
\text { Ended }\end{array}$} & $\begin{array}{l}\text { Intervention - } \\
\text { Direct Instruction }\end{array}$ & $-15.5896^{*}$ & 5.69542 & .040 & -30.6546 & -.5246 \\
\hline & & Control 1 & -7.5444 & 5.54021 & .528 & -22.1989 & 7.1100 \\
\hline & & Control 2 & -14.3179 & 6.00499 & .091 & -30.2018 & 1.5659 \\
\hline
\end{tabular}


$\underline{\text { iPad Receptive Vocabulary Results }}$

\section{Testing for Assumptions}

A two-factor split-plot ANOVA was conducted. The within-subjects factor was Pre- and Post-iPad Receptive Vocabulary scores, and the between-subjects factor was group status (four groups). There were no missing data and there was one univariate outlier. Because there were only two levels of repeated measures, the assumption of sphericity was met. The assumption of homogeneity of variance was met for the Pre- and Post-iPad Receptive Vocabulary scores (Pre-iPad Receptive Vocabulary, $F_{3,59}=1.321, p$ $=.276$; and Post-iPad Receptive Vocabulary, $\left.F_{3,59}=1.103, p=.355\right)$.

The assumption of normality was tested via examination of the residuals. Review of the Shapiro-Wilk test of normality $\left(S W_{\text {Pre-iPadReceptiveVocabulary }}=.960, d f=63, p=.039\right.$; $\left.S W_{\text {Post-iPadReceptiveVocabulary }}=.980, d f=63, p=.410\right)$ suggested some nonnormality for the Pre-iPad Receptive Vocabulary scores. Skewness (Pre-iPad Receptive Vocabulary = .687; Post-iPad Receptive Vocabulary $=.211$ ), and kurtosis (Pre-iPad Receptive Vocabulary $=1.075$; Post-iPad Receptive Vocabulary $=-.223$ ) suggested that normality was a reasonable assumption. The boxplot of the residuals for the Pre-iPad Receptive Vocabulary suggested some nonnormality with one outlier. The boxplot of the residuals for the Post-iPad Receptive Vocabulary suggested a relatively normal distributional shape with no outliers. The Q-Q plots suggested nonnormality was evident for Pre-iPad Receptive Vocabulary, but suggested normality for Post-iPad Receptive Vocabulary. Although there was one outlier and the Shapiro-Wilk test indicated nonnormality for Pre- 
iPad Receptive Vocabulary, all other normality indices suggested a relatively normal distribution. Therefore, the analysis was continued without excluding the outlier.

A scatterplot of residuals against the levels of the between-subjects factors was reviewed. A relatively random display of points around 0 provided evidence that the assumption of independence was met.

Results of the ANOVA

As shown in Table 12, there was a statistically significant within-subjects main effect for iPad Receptive Vocabulary across the time $\operatorname{span}\left(F_{1,59}=33.662, p=.000\right)$. Post-iPad Receptive Vocabulary $(M=4.63, S D=2.042)$ was significantly higher than Pre-iPad Receptive Vocabulary $(M=3.22, S D=1.442)$. Approximately $36.3 \%$ of the variance in score was able to be attributed to change in scores across the time span. Power to detect this difference was 1.0. 
Table 12

ANOVA Within-Subjects Effect and Within-Between Subjects Interaction Effect for iPad Receptive Vocabulary

\begin{tabular}{|c|c|c|c|c|c|c|c|c|c|}
\hline Source & & $\begin{array}{l}\text { Type III } \\
\text { Sum of } \\
\text { Squares }\end{array}$ & df & $\begin{array}{l}\text { Mean } \\
\text { Square }\end{array}$ & $\mathrm{F}$ & Sig. & $\begin{array}{c}\text { Partial Eta } \\
\text { Squared } \\
\end{array}$ & $\begin{array}{l}\text { Noncent. } \\
\text { Parameter }\end{array}$ & $\begin{array}{c}\text { Observed } \\
\text { Power }^{\mathrm{a}}\end{array}$ \\
\hline \multirow{4}{*}{ iPadReceptiveVocabulary } & $\begin{array}{l}\text { Sphericity } \\
\text { Assumed }\end{array}$ & 61.192 & 1 & 61.192 & 33.662 & .000 & .363 & 33.662 & 1.000 \\
\hline & $\begin{array}{l}\text { Greenhouse- } \\
\text { Geisser }\end{array}$ & 61.192 & 1.000 & 61.192 & 33.662 & .000 & .363 & 33.662 & 1.000 \\
\hline & Huynh-Feldt & 61.192 & 1.000 & 61.192 & 33.662 & .000 & .363 & 33.662 & 1.000 \\
\hline & Lower-bound & 61.192 & 1.000 & 61.192 & 33.662 & .000 & .363 & 33.662 & 1.000 \\
\hline \multirow{4}{*}{ iPadReceptiveVocabulary * Group } & $\begin{array}{l}\text { Sphericity } \\
\text { Assumed }\end{array}$ & 43.382 & 3 & 14.461 & 7.955 & .000 & .288 & 23.865 & .986 \\
\hline & $\begin{array}{l}\text { Greenhouse- } \\
\text { Geisser }\end{array}$ & 43.382 & 3.000 & 14.461 & 7.955 & .000 & .288 & 23.865 & .986 \\
\hline & Huynh-Feldt & 43.382 & 3.000 & 14.461 & 7.955 & .000 & .288 & 23.865 & .986 \\
\hline & Lower-bound & 43.382 & 3.000 & 14.461 & 7.955 & .000 & .288 & 23.865 & .986 \\
\hline \multirow{4}{*}{ Error(iPadReceptiveVocabulary) } & $\begin{array}{l}\text { Sphericity } \\
\text { Assumed }\end{array}$ & 107.253 & 59 & 1.818 & & & & & \\
\hline & $\begin{array}{l}\text { Greenhouse- } \\
\text { Geisser }\end{array}$ & 107.253 & 59.000 & 1.818 & & & & & \\
\hline & Huynh-Feldt & 107.253 & 59.000 & 1.818 & & & & & \\
\hline & Lower-bound & 107.253 & 59.000 & 1.818 & & & & & \\
\hline
\end{tabular}

Note. ${ }^{\mathrm{a} C o m p u t e d ~ u s i n g ~ a l p h a ~}=.05$ 
As shown in Table 13, there was a statistically significant between-subjects main effect between the groups $\left(F_{3,59}=4.111, p=.010\right)(\mathrm{I}-\mathrm{DI}, M=4.844, S E=.322 ; \mathrm{C}-1, M=$ 3.556, $S E=.304 ; \mathrm{C}-2, M=3.357, S E=.344$; I-OE, $M=3.933, S E=.333)$.

Approximately $17.3 \%$ of the variance in score was able to be attributed to group. Power to detect this difference was .824.

Table 13

ANOVA Between-Subjects Main Effects for iPad Receptive Vocabulary Assessment

\begin{tabular}{|c|c|c|c|c|c|c|c|c|}
\hline Source & $\begin{array}{l}\text { Type III } \\
\text { Sum of } \\
\text { Squares }\end{array}$ & df & $\begin{array}{c}\text { Mean } \\
\text { Square } \\
\end{array}$ & $\mathrm{F}$ & Sig. & $\begin{array}{c}\text { Partial Eta } \\
\text { Squared }\end{array}$ & $\begin{array}{l}\text { Noncent. } \\
\text { Parameter }\end{array}$ & $\begin{array}{c}\text { Observed } \\
\text { Power }^{\mathrm{a}}\end{array}$ \\
\hline Intercept & 1922.065 & 1 & 1922.065 & 578.868 & .000 & .908 & 578.868 & 1.000 \\
\hline Group & 40.954 & 3 & 13.651 & 4.111 & .010 & .173 & 12.334 & .824 \\
\hline Error & 195.903 & 59 & 3.320 & & & & & \\
\hline
\end{tabular}

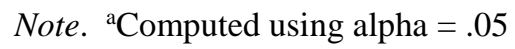

As has been shown (Table 12), there was a statistically significant within-between subjects interaction effect between iPad Receptive Vocabulary and group status $\left(F_{3,59}=\right.$ $7.955, p=.00)$. Interaction between iPad Receptive Vocabulary and group status accounted for $28.8 \%$ of the variance in score. Power to detect this effect was 986 . Examination of the plot of the data in Figure 2 indicated an increase in iPad Receptive Vocabulary across time for the I-DI, C-1, and I-OE groups, with the greatest increases occurring in the I-DI and I-OE groups. The C-2 group scores decreased slightly from pre- to post-assessment. 


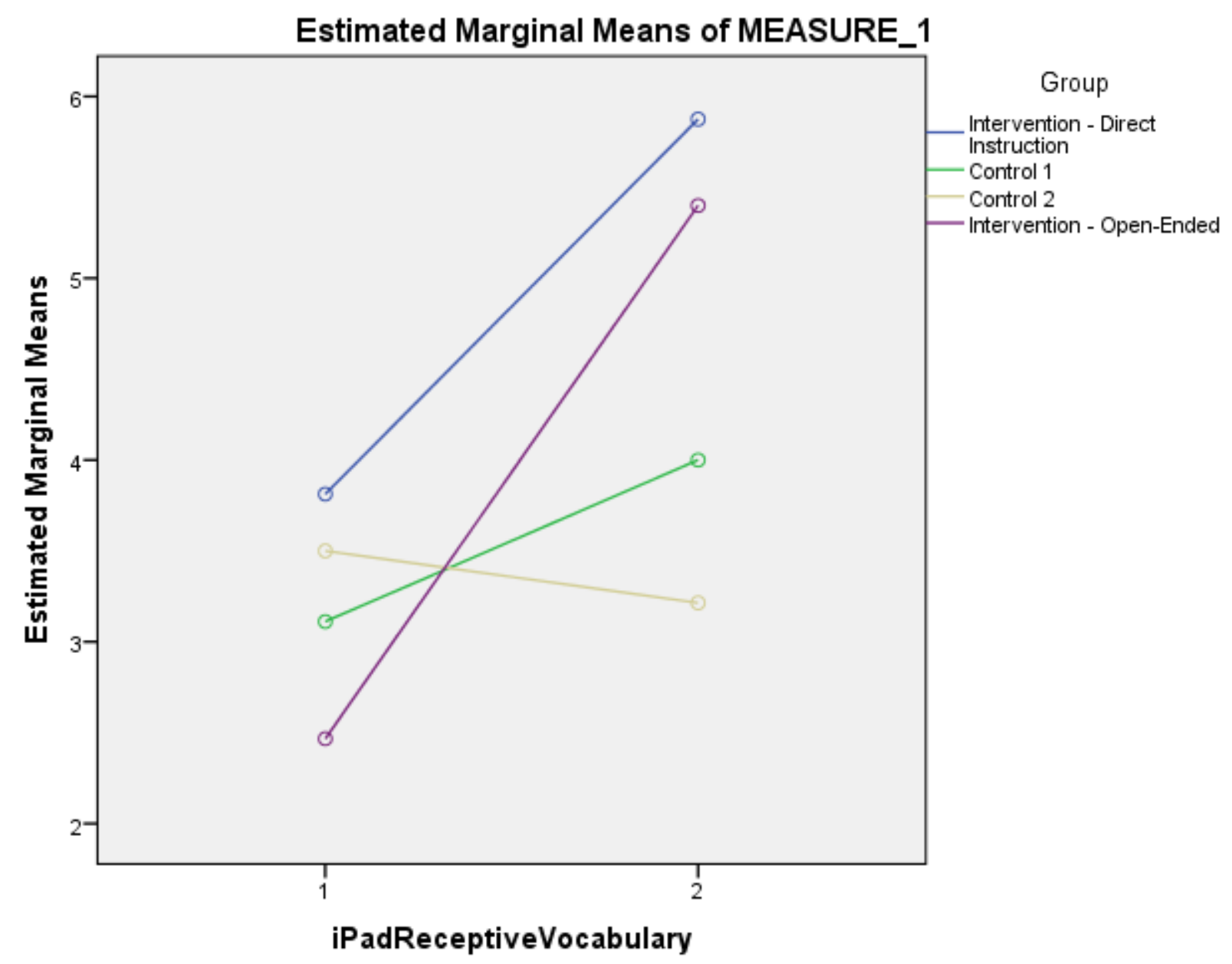

Figure 2. Plot of the within-between subjects interaction effect for the iPad Receptive Vocabulary Assessment

As displayed in Table 14, Tukey's post hoc test was performed for group status and showed a statistically significant difference between the I-DI group and the C-1 group $(p=.026, S E=.443)$. There was also a significant difference between the I-DI group and the C-2 group $(p=.013, S E=.472)$. There were no statistically significant differences between the other groups. 
Table 14

Post Hoc Analysis for Between-Subjects Effects for iPad Receptive Vocabulary

\begin{tabular}{|c|c|c|c|c|c|c|c|}
\hline \multirow[b]{2}{*}{$\begin{array}{l}\text { Tukey } \\
\text { HSD }\end{array}$} & \multirow[b]{2}{*}{ (I) Group } & \multirow[b]{2}{*}{ (J) Group } & \multirow{2}{*}{$\begin{array}{c}\text { Mean } \\
\text { Difference } \\
(\mathrm{I}-\mathrm{J})\end{array}$} & \multirow[b]{2}{*}{$\begin{array}{l}\text { Std. } \\
\text { Error }\end{array}$} & \multirow[b]{2}{*}{ Sig. } & \multicolumn{2}{|c|}{$\begin{array}{c}\text { 95\% Confidence } \\
\text { Interval }\end{array}$} \\
\hline & & & & & & $\begin{array}{l}\text { Lower } \\
\text { Bound }\end{array}$ & $\begin{array}{l}\text { Upper } \\
\text { Bound }\end{array}$ \\
\hline & Intervention & Control 1 & $1.29^{*}$ & .443 & .026 & .12 & 2.46 \\
\hline & \multirow[t]{2}{*}{ Direct Instruction } & Control 2 & $1.49^{*}$ & .472 & .013 & .24 & 2.73 \\
\hline & & $\begin{array}{l}\text { Intervention } \\
\text { Open-Ended }\end{array}$ & .91 & .463 & .213 & -.31 & 2.13 \\
\hline & \multirow[t]{3}{*}{ Control 1} & $\begin{array}{l}\text { Intervention } \\
\text { Direct } \\
\text { Instruction }\end{array}$ & $-1.29^{*}$ & .443 & .026 & -2.46 & -.12 \\
\hline & & Control 2 & .20 & .459 & .973 & -1.02 & 1.41 \\
\hline & & $\begin{array}{l}\text { Intervention } \\
\text { Open-Ended }\end{array}$ & -.38 & .450 & .836 & -1.57 & .81 \\
\hline & \multirow[t]{3}{*}{ Control 2} & $\begin{array}{l}\text { Intervention } \\
\text { Direct } \\
\text { Instruction }\end{array}$ & $-1.49^{*}$ & .472 & .013 & -2.73 & -.24 \\
\hline & & Control 1 & -.20 & .459 & .973 & -1.41 & 1.02 \\
\hline & & $\begin{array}{l}\text { Intervention } \\
\text { Open-Ended }\end{array}$ & -.58 & .479 & .627 & -1.84 & .69 \\
\hline & \multirow[t]{3}{*}{$\begin{array}{l}\text { Intervention } \\
\text { Open-Ended }\end{array}$} & $\begin{array}{l}\text { Intervention } \\
\text { Direct } \\
\text { Instruction }\end{array}$ & -.91 & .463 & .213 & -2.13 & .31 \\
\hline & & Control 1 & .38 & .450 & .836 & -.81 & 1.57 \\
\hline & & Control 2 & .58 & .479 & .627 & -.69 & 1.84 \\
\hline
\end{tabular}

Removal of Outlier

After results from the initial repeated measures ANOVA were analyzed, the ANOVA was run again with the single outlier removed. The results for the withinsubjects effects were similar to those of the initial ANOVA $\left(F_{3,58}=36.691, p=.000\right)$. 
For the between-subjects effects, as shown in Table 15, significance decreased $\left(F_{3,58}=\right.$ $3.216, p=.029)(\mathrm{I}-\mathrm{DI}, M=4.667, S E=.322 ; \mathrm{C}-1, M=3.556, S E=.294 ; \mathrm{C}-2, M=3.357$, $S E=.334 ; \mathrm{I}-\mathrm{OE}, M=3.933, S E=.322)$. Approximately $14.3 \%$ of the variance in score was able to be attributed to group. Power to detect this difference was .712.

Table 15

ANOVA Between-Subjects Main Effects for iPad Receptive Vocabulary Assessment With Outlier Removed

\begin{tabular}{|c|c|c|c|c|c|c|c|c|}
\hline Source & $\begin{array}{l}\text { Type III } \\
\text { Sum of } \\
\text { Squares }\end{array}$ & $\mathrm{df}$ & $\begin{array}{l}\text { Mean } \\
\text { Square }\end{array}$ & $\mathrm{F}$ & Sig. & $\begin{array}{c}\text { Partial Eta } \\
\text { Squared }\end{array}$ & $\begin{array}{l}\text { Noncent. } \\
\text { Parameter }\end{array}$ & $\begin{array}{c}\text { Observed } \\
\text { Power }^{\mathrm{a}}\end{array}$ \\
\hline Intercept & 1848.849 & 1 & 1848.849 & 592.938 & .000 & .911 & 592.938 & 1.000 \\
\hline Group & 30.085 & 3 & 10.028 & 3.216 & .029 & .143 & 9.648 & .712 \\
\hline Error & 180.851 & 58 & 3.118 & & & & & \\
\hline
\end{tabular}

Note. ${ }^{\mathrm{a} C}$ Computed using alpha $=.05$

The results for the within-between subjects interaction effect were similar to those of the initial ANOVA. As displayed in Table 16, after removing the outlier, Tukey's post hoc test no longer indicated a significant difference between the I-DI group and the C-1 group $(p=.063, S E=.437)$. While still present, the significance between the I-DI and C2 group also decreased $(p=.032, S E=.464)$. The plot of the data in Figure 3 indicated the change in scores by group with the outlier removed. 
Table 16

Post Hoc Analysis for Between-Subjects Effects for iPad Receptive Vocabulary Scores With Outlier Removed

\begin{tabular}{|c|c|c|c|c|c|c|c|}
\hline \multirow[b]{3}{*}{$\begin{array}{c}\text { Tukey } \\
\text { HSD }\end{array}$} & \multirow[b]{3}{*}{ (I Group) } & \multirow[b]{3}{*}{ (J) Group } & \multirow{3}{*}{$\begin{array}{c}\text { Mean } \\
\text { Difference } \\
(\mathrm{I}-\mathrm{J})\end{array}$} & \multirow[b]{3}{*}{$\begin{array}{l}\text { Std. } \\
\text { Error }\end{array}$} & \multirow[b]{3}{*}{ Sig. } & \multicolumn{2}{|c|}{ 95\% Confidence } \\
\hline & & & & & & \multicolumn{2}{|c|}{ Interval } \\
\hline & & & & & & $\begin{array}{l}\text { Lower } \\
\text { Bound }\end{array}$ & $\begin{array}{l}\text { Upper } \\
\text { Bound }\end{array}$ \\
\hline & Intervention - Direct & Control 1 & 1.11 & .437 & .063 & -.04 & 2.27 \\
\hline \multirow{2}{*}{\multicolumn{2}{|c|}{ Instruction }} & Control 2 & $1.31^{*}$ & .464 & .032 & .08 & 2.54 \\
\hline & & $\begin{array}{l}\text { Intervention - Open- } \\
\text { Ended }\end{array}$ & .73 & .456 & .382 & -.47 & 1.94 \\
\hline \multirow{3}{*}{\multicolumn{2}{|c|}{ Control 1}} & $\begin{array}{l}\text { Intervention - Direct } \\
\text { Instruction }\end{array}$ & -1.11 & .437 & .063 & -2.27 & .04 \\
\hline & & Control 2 & .20 & .445 & .970 & -.98 & 1.38 \\
\hline & & $\begin{array}{l}\text { Intervention - Open- } \\
\text { Ended }\end{array}$ & -.38 & .437 & .823 & -1.53 & .78 \\
\hline \multirow{3}{*}{\multicolumn{2}{|c|}{ Control 2}} & $\begin{array}{l}\text { Intervention - Direct } \\
\text { Instruction }\end{array}$ & $-1.31^{*}$ & .464 & .032 & -2.54 & -.08 \\
\hline & & Control 1 & -.20 & .445 & .970 & -1.38 & .98 \\
\hline & & $\begin{array}{l}\text { Intervention - Open- } \\
\text { Ended }\end{array}$ & -.58 & .464 & .603 & -1.80 & .65 \\
\hline \multirow{3}{*}{\multicolumn{2}{|c|}{$\begin{array}{l}\text { Intervention - Open- } \\
\text { Ended }\end{array}$}} & $\begin{array}{l}\text { Intervention - Direct } \\
\text { Instruction }\end{array}$ & -.73 & .456 & .382 & -1.94 & .47 \\
\hline & & Control 1 & .38 & .437 & .823 & -.78 & 1.53 \\
\hline & & Control 2 & .58 & .464 & .603 & -.65 & 1.80 \\
\hline
\end{tabular}




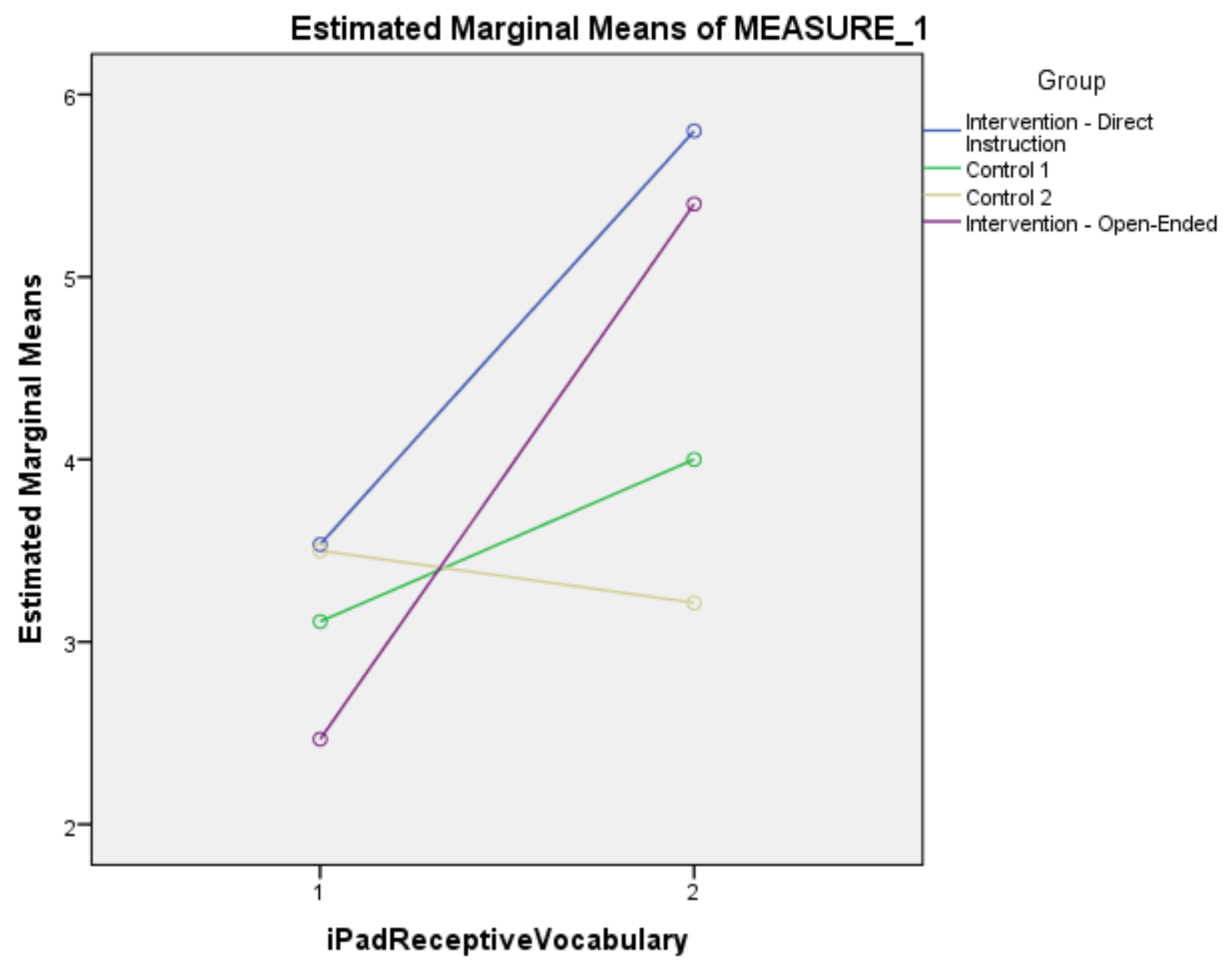

Figure 3. Plot of the within-between subjects interaction effect for the iPad Receptive Vocabulary Assessment with outlier removed

\section{Research Question 2}

Is there a mean difference over time (pre to post) in expressive vocabulary (as measured by EVT-2, Williams, 2007; and iPad Expressive Vocabulary Assessment, Vatalaro, 2015b) of preschool Head Start children based on iPad apps in the classroom (open-ended/creative apps versus direct instruction apps versus Head Start-chosen apps)?

Three repeated measures analysis of variance (ANOVA) with a two-factor splitplot design (Lomax \& Hahs-Vaughn, 2012) were generated, one for each of the 
continuous, dependent variables: EVT-2 Growth Scale Value, iPad Expressive Vocabulary Correct Word Assessment, and iPad Expressive Vocabulary Correct Word or Description Assessment. The categorical between-subjects factor was group (intervention or control). The categorical within-subjects factor was time (pre- and posttest). Templates from Lomax and Hahs-Vaughn (2012) were used to write the following analyses.

\section{EVT-2 Growth Scale Value Results}

\section{Initial Test of Assumptions}

A two-factor split-plot ANOVA was conducted. The within-subjects factor was Pre- and Post-EVT Growth Scale Value (GSV), and the between-subjects factor was group status (four groups). The initial ANOVA resulted in nonnormality with one univariate outlier, three outliers in the boxplot of the residuals for the EVT Pre-GSV scores, four outliers in the boxplot of the residuals for the EVT Post-GSV scores, failure of the assumption of the homogeneity of variance for Pre-EVT GSV scores $\left(F_{3,59}=\right.$ $5.027, p=.004)$, and failure of the Shapiro-Wilk test of normality $\left(S W_{\text {EVTPre-GSV }}=.910, d f\right.$ $\left.=63, p=.000 ; S W_{\text {EVTPost }-G S V}=.925, d f=63, p=.001\right)$. Thus, three outliers were removed in the I-DI group $(N=13)$ and four outliers were removed in the I-OE group $(N=11)$ and the ANOVA was run again. No outliers were removed in the $\mathrm{C}-1$ group $(N=18)$ or the C-2 group $(N=14)$. 


\section{Test of Assumptions After Removal of Outliers}

There were no missing data and no univariate outliers. Because there were only two levels of repeated measures, the assumption of sphericity was met. The assumption of homogeneity of variance was met for the Pre- and Post-EVT GSV (EVT Pre-GSV, $F_{3,52}=.791, p=.504 ;$ and EVT Post-GSV, $\left.F_{3,52}=2.100, p=.111\right)$.

The assumption of normality was tested via examination of the residuals. Review of the Shapiro-Wilk test of normality $\left(S W_{\text {EVTPre-GSV }}=.982, d f=56, p=.554 ; S W_{\text {EVTPost-GSV }}\right.$ $=.991, d f=56, p=.947)$, and skewness $($ EVT Pre-GSV = -.269; EVT Post-GSV = -.115), and kurtosis (EVT Pre-GSV = -.375; EVT Post-GSV = -.127) suggested that normality was a reasonable assumption. The boxplot and Q-Q plots of the residuals for the EVT Pre- and Post-GSV suggested a relatively normal distributional shape with no outliers.

A scatterplot of residuals against the levels of the between-subjects factors was reviewed. A relatively random display of points around 0 provided evidence that the assumption of independence was met.

Results of the ANOVA

As shown in Table 17, there was a statistically significant within-subjects main effect for EVT GSV across the time $\operatorname{span}\left(F_{1,52}=10.843, p=.002\right)$. EVT Post-GSV scores $(M=129.1786, S D=10.91972)$ were significantly higher than EVT Pre-GSV scores $(M=126.4821, S D=11.59936)$. Approximately $17.3 \%$ of the variance in score 
was able to be attributed to change in scores across the time span. Power to detect this difference was .898.

There was not a statistically significant between-subjects main effect between the groups $\left(F_{3,52}=1.648, p=.190\right)(\mathrm{I}-\mathrm{DI}, M=133.346, S E=2.904 ; \mathrm{C}-1, M=125.750, S E=$ 2.468; C-2, $M=127.286, S E=2.798 ; \mathrm{I}-\mathrm{OE}, M=125.409, S E=3.157)$. Approximately $8.7 \%$ of the variance in score was able to be attributed to group. Power to detect this difference was .407 .

As shown in Table 17, there was a statistically significant within-between subjects interaction effect between EVT GSV scores and group status $\left(F_{3,52}=5.951, p=.001\right)$. Interaction between EVT GSV scores and group status accounted for $25.6 \%$ of the variance in score. Power to detect this effect was .942. Examination of the plot of the data (Figure 4) indicated a large increase in EVT GSV scores across time for the I-DI group and a slight increase for the I-OE group. The $\mathrm{C}-1$ and $\mathrm{C}-2$ group scores remained relatively the same. 
Table 17

ANOVA Within-Subjects Effect and Within-Between Subjects Interaction Effect for EVT-2 GSV Scores With Outliers Removed

\begin{tabular}{|c|c|c|c|c|c|c|c|c|c|}
\hline \multicolumn{2}{|c|}{ Source } & $\begin{array}{c}\text { Type III Sum } \\
\text { of Squares }\end{array}$ & df & $\begin{array}{l}\text { Mean } \\
\text { Square }\end{array}$ & $\mathrm{F}$ & Sig. & $\begin{array}{c}\text { Partial Eta } \\
\text { Squared }\end{array}$ & $\begin{array}{l}\text { Noncent. } \\
\text { Parameter }\end{array}$ & $\begin{array}{c}\text { Observed } \\
\text { Power }^{\mathrm{a}}\end{array}$ \\
\hline \multirow{4}{*}{ EVTGSV } & $\begin{array}{l}\text { Sphericity } \\
\text { Assumed }\end{array}$ & 228.490 & 1 & 228.490 & 10.843 & .002 & .173 & 10.843 & .898 \\
\hline & $\begin{array}{l}\text { Greenhouse- } \\
\text { Geisser }\end{array}$ & 228.490 & 1.000 & 228.490 & 10.843 & .002 & .173 & 10.843 & .898 \\
\hline & Huynh-Feldt & 228.490 & 1.000 & 228.490 & 10.843 & .002 & .173 & 10.843 & .898 \\
\hline & Lower-bound & 228.490 & 1.000 & 228.490 & 10.843 & .002 & .173 & 10.843 & .898 \\
\hline \multirow{4}{*}{ EVTGSV $*$ Group } & $\begin{array}{l}\text { Sphericity } \\
\text { Assumed }\end{array}$ & 376.175 & 3 & 125.392 & 5.951 & .001 & .256 & 17.852 & .942 \\
\hline & $\begin{array}{l}\text { Greenhouse- } \\
\text { Geisser }\end{array}$ & 376.175 & 3.000 & 125.392 & 5.951 & .001 & .256 & 17.852 & .942 \\
\hline & Huynh-Feldt & 376.175 & 3.000 & 125.392 & 5.951 & .001 & .256 & 17.852 & .942 \\
\hline & Lower-bound & 376.175 & 3.000 & 125.392 & 5.951 & .001 & .256 & 17.852 & .942 \\
\hline \multirow{4}{*}{ Error(EVTGSV) } & $\begin{array}{l}\text { Sphericity } \\
\text { Assumed }\end{array}$ & 1095.744 & 52 & 21.072 & & & & & \\
\hline & $\begin{array}{l}\text { Greenhouse- } \\
\text { Geisser }\end{array}$ & 1095.744 & 52.000 & 21.072 & & & & & \\
\hline & Huynh-Feldt & 1095.744 & 52.000 & 21.072 & & & & & \\
\hline & Lower-bound & 1095.744 & 52.000 & 21.072 & & & & & \\
\hline
\end{tabular}

Note. ${ }^{\mathrm{a} C}$ Computed using alpha $=.05$ 


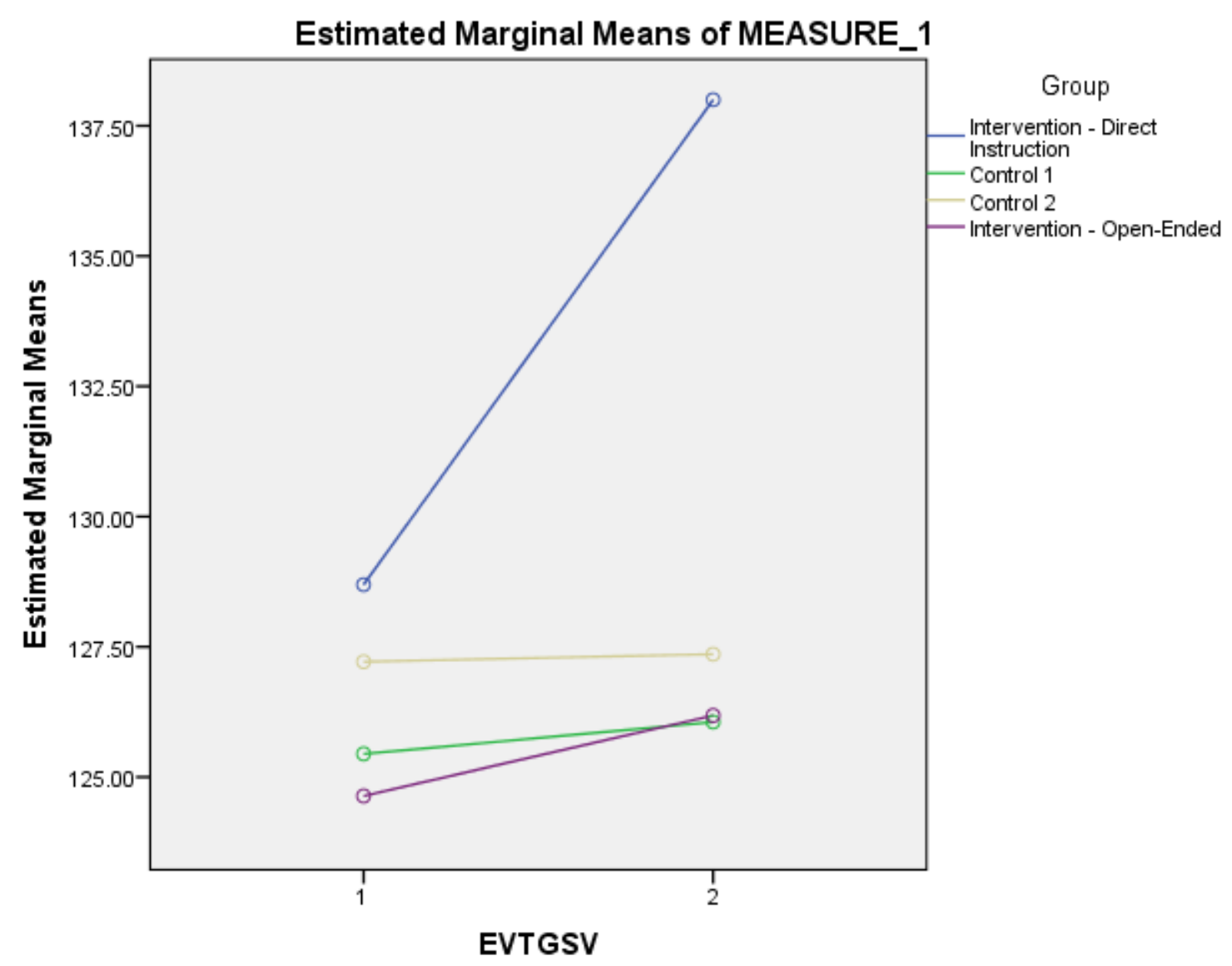

Figure 4. Plot of the within-between subjects interaction effect for the EVT-2 GSV scores with outliers removed

$\underline{\text { iPad Expressive Vocabulary Correct Word Assessment Results }}$

\section{Initial Test of Assumptions}

A two-factor split-plot ANOVA was conducted. The within-subjects factor was Pre-and Post-iPad Expressive Vocabulary Correct Word Assessment, and the betweensubjects factor was group status (four groups). The initial ANOVA resulted in no univariate outliers, but nonnormality with one outlier in the boxplot of the residuals for 
the Pre-iPad Expressive Vocabulary Correct Word scores, two outliers in the boxplot of the residuals for the Post-iPad Expressive Vocabulary Correct Word scores, failure of the assumption of the homogeneity of variance for Pre-iPad Expressive Vocabulary Correct Word scores $\left(F_{3,59}=3.179, p=.030\right)$, and failure of the Shapiro-Wilk test of normality $\left(S W_{\text {Pre-iPadExpressiveVocabCorrectWord }}=.929, d f=63, p=.001\right)$. Thus, two outliers were removed in the I-DI group $(N=14)$, one outlier was removed from the $\mathrm{C}-1$ group $(N=$ $17)$, and one outlier was removed from the $\mathrm{C}-2$ group $(N=13)$ and the ANOVA was run again. No outliers were removed in the I-OE group $(N=15)$.

\section{Test of Assumptions After Removal of Outliers}

There were no missing data and no univariate outliers. Because there were only two levels of repeated measures, the assumption of sphericity was met. The assumption of homogeneity of variance was met for the Pre- and Post-iPad Expressive Vocabulary Correct Word scores (Pre-iPad Expressive Vocabulary Correct Word scores, $F_{3,55}=$ 2.366, $p=.081$; and Post-iPad Expressive Vocabulary Correct Word scores, $F_{3,55}=.146$, $p=.932)$.

The assumption of normality was tested via examination of the residuals. Review of the Shapiro-Wilk test of normality still indicated some nonnormality (SWPre-

iPadExpressiveVocabCorrectWord $=.934, d f=59, p=.003 ;$ SW $W_{\text {Post-iPadExpressiveVocabCorrectWord }}=.929, d f$ $=59, p=.002$ ). However, skewness (Pre-iPad Expressive Vocabulary Correct Word =.736; Post-iPad Expressive Vocabulary Correct Word = -.264), and kurtosis (Pre-iPad Expressive Vocabulary Correct Word $=.048$; Post-iPad Expressive Vocabulary Correct 
Word $=-.541)$ suggested that normality was a reasonable assumption. The boxplot and Q-Q plots of the residuals for the Pre- and Post-iPad Expressive Vocabulary Correct Word scores suggested a relatively normal distributional shape with no outliers.

A scatterplot of residuals against the levels of the between-subjects factors was reviewed. A relatively random display of points around 0 provided evidence that the assumption of independence was met.

Results of the ANOVA

As shown in Table 18, there was a statistically significant within-subjects main effect for iPad Expressive Vocabulary Correct Word scores across the time span $\left(F_{1,55}=\right.$ 31.670, $p=.000)$. Post-iPad Expressive Vocabulary Correct Word scores $(M=2.07, S D$ $=1.032$ ) were significantly higher than Pre-iPad Expressive Vocabulary Correct Word scores $(M=1.10, S D=1.109)$. Approximately $36.5 \%$ of the variance in score was able to be attributed to change in scores across the time span. Power to detect this difference was 1.0 . 
Table 18

ANOVA Within-Subjects Effect and Within-Between Subjects Interaction Effect for iPad Expressive Vocabulary Correct Word Assessment With Outliers Removed

\begin{tabular}{|c|c|c|c|c|c|c|c|c|c|}
\hline Source & & $\begin{array}{l}\text { Type III } \\
\text { Sum of } \\
\text { Squares }\end{array}$ & df & $\begin{array}{l}\text { Mean } \\
\text { Square }\end{array}$ & $\mathrm{F}$ & Sig. & $\begin{array}{c}\text { Partial Eta } \\
\text { Squared } \\
\end{array}$ & $\begin{array}{l}\text { Noncent. } \\
\text { Parameter }\end{array}$ & $\begin{array}{c}\text { Observed } \\
\text { Power }^{\mathrm{a}} \\
\end{array}$ \\
\hline iPadExpressCorrectWord & $\begin{array}{l}\text { Sphericity } \\
\text { Assumed }\end{array}$ & 27.006 & 1 & 27.006 & 31.670 & .000 & .365 & 31.670 & 1.000 \\
\hline \multirow{7}{*}{ iPadExpressCorrectWord * Group } & Greenhouse-Geisser & 27.006 & 1.000 & 27.006 & 31.670 & .000 & .365 & 31.670 & 1.000 \\
\hline & Huynh-Feldt & 27.006 & 1.000 & 27.006 & 31.670 & .000 & .365 & 31.670 & 1.000 \\
\hline & Lower-bound & 27.006 & 1.000 & 27.006 & 31.670 & .000 & .365 & 31.670 & 1.000 \\
\hline & $\begin{array}{l}\text { Sphericity } \\
\text { Assumed }\end{array}$ & 11.066 & 3 & 3.689 & 4.326 & .008 & .191 & 12.977 & .843 \\
\hline & Greenhouse-Geisser & 11.066 & 3.000 & 3.689 & 4.326 & .008 & .191 & 12.977 & .843 \\
\hline & Huynh-Feldt & 11.066 & 3.000 & 3.689 & 4.326 & .008 & .191 & 12.977 & .843 \\
\hline & Lower-bound & 11.066 & 3.000 & 3.689 & 4.326 & .008 & .191 & 12.977 & .843 \\
\hline \multirow{4}{*}{ Error(iPadExpressCorrectWord) } & Sphericity Assumed & 46.900 & 55 & .853 & & & & & \\
\hline & Greenhouse-Geisser & 46.900 & 55.000 & .853 & & & & & \\
\hline & Huynh-Feldt & 46.900 & 55.000 & .853 & & & & & \\
\hline & Lower-bound & 46.900 & 55.000 & .853 & & & & & \\
\hline
\end{tabular}

Note. ${ }^{\mathrm{a} C o m p u t e d}$ using alpha $=.05$ 
There was not a statistically significant between-subjects main effect between the groups $\left(F_{3,55}=2.658, p=.057\right)(\mathrm{I}-\mathrm{DI}, M=2.071, S E=.206 ; \mathrm{C}-1, M=1.382, S E=.187$; $\mathrm{C}-2, M=1.346, S E=.214$; I-OE, $M=1.567, S E=.199)$. Approximately $12.7 \%$ of the variance in score was able to be attributed to group. Power to detect this difference was .618 .

As shown in Table 18, there was a statistically significant within-between subjects interaction effect between iPad Expressive Vocabulary Correct Word scores and group status $\left(F_{3,55}=4.326, p=.008\right)$. Interaction between iPad Expressive Vocabulary Correct Word scores and group status accounted for $19.1 \%$ of the variance in score. Power to detect this effect was .843. Examination of the plot of the data shown in Figure 5 indicated the largest increases in iPad Expressive Vocabulary Correct Word scores across time occurred in the I-DI and I-OE groups. Slight increases occurred for both control groups, with the $\mathrm{C}-1$ group having a higher increase than the $\mathrm{C}-2$ group. 


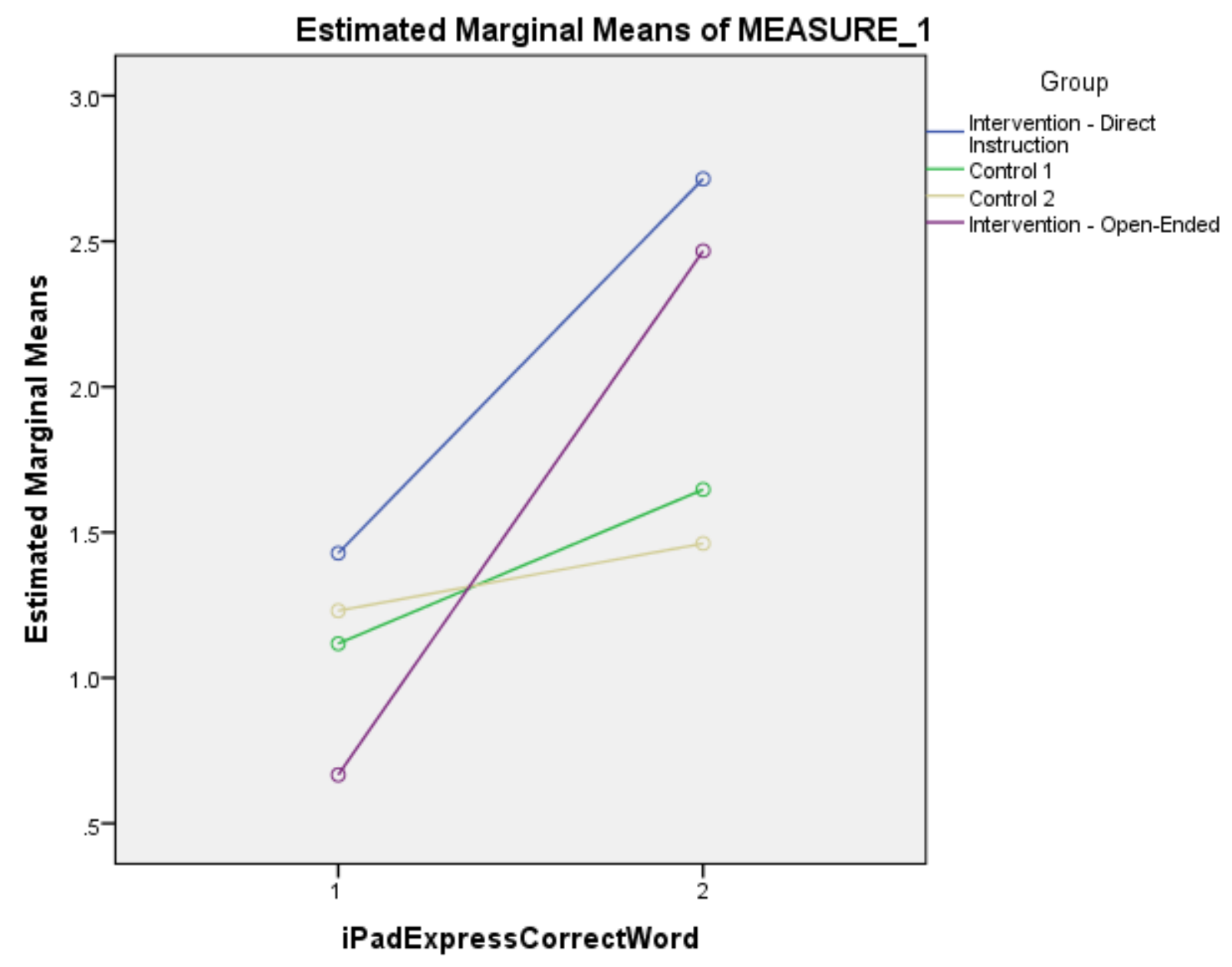

Figure 5. Plot of the within-between subjects interaction effect for the iPad Expressive Vocabulary Correct Word Assessment with outliers removed

$\underline{\text { iPad Expressive Vocabulary Correct Word or Description Assessment Results }}$

\section{Initial Test of Assumptions}

A two-factor split-plot ANOVA was conducted. The within-subjects factor was

Pre-and Post-iPad Expressive Vocabulary Correct Word or Description Assessment, and the between-subjects factor was group status (four groups). The initial ANOVA resulted 
in one univariate outlier, but nonnormality with four outliers in the boxplot of the residuals for the Post-iPad Expressive Vocabulary Correct Word/Desc scores, and failure of the assumption of the homogeneity of variance for Pre-iPad Expressive Vocabulary Correct Word/Desc scores $\left(F_{3,59}=4.251, p=.009\right)$. Because the results of the ANOVA were similar to the iPad Expressive Vocabulary Correct Word scores, the ANOVA was re-run with outliers removed. Two outliers were removed in the I-DI group $(N=14)$. No outliers were removed in the I-DI group $(N=15)$, the $\mathrm{C}$-1 group $(N=18)$ or the $\mathrm{C}-2$ $\operatorname{group}(N=14)$.

\section{Test of Assumptions After Removal of Outliers}

There were no missing data and one univariate outlier remained. Because there were only two levels of repeated measures, the assumption of sphericity was met. The assumption of homogeneity of variance was still not met for the Pre-iPad Expressive Vocabulary Correct Word/Desc scores $\left(F_{3,57}=3.605, p=.019\right)$, but the assumption was met for Post-iPad Expressive Vocabulary Correct Word/Desc scores $\left(F_{3,57}=1.309, p=\right.$ $.280)$.

The assumption of normality was tested via examination of the residuals. Review of the Shapiro-Wilk test of normality indicated normality $\left(S W_{\text {Pre- }}\right.$

iPadExpressiveVocabCorrectWord/Desc $=.979, d f=61, p=.358 ; S W_{\text {Post-iPadExpressiveVocabCorrectWord/Desc }}=$ $.984, d f=61, p=.624)$. Skewness (Pre-iPad Expressive Vocabulary Correct Word/Desc $=.090 ;$ Post-iPad Expressive Vocabulary Correct Word/Desc $=.165)$, and kurtosis (Pre- 
iPad Expressive Vocabulary Correct Word/Desc $=-.208$; Post-iPad Expressive Vocabulary Correct Word/Desc $=-.023$ ) suggested that normality was a reasonable assumption. The boxplot and Q-Q plots of the residuals for the Pre- and Post-iPad Expressive Vocabulary Correct Word/Desc scores suggested a relatively normal distributional shape with no outliers.

A scatterplot of residuals against the levels of the between-subjects factors was reviewed. A relatively random display of points around 0 provided evidence that the assumption of independence was met.

\section{Results of the ANOVA}

As shown in Table 19, there was a statistically significant within-subjects main effect for iPad Expressive Vocabulary Correct Word/Desc scores across the time span $\left(F_{1,57}=60.600, p=.000\right)$. Post-iPad Expressive Vocabulary Correct Word/Desc scores $(M=3.74, S D=1.471)$ were significantly higher than Pre-iPad Expressive Vocabulary Correct Word/Desc scores $(M=2.34, S D=1.590)$. Approximately $51.5 \%$ of the variance in score was able to be attributed to change in scores across the time span. Power to detect this difference was 1.0. 
Table 19

ANOVA Within-Subjects Effect and Within-Between Subjects Interaction Effect for iPad Expressive Vocabulary Correct Word or Description Assessment With Outliers Removed

\begin{tabular}{|c|c|c|c|c|c|c|c|c|c|}
\hline Source & & $\begin{array}{l}\text { Type III } \\
\text { Sum of } \\
\text { Squares } \\
\end{array}$ & df & $\begin{array}{l}\text { Mean } \\
\text { Square }\end{array}$ & $\mathrm{F}$ & Sig. & $\begin{array}{c}\text { Partial Eta } \\
\text { Squared } \\
\end{array}$ & $\begin{array}{l}\text { Noncent. } \\
\text { Parameter }\end{array}$ & $\begin{array}{c}\text { Observed } \\
\text { Power }^{\mathrm{a}} \\
\end{array}$ \\
\hline \multirow{4}{*}{ iPadExpCorrectWordDesc } & $\begin{array}{l}\text { Sphericity } \\
\text { Assumed }\end{array}$ & 61.488 & 1 & 61.488 & 60.600 & .000 & .515 & 60.600 & 1.000 \\
\hline & $\begin{array}{l}\text { Greenhouse- } \\
\text { Geisser }\end{array}$ & 61.488 & 1.000 & 61.488 & 60.600 & .000 & .515 & 60.600 & 1.000 \\
\hline & Huynh-Feldt & 61.488 & 1.000 & 61.488 & 60.600 & .000 & .515 & 60.600 & 1.000 \\
\hline & Lower-bound & 61.488 & 1.000 & 61.488 & 60.600 & .000 & .515 & 60.600 & 1.000 \\
\hline \multirow{4}{*}{ iPadExpCorrectWordDesc * Group } & $\begin{array}{l}\text { Sphericity } \\
\text { Assumed }\end{array}$ & 15.443 & 3 & 5.148 & 5.073 & .003 & .211 & 15.220 & .901 \\
\hline & $\begin{array}{l}\text { Greenhouse- } \\
\text { Geisser }\end{array}$ & 15.443 & 3.000 & 5.148 & 5.073 & .003 & .211 & 15.220 & .901 \\
\hline & Huynh-Feldt & 15.443 & 3.000 & 5.148 & 5.073 & .003 & .211 & 15.220 & .901 \\
\hline & Lower-bound & 15.443 & 3.000 & 5.148 & 5.073 & .003 & .211 & 15.220 & .901 \\
\hline \multirow{4}{*}{ Error(iPadExpCorrectWordDesc) } & $\begin{array}{l}\text { Sphericity } \\
\text { Assumed }\end{array}$ & 57.836 & 57 & 1.015 & & & & & \\
\hline & $\begin{array}{l}\text { Greenhouse- } \\
\text { Geisser }\end{array}$ & 57.836 & 57.000 & 1.015 & & & & & \\
\hline & Huynh-Feldt & 57.836 & 57.000 & 1.015 & & & & & \\
\hline & Lower-bound & 57.836 & 57.000 & 1.015 & & & & & \\
\hline
\end{tabular}

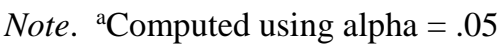


As shown in Table 20, there was a statistically significant between-subjects main effect between the groups $\left(F_{3,57}=4.008, p=.012\right)(\mathrm{I}-\mathrm{DI}, M=3.964, S E=.328 ; \mathrm{C}-1, M=$ 2.778, $S E=.290 ; \mathrm{C}-2, M=3.071, S E=.328 ; \mathrm{I}-\mathrm{OE}, M=2.467, S E=.317)$.

Approximately $17.4 \%$ of the variance in score was able to be attributed to group. Power to detect this difference was .813 .

Table 20

ANOVA Between-Subjects Main Effects for iPad Expressive Vocabulary Correct Word or Description Assessment With Outliers Removed

\begin{tabular}{|c|c|c|c|c|c|c|c|c|}
\hline \multirow[t]{2}{*}{ Source } & \multicolumn{8}{|l|}{ Type III } \\
\hline & $\begin{array}{l}\text { Sum of } \\
\text { Squares }\end{array}$ & df & $\begin{array}{l}\text { Mean } \\
\text { Square }\end{array}$ & $\mathrm{F}$ & Sig. & $\begin{array}{c}\text { Partial Eta } \\
\text { Squared }\end{array}$ & $\begin{array}{l}\text { Noncent. } \\
\text { Parameter }\end{array}$ & $\begin{array}{c}\text { Observed } \\
\text { Power }^{\mathrm{a}}\end{array}$ \\
\hline Intercept & 1137.790 & 1 & 1137.790 & 377.036 & .000 & .869 & 377.036 & 1.000 \\
\hline Group & 36.285 & 3 & 12.095 & 4.008 & .012 & .174 & 12.024 & .813 \\
\hline Error & 172.010 & 57 & 3.018 & & & & & \\
\hline
\end{tabular}

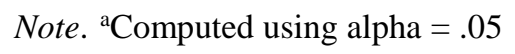

As shown in Table 19, there was a statistically significant within-between subjects interaction effect between iPad Expressive Vocabulary Correct Word/Desc scores and group status $\left(F_{3,57}=5.073, p=.003\right)$. Interaction between iPad Expressive Vocabulary Correct Word/Desc scores and group status accounted for $21.1 \%$ of the variance in score. Power to detect this effect was .901 . 
Examination of the plot of the data (Figure 6) indicated the largest increases in iPad Expressive Vocabulary Correct Word/Desc scores across time occurred in the I-DI and I-OE groups. Slight increases occurred for both control groups, with the C-2 group having a higher increase than the $\mathrm{C}-1$ group.

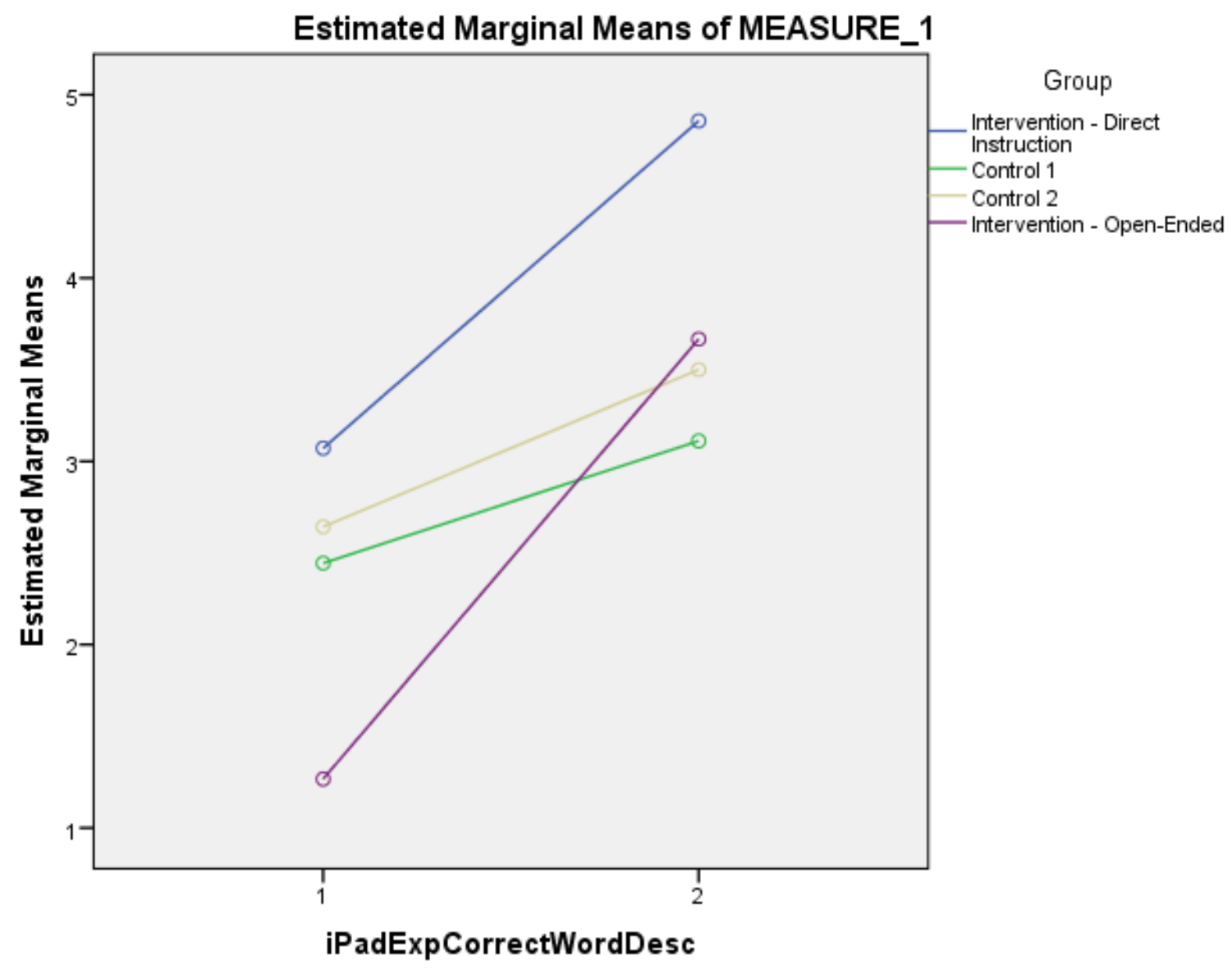

Figure 6. Plot of the within-between subjects interaction effect for the iPad Expressive Vocabulary Correct Word or Description Assessment with outliers removed 
As shown in Table 21, Tukey's post hoc test was performed for group status, which indicated a statistically significant difference between the I-DI group and the C-1 group $(p=.043, S E=.438)$. There was also a significant difference between the I-DI group and the I-OE group $(p=.009, S E=.456)$. There were no statistically significant differences between the other groups.

Table 21

Post Hoc Analysis for Between-Subjects Effects for iPad Expressive Vocabulary Correct Word or Description Assessment With Outliers Removed

\begin{tabular}{|c|c|c|c|c|c|c|c|}
\hline \multirow{2}{*}{$\begin{array}{l}\text { Tukey } \\
\text { HSD }\end{array}$} & \multirow[b]{2}{*}{ (I) Group } & \multirow[b]{2}{*}{ (J) Group } & \multirow{2}{*}{$\begin{array}{c}\text { Mean } \\
\text { Difference } \\
(\mathrm{I}-\mathrm{J})\end{array}$} & \multirow[b]{2}{*}{$\begin{array}{l}\text { Std. } \\
\text { Error }\end{array}$} & \multirow[b]{2}{*}{ Sig. } & \multicolumn{2}{|c|}{$\begin{array}{l}\text { 95\% Confidence } \\
\text { Interval }\end{array}$} \\
\hline & & & & & & $\begin{array}{l}\text { Lower } \\
\text { Bound }\end{array}$ & $\begin{array}{l}\text { Upper } \\
\text { Bound }\end{array}$ \\
\hline & Intervention - Direct & Control 1 & $1.19^{*}$ & .438 & .043 & .03 & 2.34 \\
\hline & \multirow[t]{2}{*}{ Instruction } & Control 2 & .89 & .464 & .230 & -.34 & 2.12 \\
\hline & & $\begin{array}{l}\text { Intervention - Open- } \\
\text { Ended }\end{array}$ & $1.50^{*}$ & .456 & .009 & .29 & 2.71 \\
\hline & \multirow[t]{3}{*}{ Control 1} & $\begin{array}{l}\text { Intervention - Direct } \\
\text { Instruction }\end{array}$ & $-1.19^{*}$ & .438 & .043 & -2.34 & -.03 \\
\hline & & Control 2 & -.29 & .438 & .908 & -1.45 & .86 \\
\hline & & $\begin{array}{l}\text { Intervention - Open- } \\
\text { Ended }\end{array}$ & .31 & .429 & .887 & -.83 & 1.45 \\
\hline & \multirow[t]{3}{*}{ Control 2} & $\begin{array}{l}\text { Intervention - Direct } \\
\text { Instruction }\end{array}$ & -.89 & .464 & .230 & -2.12 & .34 \\
\hline & & Control 1 & .29 & .438 & .908 & -.86 & 1.45 \\
\hline & & $\begin{array}{l}\text { Intervention - Open- } \\
\text { Ended }\end{array}$ & .60 & .456 & .551 & -.60 & 1.81 \\
\hline & \multirow[t]{3}{*}{$\begin{array}{l}\text { Intervention - Open- } \\
\text { Ended }\end{array}$} & $\begin{array}{l}\text { Intervention - Direct } \\
\text { Instruction }\end{array}$ & $-1.50^{*}$ & .456 & .009 & -2.71 & -.29 \\
\hline & & Control 1 & -.31 & .429 & .887 & -1.45 & .83 \\
\hline & & Control 2 & -.60 & .456 & .551 & -1.81 & .60 \\
\hline
\end{tabular}




\section{Research Question 3}

Within the intervention classrooms, what is the frequency of and how do Head Start teachers report using apps in the classroom?

Data from the teachers in the intervention classrooms' daily self-report logs (Appendix I) were entered into SPSS version 22 and expressed as descriptive statistics with frequencies for each area on the log presented. Direct instruction and open-ended apps were used for the child intervention, and did not necessarily reflect each teacher's specific teaching style; nevertheless for clarity, the teachers are described as I-DI teacher and I-OE teacher.

\section{Frequency of App Use in the Classroom}

For each daily log, the intervention classroom teachers were asked to check which time of the day apps were used, based on the teachers' daily schedule. The block of time for each area on the schedule was then added to create a total for each week. However, a teacher may have checked "morning circle time" which typically lasted 30 minutes, but the teacher may have only spent 10 minutes of circle time using apps. Additionally, the teachers' self-report of their daily iPad use may be questionable; this will be discussed further in Chapter 5. Therefore, the weekly totals are approximate. Weekly totals for each classroom are presented in Table 22. Overall, the teacher in the classroom assigned to I-DI apps used apps more often than the teacher in the classroom assigned to I-OE apps. 
Table 22

Frequency of App Use in Intervention Classrooms (in Minutes)

\begin{tabular}{|c|c|c|c|c|c|c|c|c|c|c|c|}
\hline & Week & Week & Week & Week & Week & Week & Week & Week & Total & Mean & $\begin{array}{l}\text { Standard } \\
\text { Deviation }\end{array}$ \\
\hline I-DI & 110 & 265 & 410 & 680 & 800 & 565 & 910 & 670 & 4,410 & 551.25 & 272.04 \\
\hline I-OE & 200 & 360 & 225 & 450 & 360 & 525 & 450 & 500 & 3,070 & 383.75 & 120.91 \\
\hline
\end{tabular}

For each daily log, the teachers were also asked to rate their app use with children based on developmentally appropriate practices for using technology with young children. There were 38 schools days in the child intervention. The frequency of each rating in each area was recorded and is expressed in Table 23 as a percentage of the total intervention. Even though the I-DI teacher spent more overall time using apps in the classroom, she reported using them on fewer days than the I-OE teacher. The I-OE teacher was more likely to rate each area in the "somewhat" category, except for encouragement of collaboration, which she most often rated "high." The I-DI teacher most often rated that app use supported learning, active involvement, and encouragement of creativity as "very," but more often rated that app use supported daily themes and activities and encouraged collaboration as "somewhat." Finally, there were no instances where the I-OE teacher rated an area as "not at all," but the I-DI teacher believed there were instances when app use did not support daily themes and activities or encouraged collaboration. 
Table 23

Intervention Teachers' Perceptions of Developmental Appropriateness of App Use in the Classroom

\begin{tabular}{|c|c|c|}
\hline App Use & $\begin{array}{l}\text { Direct Instruction } \\
\text { (I-DI) }\end{array}$ & $\begin{array}{l}\text { Open Ended Instruction } \\
\text { (I-OE) }\end{array}$ \\
\hline \multicolumn{3}{|l|}{ Support Learning } \\
\hline Very & $86.8 \%$ & $13.1 \%$ \\
\hline Somewhat & $0.0 \%$ & $78.9 \%$ \\
\hline Not At All & $0.0 \%$ & $0.0 \%$ \\
\hline Did Not Use Apps & $13.2 \%$ & $8.0 \%$ \\
\hline \multicolumn{3}{|l|}{ Active Involvement } \\
\hline Very & $86.8 \%$ & $15.7 \%$ \\
\hline Somewhat & $0.0 \%$ & $76.3 \%$ \\
\hline Not At All & $0.0 \%$ & $0.0 \%$ \\
\hline Did Not Use Apps & $13.2 \%$ & $8.0 \%$ \\
\hline \multicolumn{3}{|l|}{ Encourage Creativity } \\
\hline Very & $84.2 \%$ & $36.8 \%$ \\
\hline Somewhat & $2.6 \%$ & $55.2 \%$ \\
\hline Not At All & $0.0 \%$ & $0.0 \%$ \\
\hline Did Not Use Apps & $13.2 \%$ & $8.0 \%$ \\
\hline \multicolumn{3}{|c|}{ Support Daily Themes/Activities } \\
\hline Very & $18.4 \%$ & $18.4 \%$ \\
\hline Somewhat & $42.1 \%$ & $73.6 \%$ \\
\hline Not At All & $26.3 \%$ & $0.0 \%$ \\
\hline Did Not Use Apps & $13.2 \%$ & $8.0 \%$ \\
\hline \multicolumn{3}{|c|}{ Encourage Collaboration } \\
\hline Very & $18.4 \%$ & $57.8 \%$ \\
\hline Somewhat & $42.1 \%$ & $34.2 \%$ \\
\hline Not At All & $26.3 \%$ & $0.0 \%$ \\
\hline Did Not Use Apps & $13.2 \%$ & $8.0 \%$ \\
\hline
\end{tabular}




\section{Teacher Technology Perception and Use Survey}

The intervention and control group teachers and assistants completed the Teacher Technology Perception and Use Survey (Appendix H) pre- and post-children's use of intervention apps. In reviewing the data, there were no remarkable differences between the groups or the responses from pre- to post-child intervention. Overall, the teachers and assistants indicated they were confident that they were using mobile devices and apps with children in developmentally appropriate ways, but none of the teachers were aware

of the NAEYC and Fred Rogers Center position statement (2012). They had not received professional development or support for using mobile devices in the classroom and believed that it would be desirable. Finally, the teachers and assistants generally agreed that mobile devices could support various aspects of learning and child development, but were limited by lack of time to incorporate technology in the classroom.

\section{Summary}

In this chapter, the results of the quasi-experiment were presented. For all assessments, the post-assessments were statistically significantly higher than the preassessments. For the first research question, receptive vocabulary was examined via the PPVT-4 (Dunn \& Dunn, 2007) and iPad Receptive Vocabulary Assessment (Vatalaro, 2015a). For the PPVT-4, after the outliers were removed, there was a between-subjects effect, with the I-DI group performing statistically significantly higher than the I-OE group. The effect size and power to detect this difference were high. The one-way ANOVA conducted for baseline equivalency of pre-assessment scores indicated that the 
between-subjects effects results for the PPVT-4 were conservative. There were no significant differences between any of the other groups. There was no within-between subjects interaction effect for the PPVT-4.

For the iPad Receptive Vocabulary Assessment, there was a between-subjects effect with the I-DI group performing statistically significantly better than the C-1 group and the $\mathrm{C}-2$ group. The effect size and power to detect these differences were high. There were no significant differences between any of the other groups. There was also a significant within-between subjects interaction effect for the iPad Receptive Vocabulary Assessment, with the plot of the data indicating the I-DI, I-OE, and C-1 group scores increased across time, and the C-2 scores decreased. However, once an outlier was removed and the analysis was run again, the overall significance decreased, and there was no longer a between-subjects effect between the I-DI and C-1 group.

For the second research question, expressive vocabulary was examined via the EVT-2 (Williams, 2007) and the iPad Expressive Vocabulary Assessment (Vatalaro, 2015b). The iPad Expressive Vocabulary was analyzed twice: Correct Word and Correct Word or Description. For the EVT-2, after removing outliers, there was no statistically significant difference between the groups. Yet, the effect size and power to detect this difference were weak. There was a statistically significant within-between subjects interaction effect, with the plot of the data indicating a large increase in scores across time for the I-DI group, a slight increase for the I-OE group, and scores remaining relatively the same for the $\mathrm{C}-1$ and $\mathrm{C}-2$ groups. 
For the iPad Expressive Vocabulary Correct Word Assessment, after outliers were removed, there was no statistically significant difference between the groups. The effect size and power to detect this difference were moderate. There was a statistically significant within-between subjects interaction effect with the plot of the data indicating the largest increases occurring in the I-DI and I-OE groups with a moderate increase in the $\mathrm{C}-1$ group and a slight increase in the C-2 group.

For the iPad Expressive Vocabulary Correct Word or Description Assessment, after outliers were removed, there was a between-subjects effect, with the I-DI group performing statistically significantly higher than the C-1 and the I-OE groups. The effect size and power to detect these differences were high. The one-way ANOVA conducted for baseline equivalency of pre-assessment scores indicated that the between-subjects effects results for the iPad Expressive Vocabulary Correct Word or Description Assessment were conservative. There was also a statistically significant within-between subjects interaction effect with the plot of the data indicating the largest increases occurring in the I-DI and the I-OE groups with moderate increases in the C-1 and C-2 groups.

For the third research question, the self-report daily logs of the teachers whose classrooms received the intervention apps were examined to get a general sense of the frequency of use of iPads in their classrooms as well as the degree to which the iPads were being used in developmentally appropriate ways. Overall, the I-DI teacher spent more minutes across the eight weeks using apps in the classroom but was less likely to believe that app use supported daily themes and activities or encouraged collaboration. 
The I-OE teacher was more likely to assign each item the "somewhat" rating except for encouragement of collaboration which she most often rated as "very."

The next chapter, Chapter 5, contains a summary and discussion of the findings along with implications for practice and limitations based on the findings and previously reviewed literature. Implications for future research will also be offered. 


\section{CHAPTER 5 \\ DISCUSSION}

\section{$\underline{\text { Introduction }}$}

The purpose of this study was to examine the efficacy of using iPads and intentionally chosen applications (apps) to increase the receptive and expressive vocabulary of preschool children who were economically disadvantaged. A secondary purpose was to examine how the Head Start teachers used the apps with the children when given mentoring and support. The following discussion has been organized around the findings for each of the research questions and program fidelity. Implications for practice, limitations of the present study, and future research directions are also presented along with a final summary statement.

\section{Discussion of the Findings}

\section{Research Questions 1 and 2}

1. Is there a mean difference over time (pre to post) in receptive vocabulary (as measured by PPVT-4, Dunn \& Dunn, 2007; and iPad Receptive Vocabulary Assessment, Vatalaro, 2015a) of preschool Head Start children based on iPad apps in the classroom (open-ended/creative apps versus direct instruction apps versus Head Start-chosen apps)?

2. Is there a mean difference over time (pre to post) in expressive vocabulary (as measured by EVT-2, Williams, 2007; and iPad Expressive Vocabulary Assessment, Vatalaro 2015b) of preschool Head Start children based on iPad 
apps in the classroom (open-ended/creative apps versus direct instruction apps versus Head Start-chosen apps)?

\section{App Comparison Across Groups: Open-Ended Versus Direct Instruction Versus Head}

\section{$\underline{\text { Start-Chosen Apps }}$}

Results of Receptive Vocabulary Measures: PPVT-4

For the original PPVT-4 analysis, there were no statistically significant findings between groups. However, after one extreme low score in the control 2 group was removed from the analysis, the children who were given direct instruction apps performed significantly better on receptive vocabulary Growth Scale Value scores than the children who received open-ended apps. There were no statistically significant differences between either of the intervention groups and the control groups. These findings are conservative given that the children receiving direct instruction apps were already performing significantly higher than the children receiving open-ended apps at the pre-assessment.

Results of Receptive Vocabulary Measures: iPad Receptive Vocabulary Assessment

For the iPad Receptive Vocabulary Assessment, the initial ANOVA indicated the children using the direct instruction apps performed significantly higher than both control groups. Conversely, after removing one extremely high score in the direct instruction group, the children in the direct instruction group no longer performed significantly 
higher than the control 1 group, but still performed higher than the control 2 group. In reviewing the change in scores from pre- to post-assessment, the scores for the direct instruction, open-ended, and control 1 groups increased, but the control 2 group scores decreased. Thus, this measure captured a difference between the children with direct instruction apps significantly outperforming one control group of children. These findings are robust given that the children receiving direct instruction apps were not performing significantly higher than the children in the control groups at the preassessment.

\section{Results of Expressive Vocabulary Measures: EVT-2}

There were no findings to indicate that any group of children significantly differed from each other in their expressive vocabulary scores as measured by the EVT-2. Nevertheless, the children who had the direct instruction apps increased their own scores by 9.3 points from a mean of 128.69 to a mean of 138.00 , and the children who had openended apps slightly increased their scores by less than two points from a mean of 124.64 to a mean of 126.19. The children in the control groups had EVT-2 scores that remained relatively the same.

\section{Results of Expressive Vocabulary Measures: iPad Expressive Vocabulary} Assessment

During the post-assessment of the iPad Expressive Vocabulary Assessment, the primary researcher noticed that many children, when presented with a picture of an iPad component, would correctly define its function, yet could not correctly state the technical 
vocabulary word. Thus, the data were re-scored and the iPad Expressive Vocabulary was analyzed twice, including a Correct Word analysis plus a Correct Word or Description analysis.

Results of Expressive Vocabulary Measures: iPad Expressive Vocabulary Assessment Correct Word Analysis

In examining children's ability to just produce the correct word, there were no significant differences between the groups. Yet, for the Correct Word analysis, there was a steep increase in scores for the children with the direct instruction apps and open-ended apps, a moderate increase for the control 1 children, and a slight increase for the control 2 children. This could indicate that though the intervention teachers were using the iPad vocabulary, the usage was insufficient for differences to show up between the groups.

Results of Expressive Vocabulary Measures: iPad Expressive Vocabulary Assessment Correct Word or Description Analysis

When analyzing the iPad Expressive Vocabulary Correct Word or Description results, the children using the direct instruction apps performed statistically significantly higher than the children with the open-ended apps and the children in the control 1 group. When examining the results of the scores from pre- to post-assessment, all groups of children increased their scores, with the greatest increases occurring in the direct instruction and open-ended app groups. This could indicate that the children in the intervention groups understood the functions of the iPad vocabulary better than the control groups of children, they just could not state the exact vocabulary word. This could also indicate that teachers did not emphasize the word, but rather the function when 
teaching the children with the iPad. The finding that the direction instruction app group performed better than the open-ended app group is conservative given that the children receiving direct instruction apps were already performing significantly higher than the children receiving open-ended apps at the pre-assessment. The finding that the direction instruction app group performed better than the control 1 group is robust given that the children receiving direct instruction apps were not performing significantly higher than the children in the control 1 group at the pre-assessment.

\section{Interpreting Findings From Receptive and Expressive Vocabulary Measures}

The control group children used only the Head Start-chosen apps, which did not have embedded within them a large range of vocabulary. Though Head Start-chosen apps were generally interactive, they did not promote creativity and were not open-ended. Therefore, it was not surprising that the children in the control groups had vocabulary scores that remained static. ${ }^{1}$

Despite meta-analysis of early childhood interventions indicating stronger effect sizes for studies for teachers who used direct instruction interventions than with openended instruction interventions (Camilli et al., 2010), the authors of that meta-analysis interpreted their findings that direct instruction interventions were better than open-ended interventions with caution. In an additional second-order meta-analysis, Tamim et al. (2011) found stronger effect sizes in Kindergarten through Grade 12 interventions when

\footnotetext{
${ }^{1}$ Even though both groups of intervention children had access to the 13 Head Start-chosen apps on their iPads, the teachers with intervention apps emphasized the intervention apps given to them for the study. By teacher report, the intervention groups did not use the Head Start-chosen apps during their whole group iPad instruction. No record exists to determine how often the intervention children chose Head Start apps when the children were using the iPads on their own.
} 
technology was used to support education, rather than the teacher using technology for direct instruction. However, it should be noted that both teachers in the present study's intervention groups followed a curriculum and demonstrated a teaching style that were developmentally appropriate and allowed for a great deal of daily open-ended instruction. The design of the specific apps were either direct instruction or open-ended and, although children using the direct instruction apps performed better on the PPVT-4, this does not mean that an overall direct instruction teaching style is better in early childhood classrooms.

Although guidelines for developmentally appropriate use for technology (NAEYC \& Fred Rogers Center, 2012) promote opportunities for children to engage in creative, open-ended activities, the guidelines are not necessarily linked to learning new vocabulary using technology. It might be that for something specific like learning new words, apps with direct instruction have a stronger impact on receptive vocabulary than open-ended apps. The direct instruction apps chosen for this study were reviewed by professionals in the field as apps that promoted receptive vocabulary. Thus, it was not completely surprising that the children with direct instruction apps performed well on the PPVT-4.

In contrast, the open-ended apps encouraged the children in the present study to talk out loud. The open-ended apps included tasks using the iPad's microphone and camera functions. Thus, it was anticipated that there would be an EVT-2 expressive vocabulary increase for the children using the open-ended apps. Yet, this did not happen. Although there was not statistical significance between groups, the children using the 
direct instruction apps had a greater mean increase in EVT-2 scores than the children using open-ended apps. A possible explanation for the children in the direct instruction group performing better could be differences in teacher ability and commitment to intervention which will be explained more extensively in the Program Fidelity section of this chapter.

The findings in the present study echo findings of qualitative researchers: intentionally chosen apps can support and transform learning (Beschorner \& Hutchison, 2013). Yet, when apps are difficult for children to use independently and have minimal embedded learning scaffolds, they may not be effective for learning (Falloon, 2014). Overall, it is promising that the children using the direct instruction apps performed significantly higher on the PPVT-4 after a relatively short intervention period. In a previous study conducted to examine the efficacy of using audio-books versus traditional books to increase kindergarten students' PPVT-4 scores during a six-week intervention (Boeglin-Quintana \& Donovan, 2013), there was no significant increase in vocabulary knowledge. The findings in the present study provided insight into the types of apps that could promote receptive vocabulary growth in preschool children.

Although previous research has not been conducted to specifically examine young children's mobile media vocabulary, the findings in the present study have implications for information, communication, and technology (ICT) literacy which will be discussed in more detail in the Implications for Practice section of this chapter. 


\section{Research Question 3}

Within the intervention classrooms, what is the frequency of and how do Head Start teachers report using apps in the classroom?

\section{Intervention Teachers' Daily Self-Report Logs: Frequency of Use}

In examining both intervention teachers' daily logs across the eight-week intervention, the teacher in the classroom using direct instruction apps spent approximately 4,410 minutes using the iPads and apps with the children; and the teacher in the classroom using open-ended apps spent approximately 3,070 minutes. Although these times were best estimates based on teacher reports, it is certain from the primary researcher's weekly observations that the teacher using direct instruction apps spent more minutes using the iPads than the teacher using open-ended apps. This could explain why the children using direct instruction apps outperformed the children using open-ended apps on the PPVT-4. Interestingly, the teacher using direct instruction apps reported using the iPads on fewer days than the teacher using open-ended apps. Further discussion of the teacher-reported data is included in the Program Fidelity section.

\section{Intervention Teachers' Daily Self-Report Logs: How the Apps Were Used}

The intervention group teachers completed a section on the daily log focused on developmentally appropriate practices for using technology with young children (Harms et al., 2005; NAEYC \& Fred Rogers Center, 2012). The primary researcher discussed and mentored the practices with the intervention teachers during weekly meetings. The 
teachers then assessed their usage by checking "very", "somewhat", and "not at all" for each developmentally appropriate practice.

\section{Teacher With Direct Instruction Apps}

The teacher with the direct instruction apps always felt that her app use very much supported children's learning and encouraged active involvement. Further, although she occasionally rated the app use as somewhat encouraging creativity, she most often rated the app use as very much encouraging creativity. This was surprising because her intervention apps did not tend to encourage creativity. Prior to the end of the child intervention, the primary researcher asked her what it meant when she indicated an app encouraged children to be creative. She responded, "Because they think more. They answer, 'It's in the in iPad'. They have more choices. They think more about what they are doing." Thus, her definition of creativity was linked to critical thinking.

The teacher with the direct instruction apps most often indicated that app use somewhat supported daily classroom themes and activities, but there were some instances where she believed that apps did not support classroom activities at all. Finally, she most often indicated that app use was somewhat useful in encouraging children to collaborate with one another, but there were some instances where she indicated that app use was not at all supportive of collaboration. At the beginning of the study, she was very skeptical about the three-year-olds in her classroom sharing the iPads, and it was an on-going process of encouraging her to facilitate the sharing practice. 


\section{Teacher With Open-Ended Apps}

The teacher with the open-ended apps tended to take a "middle-of-the-road" approach and rarely used the highest ratings for each category on the daily log. The only area in which she consistently used the highest rating was in the encouragement of collaboration category, indicating that she believed app use very much encouraged children to collaborate with one another. This was the first topic that was discussed before the intervention began and one area of the intervention in which she actively participated. She never indicated app use as being not at all supportive of daily themes and activities.

\section{Interpreting Findings From the Intervention by Teacher to the Children}

The intervention by the teacher to the children was loosely modeled on findings from Ciampa and Gallagher's (2013) intervention. They utilized a pre-intervention needs assessment and a teacher questionnaire. They were concerned with teachers' desire to have differentiated mobile media mentoring and the ability to work alongside with researchers as they discovered the best ways to incorporate mobile media in the classroom.

The intervention teachers were chosen by the Head Start director, with guidelines from the primary researcher that the teachers be close to equal in their demographics, years of teaching experience, and education, plus had the most three-year-olds in their classroom at the beginning of the school year. Both of the intervention teachers 
expressed interest in the present study before it began and appeared equally enthusiastic to work with the primary researcher.

After teacher demographic data were collected through the Teacher Technology Perception and Use Survey, the primary researcher discovered that the teacher whose classroom received direct instruction apps held a Bachelor's degree, and the teacher whose classroom received open-ended apps held a Master's degree. Further, the teacher with direct instruction apps had many more years of teaching experience than the teacher with open-ended apps. Thus, the teacher demographics were not matched, but could be considered equal when one teacher's years of experience was counted for the other teacher's Master's degree.

During the eight weeks of the child intervention, the teachers each varied on their levels of commitment and displayed different levels of teaching ability, which potentially could have impacted the children's scores. The teacher with the direct instruction apps exhibited the same qualities found in the teachers examined in Marklund's (2015) study. The teacher with the direction instruction apps on several occasions requested information about technological knowledge, such as how to use the iPad device and its software. She indicated that she was very comfortable asking the primary researcher for help in the middle of her small group and whole group iPad instruction. She also had concerns about the developmental appropriateness of technology for three-year-olds, which seemed to center around her fear of the device being broken and her being responsible for the damage. She also expressed a desire to be able to integrate iPad use into the classroom's daily themes, but could not because of the restrictions placed on the 
iPads. The teachers could not connect the iPads to Wi-Fi and they felt restricted by this. There were instances when the teacher with the open-ended apps would download ebooks on her personal iPad to show during whole group lessons in order to support daily themes and activities.

The teacher whose classroom received open-ended apps indicated on her Technology Perceptive and Use Survey that she agreed mobile device apps could help develop children's critical thinking skills, improve individualized learning, were useful for social interactions among children, and could develop children's content knowledge. Conversely, she also stated:

I believe there should be a screen time limit in the classroom. Many kids use this technology in the home and when not use intentionally [mobile media] can be addictive. [Mobile media] should be used more so as a tool for teachers. Therefore, her self-report survey data was somewhat conflicting. Like some of the teachers in Masoumi's (2015) study, based on her comment on the survey, daily observation, and weekly conversations, the teacher using open-ended apps did not seem to see the iPads as a valuable teaching tool or a vehicle for play, nor did she seem to appreciate the weekly mentoring meetings that were desired by teachers in previous research (Ciampa \& Gallagher, 2013). However, it is possible that teaching with the open-ended apps was difficult for her, causing her to be less enthusiastic about using them. Below is a brief description of the program fidelity for each group of children. 
Program Fidelity: Did the Children Receive the Intervention?

\section{Children Assigned to Direct Instruction Apps}

As per Head Start requirements (Head Start Act, 2007), all children in the analyses were in attendance for at least $85 \%$ of the eight-week child intervention. The children in the classroom with direct instruction apps received approximately 4,410 minutes of instruction with the apps, across 38 days, as reported by the teacher. Across the 38 days of the child intervention, the teacher reported that she did not use apps on five of the days. The teacher attended all eight of the scheduled weekly mentoring meetings with the primary researcher. Three additional five- to ten-minute meetings were held at the request of the teacher, and she called the primary researcher on the phone three times for clarification and additional assistance on how to incorporate iPad and app use in her classroom. She missed none of the scheduled meetings. During the meetings, she discussed why she thought plans did not work, and offered solutions for making alternate plans. For example, the children could not use the iPads without the teacher inputting the passcode, so she created visual instructions and taught small group lessons to help the children learn the passcode and more independently use the iPads.

The primary researcher observed the teacher during the times the children were interacting with the direct instruction intervention apps. The children received whole group, small group, and one-on-one instruction on how to use the iPad device and the apps. Additionally, the children used the apps independently or with a peer during free choice centers. The children were given repeated instruction by the teacher and, at times, 
by the primary researcher, who would be in attendance during free choice centers and whole group, small group, and one-on-one instruction. Thus, the children in the classroom with direct instruction apps received the intervention as intended by the primary researcher.

\section{Children Assigned to Open-Ended Apps}

As per Head Start requirements (Head Start Act, 2007), all children in the analyses were in attendance for at least $85 \%$ of the eight-week intervention. The children in the classroom with open-ended apps received instruction on the iPad by the teacher, the teacher's assistant, and the primary researcher for approximately 3,070 minutes, across 38 days, as reported by the teacher. Across the 38 days of the child intervention, the teacher reported that she did not use apps on three of the days. The teacher attended six of the scheduled weekly mentoring meetings with the primary researcher. She missed two meetings and the meetings were rescheduled within the week. During the meetings she discussed her frustration with having enough time in the school day to work on incorporating more iPad use into the classroom.

The primary researcher observed the teacher during the times the children were interacting with the open-ended apps. The children mainly used the apps independently or with a peer during free choice centers. Although the teacher used apps approximately three times during whole group learning, she did not use the intervention apps during this instruction. The teacher scheduled time for the primary researcher to demonstrate to the 
children the use of one of the open-ended apps during a whole group lesson. There were no instances where the teacher used apps during small group instruction.

The children in the classroom with open-ended app instruction received the intervention, albeit not totally from their primary teacher, but from the teacher's assistant and primary researcher. Beginning at Week 5 of the child intervention, the primary researcher was given the opportunity to instruct the children on how to use the apps during free choice centers every day for the remaining duration of the intervention. Any time a research study must rely on teacher report, one realizes that the teachers may make mistakes in their reports. Nevertheless, the primary researcher was in the building most days of the week during the eight-week intervention. The observations of the primary researcher indicated that the teacher reports for amount of usage was not accurate for the teacher assigned to open-ended apps. For example, one day the researcher expected to observe during a time when iPads were typically in use; however, the class took a field trip to the library that day. In checking the teacher's daily log, she wrote that she instructed the children on open-ended apps on the day she took them to the library. Thus, the children in the classroom with open-ended apps did not consistently receive the intervention as intended by the primary researcher, but they did receive enough instruction from the teacher, the teacher's assistant, and the primary researcher to keep them in the study. 


\section{$\underline{\text { Implications for Practice }}$}

With children having more access to mobile media in the home (Common Sense Media, 2013) and early childhood programs investing in mobile media for the classroom, educators need to become experts on how to use mobile media in the classroom in order to capitalize on the potentials of the technology (Chang et al., 2005; Fritz, 2005; Kuhlman et al., 2005). The present study echoes previous findings that teachers first need to believe that mobile media is beneficial and developmentally appropriate before they can be given support for using it in the classroom (Masoumi, 2015; Nuttall et al., 2015). With a focus on "Kindergarten Readiness" teachers are also seeking to learn how to make mobile media use relevant to academic subjects (Marklund, 2015). As discovered in the present study, teachers are severely limited in what they are able to do with mobile media when they cannot access the Internet on their devices and do not have the ability to download new apps. Additionally, teachers in the present study were less likely to use mobile media with their students when they were required to sign a contract stating they would be responsible for any damage incurred on the device. No matter how well intentioned the restrictions put on the iPads were, ultimately they hindered teachers' ability to effectively and confidently use them. Thus, it is important for programs to discover ways to ensure proper use of mobile media, while still support teachers as they discover how to add this to their array of teaching tools.

The present study also provided additional insight into apps that can promote learning in the classroom. The children who used the direct instruction intervention apps had higher PPVT-4 receptive vocabulary scores (Dunn \& Dunn, 2007) than the children 
with open-ended apps. All of the direct instruction apps had different methods for helping children understand the meanings of words. The Endless ABC, Noodle Words, and Goodnight $\mathrm{ABC}$ apps animated the words in various, engaging ways. The ABC GO app had an additional element of providing real-world pictures. In general, these apps worked well in the classroom because, after the teacher introduced the apps to the children in small and whole group settings, the children could use them on their own or with peer assistance. This allowed for a child to persist using each app instead of moving on to another app.

In contrast, the open-ended apps needed much more teacher support to assist the children in understanding how to get to the area in an app where the camera is accessed or to record and animate their drawings. Researchers have stated that the most appropriate use of mobile media include activities where children can guide their learning and construct their own knowledge (Chang et al., 2005; Kuhlman et al., 2005; Lan, Sung, \& Chang, 2007). Because the design of the open-ended apps required child to receive more support from the teacher, rather than allow them to guide their learning, the children spent less time on these apps and their features were never used to their full potential. If the open-ended apps had been assigned to the teacher who had the direct instruction apps, the children may have spent more time on the apps than they spent with the teacher who was assigned to the open-ended apps. It is possible that the teacher with direct instruction apps would have struggled with the open-ended apps also, because the instruction required a very different approach than the direct instruction apps. 
Finally, there were no previous studies conducted to directly examine young children's technology vocabulary. However, once the intervention teachers became intentional about teaching the children how to use the iPads, the children became technically proficient in how to use them. Children with the direct instruction apps significantly increased their iPad Receptive Vocabulary and iPad Expressive Vocabulary Word or Description knowledge, indicating that weaving ICT terminology and functions into teaching practice allows children to understand the functions of specific devices and become more autonomous in their use of the devices.

\section{$\underline{\text { Limitations }}$}

The present study was limited in several ways. First, the number of participants was small, which limited the generalizability of the results. Additionally, due to requirements of the district Head Start administration, the research design was quasiexperimental instead of a true experiment with random assignment. The children in the intervention classrooms also had access to the apps that the children in the control classrooms were using. Thus, there was no guarantee the children in the intervention classrooms were always using an intervention app outside of the specific iPad instruction time. A consistent way to measure that factor was beyond the scope of the study.

Second, there was not a guarantee that the children in the present study were exposed to the vocabulary included on the PPVT-4 and EVT-2. This may especially be the case with the EVT-2, as the apps that were open-ended relied more on the children generating their own vocabulary, rather than the app supplying the words. Moreover, the 
PPVT-4 and EVT-2 measure Standard American English. The majority of the children in the present study were exposed to a language other than English in the home (i.e., Spanish). Although all of the apps except for one Head Start-chosen app instructed children in English, differences in vocabulary scores may have been present if the children were assessed in the language that was primarily spoken in their home.

Third, the child intervention should not have been impacted so much by the teacher as long as the children were using the apps, but the design of the open-ended apps required more adult assistance. The teacher with the open-ended apps may have found it difficult to teach with this type of app, rather than the direct instruction apps. Thus, the teacher quality, particularly between the teacher who used the open-ended apps and the teacher who used the direct instruction apps, was different. The primary researcher supported the teacher and the teacher's assistant in using the open-ended apps with children in their classroom and indeed mentored the children herself to ensure that the children were exposed to the open-ended apps.

Finally, the PPVT-4 and EVT-2 include standardized measures of vocabulary that children at a specific age or grade level should know. Knowing this, the primary researcher created the iPad Receptive and Expressive Vocabulary Assessments, and modeled them on the way the PPVT-4 and EVT-2 were administered. However, the iPad Receptive and Expressive Vocabulary Assessments were not standardized and were not extensively piloted prior to the beginning of the study, which constitutes as a limitation. 


\section{$\underline{\text { Recommendations for Further Research }}$}

Ideally, though it would not be practical, a randomized experiment is needed. One potential design could include randomly assigning children to an intervention group and removing them from the classroom setting in order to interact with a researcher and apps in their assigned group. This method, although not a natural learning environment, would remove the teacher as a variable in the impact of different types of apps on children's development. If a randomized design cannot be used, future research would benefit from surveying all teachers in a center and then choosing intervention teachers based on desired responses. Additionally, insight may be gained if a comparison group of children who do not use apps in their classroom was added. Just as important, an eight-week intervention is relatively short, and more significant gains could potentially occur given a longer intervention plan.

Expressive and receptive vocabulary scores were examined in the present study. The PPVT-4 and EVT-2 were chosen because of their reliability and validity as well as the relatively simple administration process. Yet, when determining which assessment to use, it may be beneficial to establish what the early childhood program is already using and measure children's gains through that assessment.

Some interesting insights arose with the researcher-created iPad Receptive and Expressive Vocabulary Assessments as well. The iPad Receptive and Expressive Vocabulary Assessments were simply meant to assess knowledge of nine common functions of an iPad in order to promote ICT literacy (ISTE Standards•S, 2007; Partnership for $21^{\text {st }}$ Century Skills, 2011; U.S. Department of Education, 2010). The 
intervention group teachers were instructed to intentionally use the nine words, but some words (e.g., dock port) did not come up naturally during regular teaching practice. Prior to this study, the primary researcher never used the term, dock port. Is it important for children to use the term, dock port, or is the term, charger, acceptable? Additionally, in order to keep the assessments consistent, the iPad assessments were administered exactly in the same way as the PPVT-4 and EVT-2. However, the iPad is a very threedimensional object. When shown a picture of the iPad, many children responded "rectangle" or "black". Most likely, it would have been more effective to show the children a physical iPad for the assessment and guide them through labeling the parts and functions.

It is difficult to determine which apps will and will not be successful for classroom use. When choosing apps, a balance should be found for how much scaffolding is required for using an app. Just as important, children should be observed using an app, and if it does not serve its desired purpose or does not seem to be working

well with a specific group of children, it should be rotated out for a different app. Future research would also benefit from a more effective method for monitoring duration of app use in the classroom, which apps were used, and how the teacher and children used the apps in order to more accurately state the impact of apps on child outcomes.

\section{Summary}

The findings in this study revealed that preschool Head Start children who participated in an intervention with direction instruction vocabulary apps performed 
statistically significantly better on a receptive vocabulary assessment (PPVT-4, Dunn \& Dunn, 2007) than children who participated in an intervention with open-ended vocabulary apps, but neither group differed from the control groups. Additionally, the intervention teachers received mentoring and support in the area of mobile media technology, including intentionally using common vocabulary functions. The children in the classroom with direct instruction apps performed statistically significantly higher on an iPad Receptive Vocabulary Assessment (Vatalaro, 2015a) when compared to two control groups. Further, the children who received direct instruction apps with a highly involved teacher outperformed the control children and the children using open-ended apps on the iPad Expressive Vocabulary Assessment (Vatalaro, 2015b) when their ability to describe iPad functions was taken into account.

Moreover, differentiated mentoring with two Head Start teachers resulted in the teacher who used direct instruction apps using the apps more frequently, intentionally, and in diverse ways than the teacher assigned to open-ended apps. The findings suggested that interactive, animated apps that provide the meanings of words may have the ability to increase receptive vocabulary. However, apps are just one tool of many that effective, developmentally appropriate teachers can use to support learning. Future research is warranted in order for the field of early childhood educational apps to conclude if one type of app or another is any better related to an increase in children's vocabulary growth. 
APPENDIX A

IRB APPROVAL LETTER 
University of Central Florida Institutional Review Board Office of Research \& Commercialization

12201 Research Parkway, Suite 501

Orlando, Florida 32826-3246

Telephone: 407-823-2901 or 407-882-2276

www.research.ucf.edu/compliance/irb.html

\section{Approval of Human Research}

From: $\quad$ UCF Institutional Review Board \#1 FWA00000351, IRB00001138

To: $\quad$ Angela M. Vatalaro

Date: November 04, 2014

Dear Researcher:

On 11/4/2014, the IRB approved the following human participant research until 11/03/2015 inclusive:

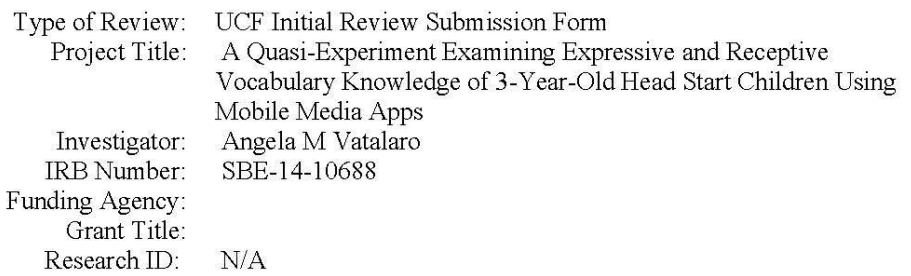

The scientific merit of the research was considered during the IRB review. The Continuing Review Application must be submitted 30 days prior to the expiration date for studies that were previously expedited, and 60 days prior to the expiration date for research that was previously reviewed at a convened meeting. Do not make changes to the study (i.e., protocol, methodology, consent form, personnel, site, etc.) before obtaining IRB approval. A Modification Form cannot be used to extend the approval period of a study. All forms may be completed and submitted online at https://iris.research.ucf.edu .

If continuing review approval is not granted before the expiration date of $11 / 03 / 2015$, approval of this research expires on that date. When you have completed your research please submit a Study Closure request in iRIS so that IRB records will be accurate

Use of the approved. stamped consent document(s) is required. The new form supersedes all previous versions, which are now invalid for further use. Only approved investigators (or other approved key study personnel) may solicit consent for research participation. Participants or their representatives must receive a copy of the consent form(s)

All data, including signed consent forms if applicable, must be retained and secured per protocol for a minimum of five years (six if HIPAA applies) past the completion of this research. Any links to the identification of participants should be maintained and secured per protocol. Additional requirements may be imposed by your funding agency, your department, or other entities. Access to data is limited to authorized individuals listed as key study personnel

In the conduct of this research, you are responsible to follow the requirements of the Investigator Manual.

On behalf of Sophia Dziegielewski, Ph.D., L.C.S.W., UCF IRB Chair, this letter is signed by:

Page 1 of 2 


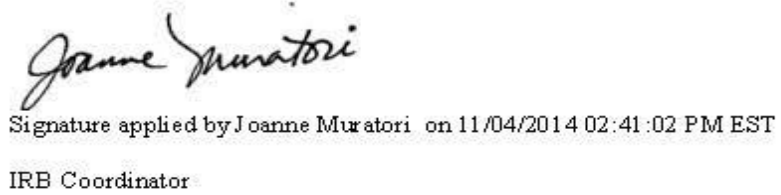

Page 2 of 2 
APPENDIX B

HEAD START-CHOSEN APPS 


\begin{tabular}{|c|c|c|c|c|c|c|}
\hline App Name & Ages & $\begin{array}{l}\text { Category } \\
\text { in iTunes }\end{array}$ & $\begin{array}{l}\text { iTunes } \\
\text { App } \\
\text { Store } \\
\text { Rating } \\
(1-5)\end{array}$ & $\begin{array}{l}\text { Common } \\
\text { Sense Media } \\
\text { Learning } \\
\text { Rating (1-5) }\end{array}$ & $\begin{array}{c}\text { AppoLearning } \\
\text { Rating } \\
(1-10)\end{array}$ & $\begin{array}{c}\text { Children's } \\
\text { Technology } \\
\text { Review Rating } \\
(1-100)\end{array}$ \\
\hline $\begin{array}{l}\text { Smarty } \\
\text { Pants School }\end{array}$ & $\begin{array}{l}\text { No } \\
\text { longer } \\
\text { available } \\
\text { in iTunes } \\
\text { store }\end{array}$ & N/A & N/A & Not Rated & Not Rated & Not Rated \\
\hline $\begin{array}{l}\text { Letter } \\
\text { School }\end{array}$ & $\begin{array}{l}5 \text { and } \\
\text { under }\end{array}$ & Education & 4.5 & 4 & 9.6 & 96 \\
\hline $\begin{array}{l}\text { TJ's Picture } \\
\text { Dictionary }\end{array}$ & $4+$ & Education & 4.5 & Not Rated & Not Rated & Not Rated \\
\hline $\begin{array}{l}\text { Gazzili } \\
\text { Science }\end{array}$ & $\begin{array}{l}5 \text { and } \\
\text { under }\end{array}$ & Education & 3.5 & Not Rated & 8.7 & Not Rated \\
\hline $\begin{array}{l}\text { Interactive } \\
\text { Telling Time }\end{array}$ & $\begin{array}{l}5 \text { and } \\
\text { under }\end{array}$ & Education & 4 & Not Rated & 9.3 & Not Rated \\
\hline $\begin{array}{l}\text { Yumiloo } \\
\text { Rainbow } \\
\text { Power }\end{array}$ & $\begin{array}{l}5 \text { and } \\
\text { under }\end{array}$ & Education & 4 & Not Rated & Not Rated & Not Rated \\
\hline $\begin{array}{l}\text { Faces iMake } \\
\text { ABC }\end{array}$ & $\begin{array}{l}5 \text { and } \\
\text { under }\end{array}$ & Education & 5 & 3 & Not Rated & 82 \\
\hline $\begin{array}{l}\text { Counting } \\
\text { Bear }\end{array}$ & $4+$ & Education & 4 & Not Rated & 8.3 & Not Rated \\
\hline $\begin{array}{l}\text { Lazy Larry } \\
\text { Lizard }\end{array}$ & $\begin{array}{l}5 \text { and } \\
\text { under }\end{array}$ & Books & 4 & Not Rated & Not Rated & Not Rated \\
\hline $\begin{array}{l}\text { Look Out } \\
\text { Larry }\end{array}$ & $\begin{array}{l}5 \text { and } \\
\text { under }\end{array}$ & Books & 4.5 & Not Rated & Not Rated & Not Rated \\
\hline Lost Larry & $\begin{array}{l}5 \text { and } \\
\text { under }\end{array}$ & Books & 4.5 & Not Rated & Not Rated & Not Rated \\
\hline $\begin{array}{l}\text { Feed Me! } \\
3.0 \\
\text { (Mexican } \\
\text { Spanish) }\end{array}$ & $4+$ & Education & $\begin{array}{c}\text { Not } \\
\text { Rated }\end{array}$ & Not Rated & Not Rated & Not Rated \\
\hline AniMatch & $4+$ & Games & 4 & Not Rated & Not Rated & Not Rated \\
\hline
\end{tabular}


APPENDIX C

WEEKLY INTERVENTION AGENDAS 


\section{Screen Time Debate}

\section{Week 1: January 19 - January 23 (Intervention-Direct Instruction)}

- The American Academy of Pediatrics states that all screens should be banned for children under 2 years. For children over 2 years, screen time should be limited to 30 minutes per day.

- The recommendation is based on research surrounding the effects of television on child development.

- A growing number of early childhood stakeholders are challenging the American Academy of Pediatrics position, stating that not all screens are created equal and a ban is not practical.

National Association for the Education of Young Children and Fred Rogers Position Statement: technology should be used...

- Intentionally

- Appropriately

- Limitations should be set

- Technology use should support active engagement, creativity, and collaboration

Adults should model responsible technology use

Teachers need comprehensive professional development

More research needs to be conducted

\section{Current Struggles in the Classroom}

What are your thoughts???

- Having to sit with the children using iPads during center time/child independence

- Afraid children will break iPads and teacher will be responsible

Making sure all children get time on the iPad/dividing the time

Quality of the apps/children's ability to use apps

Is volume an issue?

Other struggles?

$>$ Apps chosen by UCF for your iPad to support vocabulary knowledge

- Beck and Bo (children work within "scenes" and vocabulary is stated for the children)

- Draw \& Tell HD (children draw a picture and record their ideas about the picture; can create digital storybooks with multiple scenes)

- Don't Let the Pigeon Run This App (several options for children to interact with the story and record their voices)

- Alien Assignment (children go on several "missions", where the app directs them to take pictures of items around the classroom)

$>$ Goals for next week

- Allow two children at the iPad AIR and one child at the iPad mini during centers

- During small group or centers, introduce one of the UCF apps to the children and, as much as possible, keep the children on that app

- Brainstorm ways children can be more independent (less teacher control), while still working together as they do in other centers

- Begin intentionally using iPad vocabulary (children are not expected to learn all of this in one week!)

- iPad

- Screen

- Swipe

- Home Button

- Apps

- Dock Port

- Lock Screen

- Volume Control

- Camera (Primary Researcher is checking with Head Start Manager about using the camera function)

- Think of what else you want to do, learn, or explore with the children in the iPads. Remember, you are the expert in the classroom! 


\section{Screen Time Debate}

\section{Week 1: January 19 - January 23 (Intervention-Open-Ended)}

- The American Academy of Pediatrics states that all screens should be banned for children under 2 years. For children over 2 years, screen time should be limited to 30 minutes per day.

- The recommendation is based on research surrounding the effects of television on child development.

- A growing number of early childhood stakeholders are challenging the American Academy of Pediatrics position, stating that not all screens are created equal and a ban is not practical.

National Association for the Education of Young Children and Fred Rogers Position Statement: technology should be used...

- Intentionally

Appropriately

Limitations should be set

Technology use should support active engagement, creativity, and collaboration

Adults should model responsible technology use

Teachers need comprehensive professional development

More research needs to be conducted

\section{What are your thoughts???}

\section{Current Struggles in the Classroom}

- Having to sit with the children using iPads during center time/child independence

Afraid children will break iPads and teacher will be responsible

Making sure all children get time on the iPad/dividing the time

Quality of the apps/children's ability to use apps

Is volume an issue?

Other struggles?

\section{Apps chosen by UCF for your iPad to support vocabulary knowledge}

- Endless ABC (words are arranged alphabetically; children arrange the letters and then word definitions are narrated/acted out by animated monsters)

- ABC Go (words are arrange alphabetically; children click on a picture to find out more about the word and do simple activities)

- Noodle Words (animated actions words)

- Goodnight ABC (different scenes where words are labeled once a child presses on the picture)

\section{Goals for next week}

- Allow two children at the iPad AIR and one child at the iPad mini during centers

- During small group or centers, introduce one of the UCF apps to the children and, as much as possible, keep the children on that app

- Brainstorm ways children can be more independent (less teacher control), while still working together as they do in other centers

- Begin intentionally using iPad vocabulary (children are not expected to learn all of this in one week!)

- iPad

- Screen

- Swipe

- Home Button

- Apps

- Dock Port

- Lock Screen

- Volume Control

- Camera (Primary Researcher is checking with Head Start Manager about using the camera function)

- Think of what else you want to do, learn, or explore with the children in the iPads. Remember, you are the expert in the classroom! 
Week 2: January 26 - January 30

Follow Up From Last Week

- "Clean up" procedure(s)

- Child independence/more than one child using an iPad

Progress using UCF apps

Progress using iPad vocabulary

Thoughts about how to implement iPad use during other times of the day?

Daily forms

Feelings about Head Start apps: what do you like/what do you dislike?

Approximate total amount of time using each day?

Do you use in the afternoons?

$>$ Notes from Primary Researchers's Observations

- Rotating children through iPads: set a timer vs. keeping a list of children who used iPad

- How do you feel about the built-in stands?

- When a child gets stuck, explicitly show what to do to solve the problem. This is also a good time to use the iPad vocabulary.

- If a child seems bored or off-task on the iPad, move out of center? Or??

- Do the children have too many choices for the apps? Is this more of an issue with younger children (I-DI) than older children (I-OE)?

- What do you do if a child does not want to go the iPad center (I-DI)?

- When children use both iPads at the same table (one child/iPad), they stop and often look at and discuss what the other is doing (I-DI).

- When children use iPads at separate tables (two children/iPad), one seems to control while the other looks on (I-OE).

- Is sharing iPads better for some children and not others?

Disabling by inputting incorrect password too many times. How to problem solve? (I-OE)

- Comfortable having primary researcher work alongside and model iPad use for children?

- Are you limited by not having Internet access on the iPads?

\section{$>$ Review Head Start Manager's Email}

- Allowed to use other iPad functions

- Head Start Manager would like us to see if using the camera, notes, audio-recording slows down performance or eats up too much memory

- Can be used to create digital portfolio of child's abilities, plus support other social, emotional, and learning goals

- Ideas for the camera function:

- Creating digital stories with photos

- Develop emotional vocabulary (can be used for "pro-social word of the week")

- Model desired behaviors and help children learn from one another (take photos of desired behaviors and display in classroom and/or take photos of projects and discuss problemsolving/creative thinking as a class; can help facilitate "Review")

- Recall a learning experience (carnival day is a good example!)

- Build a classroom and school community (take and display photos of children and parents in the classroom)

- Ideas for other iPad functions:

- Support assessment (take a photo, video, or audio-recording of a child exhibiting or not exhibiting a behavior on the Galileo to help you document later)

- Support letter recognition/writing by allowing children to type notes

- Take your own notes (easier or more difficult than writing by hand?) 
Why Apps That Focus on Vocabulary?

Week 3: February 2 - February 6

0 Researchers (Hart \& Risley, 1995) discovered three-year-old children who come from families who are on welfare had on average 38 IQ points lower than children from professional families did.

- During a 14-hour day, children from welfare families heard 21,518 fewer words than children from professional families did.

- When children do not have rich language experiences, they are behind in brain stimulation, cultural learning, vocabulary growth, and verbal skill.

- Vocabulary knowledge is vital for later reading success.

Follow Up From Last Week

- As of Monday, February 2nd, you are able to use the cameras on your iPads. I-DI teacher took pictures during the puppet show on Tuesday.

- Other progress or thoughts about using the cameras?

- I-OE teacher's vocabulary Alien Assignment and Pigeon apps probably were not functional with the camera disabled. They should be now.

- "Clean up" procedure(s) - Sharing I-DI teacher's plan with I-OE teacher. Primary researcher can get materials if I-OE teacher would like to incorporate.

- Daily forms (primary researcher would like to collect from last week if she has not already done so; feedback filling them out; you can write on the back, if needed)

\section{Notes from Primary Researcher's Observations}

- On Tuesday, I-DI teacher used the iPads during whole group, small group, centers, while waiting for the puppet show to start, and to take photos during the puppet show.

- When incorporating the iPads in whole group, I-DI teacher was able to use the iPad AIR as an engaging tool to review the letter of the week (including letter recognition, letter sound, and letter formation), the "careers" theme, counting concepts, add visuals to rich vocabulary discussions, and reinforce iPad vocabulary (home button, apps, volume button, etc...).

- I-DI teacher was able to take notes on children's progress (Galileo skills) based on the whole group lesson.

- During small group, I-DI teacher explicitly taught half of the children how to unlock the iPads with the passcode while I-DI assistant worked on a non-iPad activity with the other half of the children. Would I-OE teacher like a copy of the laminated passcode forms I-DI teacher created?

- During another whole group lesson, I-DI teacher was able to use the Yumiloo app to reinforce healthy eating, the difference between fruits and vegetables, and what to do when one becomes rotten.

- While one iPad was disabled, primary researcher was able to facilitate two children working together on one iPad in I-DI class, but several reminders were needed to get them to interact with one another. 2 children per iPad is something that will be an on-going learning curve.

- When children are two to an iPad in I-OE teacher's class, it seems like one child is using the iPad while the second looks on doing very little.

- During the afternoon in I-OE teacher's class, children were using the iPads while sitting on the carpet. This allowed for the children to lie on their stomach, more easily pass back and forth, and children were much more interactive.

- Thoughts about moving iPad morning centers to a carpeted area?

- Other than children sitting on the floor, it does not seem that children are using the iPads any differently in the afternoon in I-OE teacher's class. Correct?

- Primary researcher would like to continue to work alongside and model iPad use for children in both classrooms. If there is a specific lesson you want me to observe or areas you would like to incorporate, but need help modeling, let primary researcher know! 


\section{Week 4: February 9 - February 13}

Revisiting the National Association for the Education of Young Children (NAEYC) and Fred Rogers Center Position Statement on Technology:

- Active screen time involves the children interacting with the screen. It is theorized that iPads and similar tablets can provide active screen time experiences.

- Passive screen time involves a child sitting in front of a screen, but having no interaction. An example of passive screen time is television watching.

- Research indicates that passive screen time can have negative effects on child development, while active screen time can produce positive effects.

- There is very little published research on the impact of mobile devices on child development.

- NAEYC and the Fred Rogers Center hold the position that mobile media used as active screen time can be used as a tool to support learning at home and in the classroom.

- Part of active screen time includes a child interacting with the screen and an adult or peer.

- Some apps may support active screen time and some apps may support passive screen time.

- Your thoughts?????

\section{Mid-Way Through the Intervention}

- After this week, there are 4 more weeks of observation and weekly meetings.

- Where would you like to go from here?

- Progress on collecting parent surveys?

- Successes?

- Difficulties?

- Things you still want to do or learn about?

- Things you absolutely do not want to try to incorporate?

- Other feedback?

\section{Follow Up From Last Week}

- Primary researcher began to work more intentionally with children in I-OE classroom to help them get exposure to different apps.

- Children are now given the option to use iPads on a carpeted area. Some choose the carpet and some choose to stay at the table. This is fine! Children who lie of their bellies and use the iPads are also building core muscle strength.

- Primary researcher made copies of the materials I-DI teacher made for I-OE teacher to teach the children the passcode and for "iPad Center" clean up.

- Collect daily forms. Make sure recording apps that are used each day. Can use the back of the form, if needed.

Notes from Primary Researcher's Observations: Classroom Management and iPads

- A teacher needs to know each app and what it does in order to effectively introduce it to students

- Each new procedure needs to be explicitly taught and reinforced several times before children can become independent

- New procedures need to be introduced slowly in order for each component to be successful

- When using the iPads during whole group/circle time, it seems most effective for children to sit around the perimeter of the carpet with the teacher standing in the center and walking around to show each child what is happening on the screen

- Children sharing the iPads will be a learning process. Some may need more support on sharing than others

- Discover a system so that the same children are not using the iPads during center time every day (unless other children do not want to use them)

- Capitalize on teachable moments:

- For example, children are recognizing the first letter of their names during app use

- For example, some pictures or components of the apps support the weekly theme 
Week 5: February 16 - February 20

What does it mean to you when you indicate an app encourages children to be creative?

Follow Up From Last Week

- Parent Surveys: Need any extra copies?

- I-DI teacher indicated that there is an on-going problem with children sharing the iPad AIR. This will probably continue until children mature and/or get used to sharing.... as long as the sharing routine is consistent.

- I-OE teacher indicated that she would be willing for primary researcher to model and explicitly use iPads with children during centers.

Notes from Primary Researcher's Observations:

- Primary Researcher caught part of I-OE teacher doing a whole group lesson with her iPad discussing different tools people in various trades use (matching the weekly theme). Which app was this?

- Are you hindered in your teaching by not being able to choose which apps are on the iPads and download new apps based on current classroom themes?

- In I-OE classroom, when children had trouble sharing, primary researcher directed the children to lie on their stomachs and put the iPad between them. This seemed to be effective in getting the children to share the iPads.

- During whole group in both I-OE and I-DI classrooms, children sat around the perimeter of the carpet while the teacher walked around, questioned, and prompted children. The lessons were engaging and contributed to the weekly themes and learning goals.

- Children in I-OE classroom exhibited parallel play while using the iPads: when children on the AIR chose an app, the child on the mini would choose the same app. No conversations between the children, but this happened with at least 4 apps.

- Children in I-DI class connected letters in the apps to the letter of the week.

\section{Looking Ahead:}

- Is there anything else concerning technology or iPads that you would like more information about?

- Is there any area where you would like me to offer more support?

- Are you at a point where you would like to print photos taken on the iPads? 
Follow Up From Last Week

Week 6: February 23 - February 27

- Parent Surveys: Need any extra copies?

What to do With the Photos on Your iPads:

- How to take them off: Primary researcher can troubleshoot this for you if you would like her to sit in your classroom at your desktop computer with the iPad

- What to do with the photos to document children's learning: There are several ways to do this. IDI teacher and primary researcher discussed creating a separate electronic folder for each child and placing the photos in the children's folders. If there is something you want to remember about the photo, you can label it accordingly. For example, if a child created something with blocks and then told you she created a "satellite", you can take a photo and, once downloaded on your computer, label the photo satellite.

- Other thoughts?

\section{Notes from Primary Researcher's Observations:}

- Primary researcher did a whole group lesson in I-OE classroom on Friday, 2/20, explicitly teaching children about the Pigeon app. Explicitly used vocabulary: home button, lock screen, app, and swipe. Children then used the Pigeon app during work time and continued to use it this week.

- A child in I-DI classroom found the "letter of the week" $(Y)$ in the Letter School app. He was able to recognize that it was the letter of the week, but could not tell I-DI teacher or primary researcher what letter it was. There is an issue with the Letter School app: it does not reinforce the letter name or letter sound. Even the animations are not related to the letter: for example, in IOE classroom a child was excited because $m$ turns into a "bomb" and explodes, however he could not tell I-OE teacher or primary researcher that it was the letter $\mathrm{m}$.

- The I-DI teacher suggested that a child go around the room and take photos of the letter of the week. This is a great learning activity and also a great way to assess the child's knowledge, while also getting an active child moving around the classroom.

- Primary researcher fixed the settings on both I-DI and I-OE iPads. Including:

- The microphone was disabled for children to use on the Draw \& Tell app on I-OE classroom's AIR

- The orientation was locked on I-OE classroom's AIR, which caused some apps and the display screen to show only in the landscape orientation

- Features that could benefit the children on some apps (including apps that Head Start purchased) were turned off

- Two of the apps on one of I-DI teacher's iPads were dragged and placed in a separate folder

$>$ Looking Ahead:

$\circ$ Week of March $2^{\text {nd }}$ :

- Primary researcher would like to go through all apps (UCF's and those purchased by Head Start) to determine which apps you like, which apps you do not like, and why.

- This will be the last "formal" meeting.

Week of March $9^{\text {th }}$ :

- Primary researcher would like to meet with I-OE teacher and I-DI teacher briefly to get final thoughts about the project and any final issues you would like to have presented to upper management.

- Week of March $16^{\text {th }}$ :

- Primary researcher and her UCF assessors will pull all children in the classroom again to complete post-assessments 
Follow Up From Last Week

\section{Week 7: March 2 - March 6 (Intervention-Direct Instruction)}

$$
\text { - Daily Forms }
$$

No response yet from upper management on where you can save the photos taken on your iPad. But, once I receive that response, your photos can be taken off by plugging the USB end of your iPad charger into your computer, press "trust this device" on your iPad, and opening the "Apple iPad" folder under "My Computer"

What does it mean to you when you indicate an app encourages children to be creative?

- I-DI teacher's response: Because they think more. They answer, "it's in the iPad". They have more choices. They think more about what they are doing.

Evaluating Your Apps: Indicate if you like the app, do not like the app, or if you are not familiar with the app. Brief description of your response. Primary researcher will take notes during this discussion.

\begin{tabular}{|c|c|c|c|}
\hline app & Like & Do Not Like & Not Familiar With This App \\
\hline Yumiloo & $\begin{array}{l}\text { It is like a game, but also } \\
\text { encourages healthy foods, } \\
\text { recycling }\end{array}$ & & \\
\hline Lazy Larry & $\begin{array}{l}\text { Would like it if the kids were } \\
\text { older }\end{array}$ & & \\
\hline Look Out Larry & $\begin{array}{l}\text { Would like it if the kids were } \\
\text { older }\end{array}$ & & \\
\hline Lost Larry Lizard & $\begin{array}{l}\text { Would like it if the kids were } \\
\text { older }\end{array}$ & & \\
\hline Counting Bear & $\begin{array}{l}\text { Simple. Enhances 1-1 } \\
\text { correspondence }\end{array}$ & & \\
\hline Telling Time & & It's too advanced & \\
\hline Gazilli Science & $\begin{array}{l}\text { Like it, but the explanations in } \\
\text { the app go too fast for the } \\
\text { teacher to explain in between } \\
\text { concepts }\end{array}$ & & \\
\hline Smarty School & & Have to sign in & \\
\hline Faces ABC & Like it & & \\
\hline TJ's Picture Dictionary & & & Not familiar with it \\
\hline Letter School & $\begin{array}{l}\text { Like it, but does not reinforce } \\
\text { the sound of the letter }\end{array}$ & & \\
\hline AniMatch & & $\begin{array}{l}\text { Would like it better if it was } \\
\text { more educational. If matching } \\
\text { was related to letters or } \\
\text { numbers and not animals }\end{array}$ & \\
\hline Feed Me! & $\begin{array}{l}\text { Like it, wish it was in English. } \\
\text { English-speaking students can } \\
\text { use it }\end{array}$ & & \\
\hline $\mathrm{ABC}$ Go & $\begin{array}{l}\text { Like it, would like more } \\
\text { variety for each letter }\end{array}$ & & \\
\hline Noodle Words & & Not really & \\
\hline Endless ABC & Like it & & \\
\hline Goodnight $\mathrm{ABC}$ & Like it & & \\
\hline
\end{tabular}

\section{Looking Ahead:}

- Week of March $9^{\text {th }}$ :

- Primary researcher would like to meet with I-OE teacher and I-DI teacher briefly to get final thoughts about the project and any final issues you would like to have presented to upper management.

Week of March $16^{\text {th }}$ :

- Primary researcher and her UCF assesors will pull all children in the classroom again do complete post-assessments 


\section{Week 7: March 2 - March 6 (Intervention Open-Ended)}

\section{Follow Up From Last Week}

- Daily Forms

- Parent Surveys: Need any extra copies?

$>$ No response yet from upper management on where you can save the photos taken on your iPad. But, once I receive that response, your photos can be taken off by plugging the USB end of your iPad charger into your computer, press "trust this device" on your iPad, and opening the "Apple iPad" folder under "My Computer"

What does it mean to you when you indicate an app encourages children to be creative?

- I-OE teacher's response: Only Draw \& Tell and Pigeon because they are putting their own ideas. Creativity $=$ when they use their own words and do what they want to do

Evaluating Your Apps: Indicate if you like the app, do not like the app, or if you are not familiar with the app. Brief description of your response. Primary researcher will take notes during this discussion.

\begin{tabular}{|l|l|l|l|}
\hline app & Like & Do Not Like & Not Familiar With This App \\
\hline Yumiloo & $\begin{array}{l}\text { Kids like it, but a little } \\
\text { redundant }\end{array}$ & & \\
\hline Lazy Larry & $\begin{array}{l}\text { Like them because it reads to } \\
\text { them. }\end{array}$ & & \\
\hline Look Out Larry & Like it & & \\
\hline Lost Larry Lizard & Like it & & \\
\hline Counting Bear & Like it & & \\
\hline Telling Time & & Too advanced & \\
\hline Gazilli Science & Like it & & \\
\hline Smarty School & Like it & & \\
\hline Faces ABC & Like it & & \\
\hline TJ's Picture Dictionary & Like it & Does not like it because it does & \\
\hline Letter School & & Need something more. & \\
& & & \\
\hline AniMatch & Kids like it & & \\
\hline Feed Me! & Like it & & \\
\hline $\begin{array}{l}\text { Don't Let the Pigeon Run This } \\
\text { App }\end{array}$ & Like it & & \\
\hline Alien Assignment & Like it & & \\
\hline Beck and Bo & Like it & Like it & \\
\hline Draw and Tell & & & \\
\hline
\end{tabular}

Talking ABC. Likes

$>$ Looking Ahead:

- Week of March $9^{\text {th }}$ :

- Primary researcher would like to meet with I-OE teacher and I-DI teacher briefly to get final thoughts about the project and any final issues you would like to have presented to upper management.

- Week of March $16^{\text {th }}$ :

- Primary researcher and her UCF assessors will pull all children in the classroom again do complete post-assessments 


\section{Week 8: March 9-March 13}

$>$ Wrapping Up:

- Primary researcher needs remaining completed parent surveys from I-OE teacher

- Would like to have all collected on Monday, 3/16

- Primary researcher and her UCF assessors will be assessing next week

\section{$>$ Summary of the Project:}

- Encouraged more than one child to use the iPad at a time

- Intentionally taught iPad vocabulary and the apps so that children can use more independently

- Moved children to a carpeted area to facilitate sharing of iPads

- Used iPads during learning experiences other than work time (e.g., small group and whole group)

- Had the cameras enabled and began to use them to document children's learning and create digital portfolios

- Created a "clean up" procedure so that the iPad center had the same accountability as all other centers

- Attempted to discover systems so that the same children are not using the iPad every day

Review of developmentally appropriate use of technology in early childhood settings (NAEYC and Fred Rogers Position Statement:

- Intentional

- Appropriate

Limitations should be set

- Technology use should support active engagement, creativity, and collaboration

- Adults should model responsible technology use

- Teachers need comprehensive professional development

- Mobile media used as active screen time can be used as a tool to support learning at home and in the classroom.

- Part of active screen time includes a child interacting with the screen and an adult or peer.

- Some apps may support active screen time and some apps may support passive screen time.

Thank you for your participation in this study! 
iPad Receptive Vocabulary

Assessment

Angela Vatalaro, Dissertation Study

2014-2015 

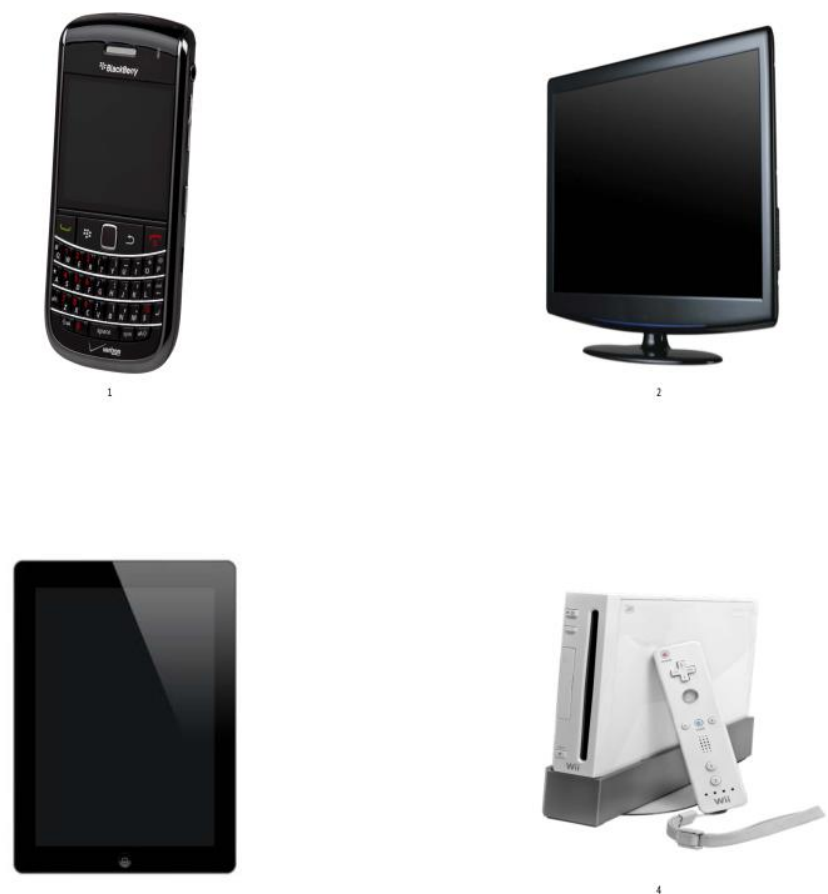

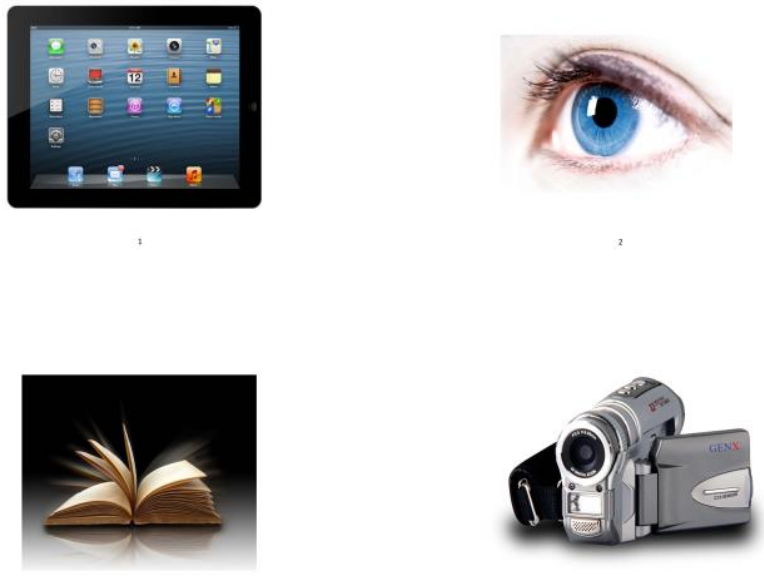
1/2/15
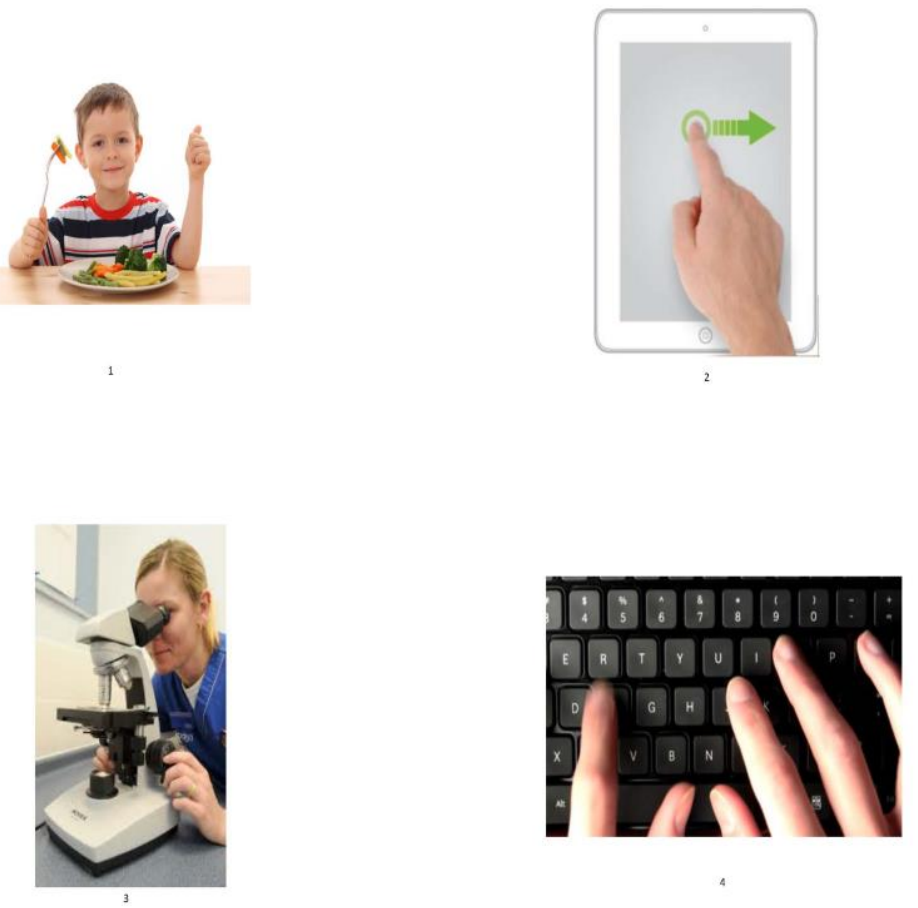

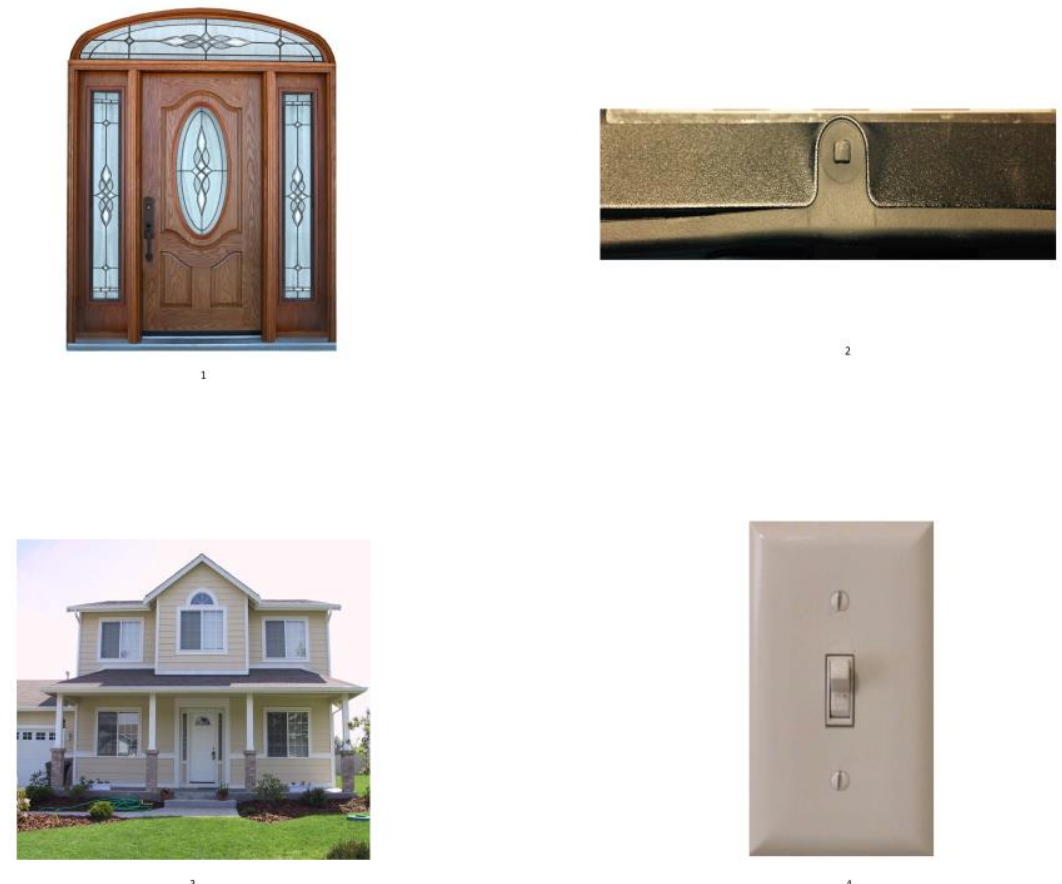

5 

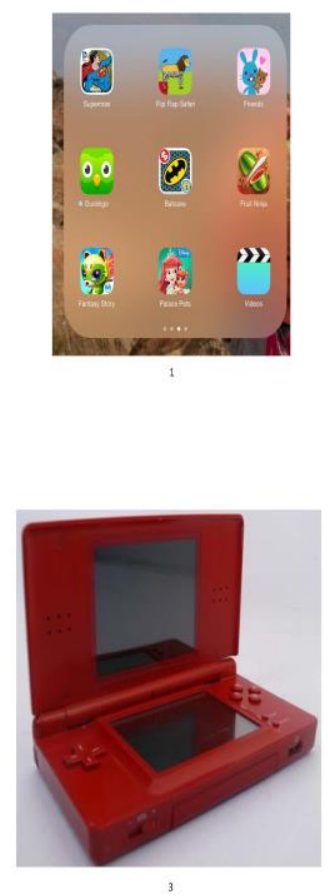
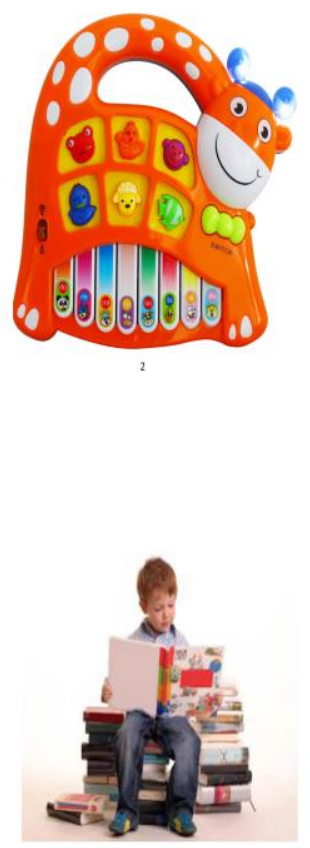

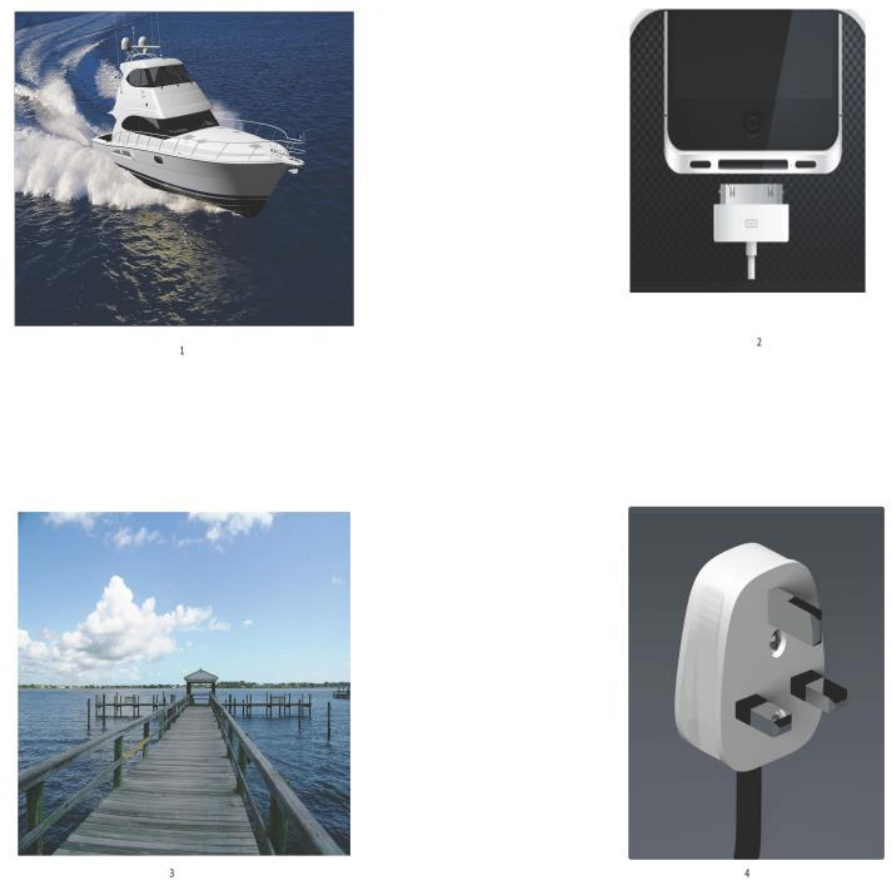

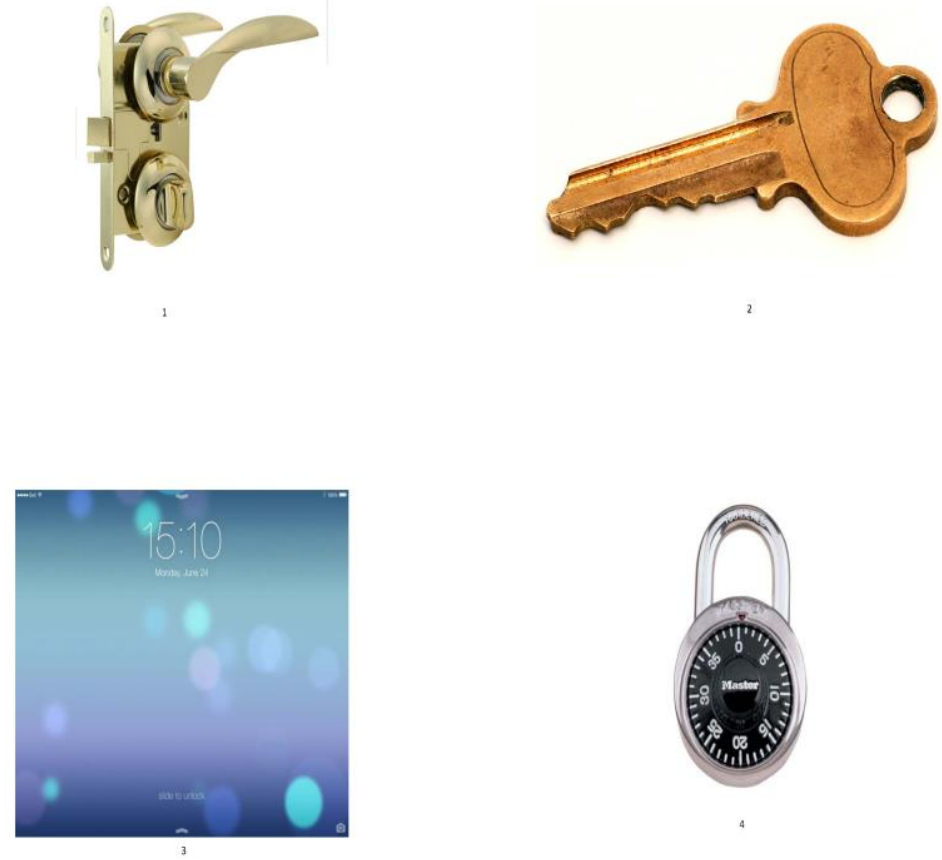

8 

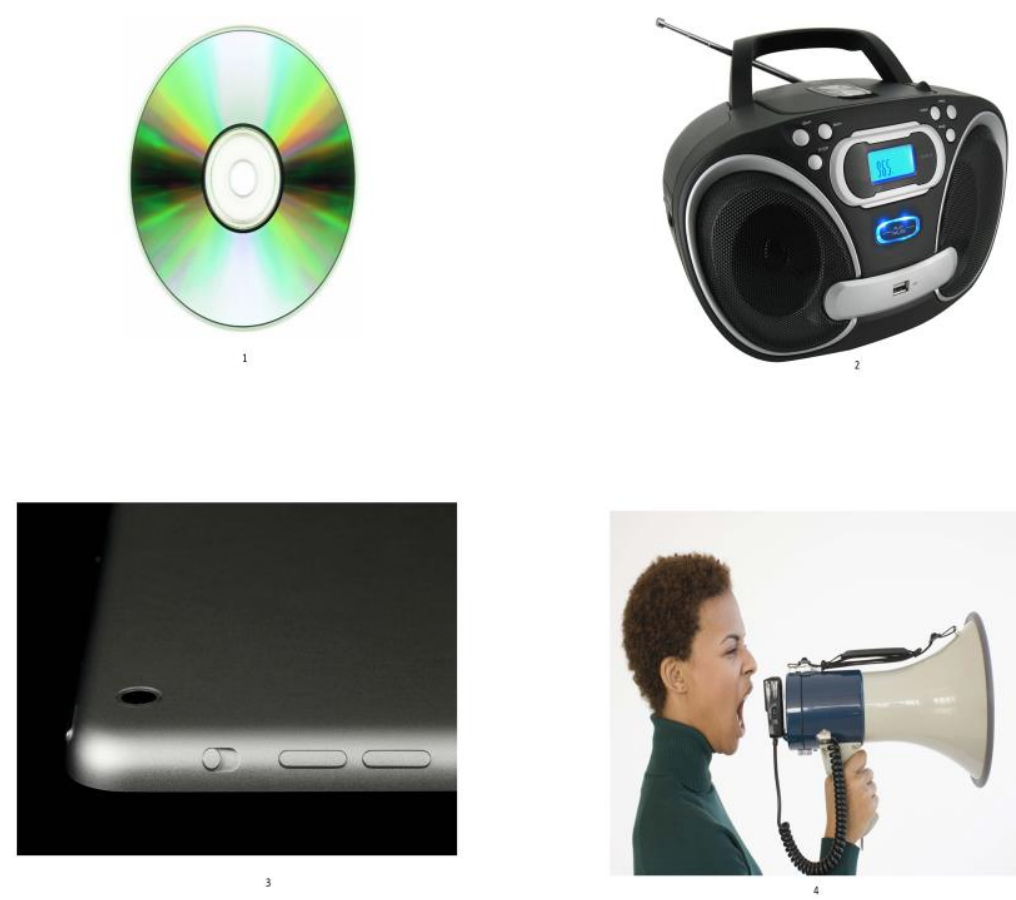

9 

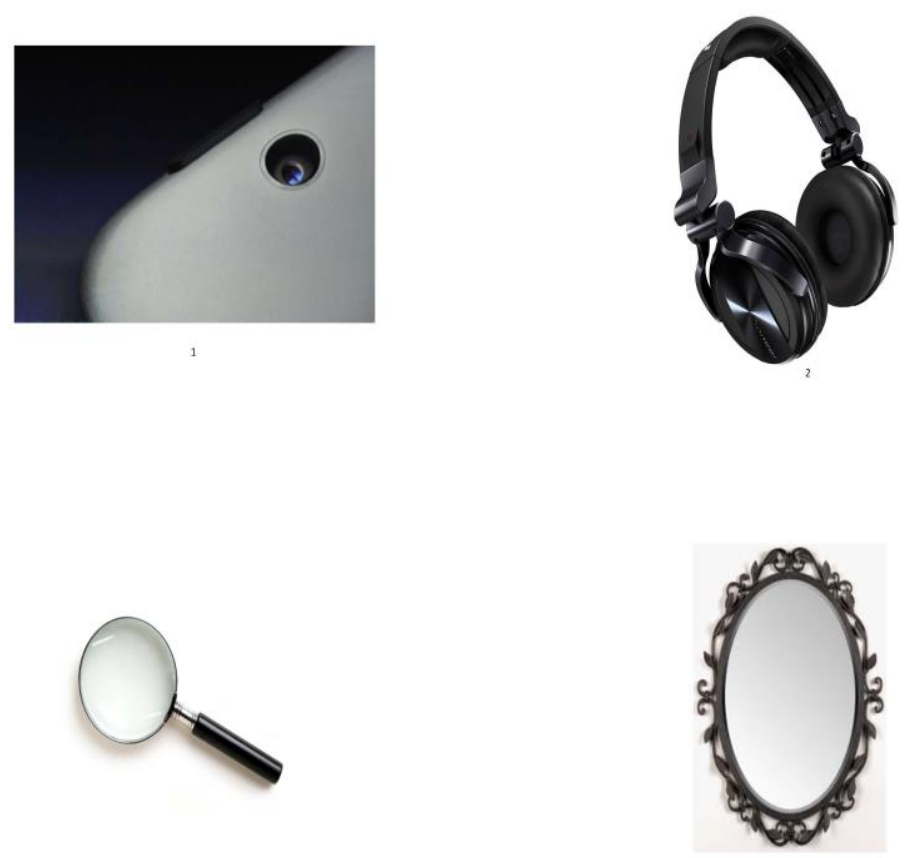
Child's Code:

Date:

Assessor:

\section{iPad Receptive Vocabulary Assessment}

Instructions: Open the set of pictures for each word below. Say, "Point to [specific targeted vocabulary item]." Circle the child's response. The correct response for each item is indicated in red. If the child does not respond, circle the $E$. If the child states other words or asks questions, write them in the blank space under the word. Add any other comments about the assessment situation or child's behaviors at the bottom.

\begin{tabular}{|l|lllll|}
\hline 1. iPad & 1 & 2 & 3 & 4 & $E$ \\
\hline 2. screen & 1 & 2 & 3 & 4 & $E$ \\
\hline 3. swipe & 1 & 2 & 3 & 4 & $E$ \\
\hline 4. home button & 1 & 2 & 3 & 4 & $E$ \\
\hline 5. apps & & & & & \\
\hline
\end{tabular}


Child's Code:

Date:

Assessor:

\begin{tabular}{|l|lllll|}
\hline 6. dock port & 1 & 2 & 3 & 4 & $E$ \\
\hline 7. lock screen & 1 & 2 & 3 & 4 & $E$ \\
\hline 8. volume control & 1 & 2 & 3 & 4 & $E$ \\
\hline 9. camera & 1 & 2 & 3 & 4 & $E$ \\
\hline
\end{tabular}

\section{Comments:}


APPENDIX E

iPAD EXPRESSIVE VOCABULARY ASSESSMENT 
iPad Expressive Vocabulary Assessment

\section{Angela Vatalaro, Dissertation Study 2014-2015}




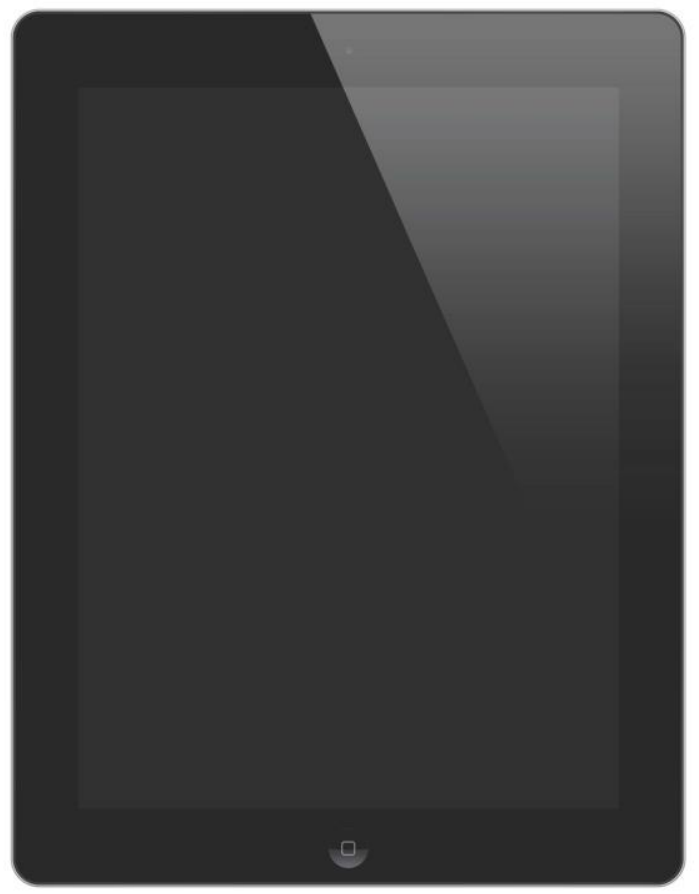




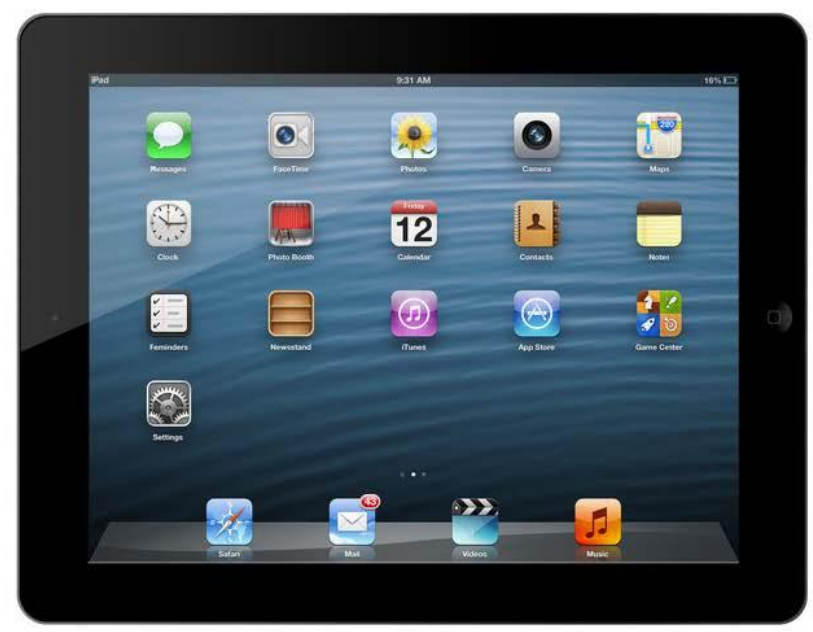




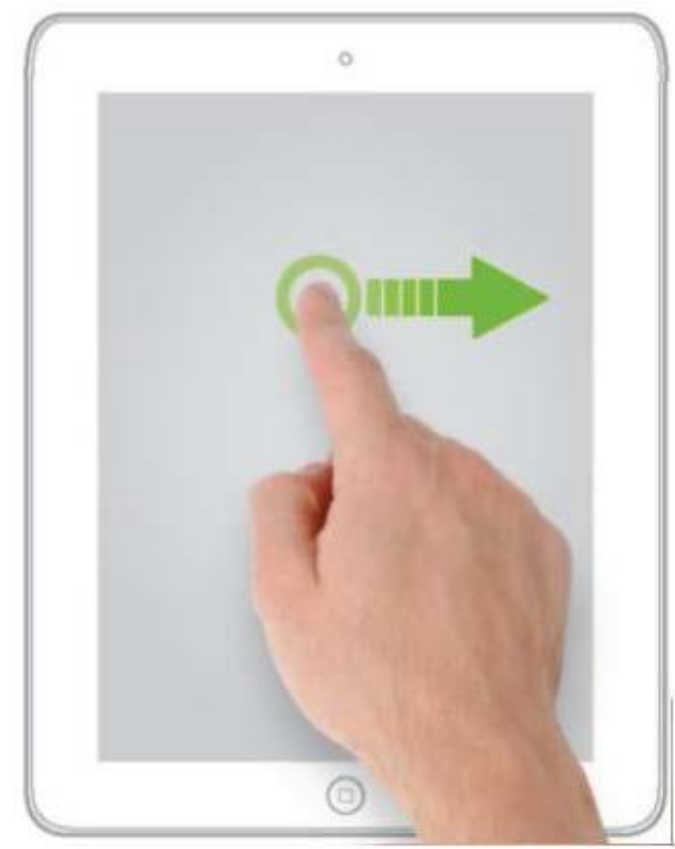




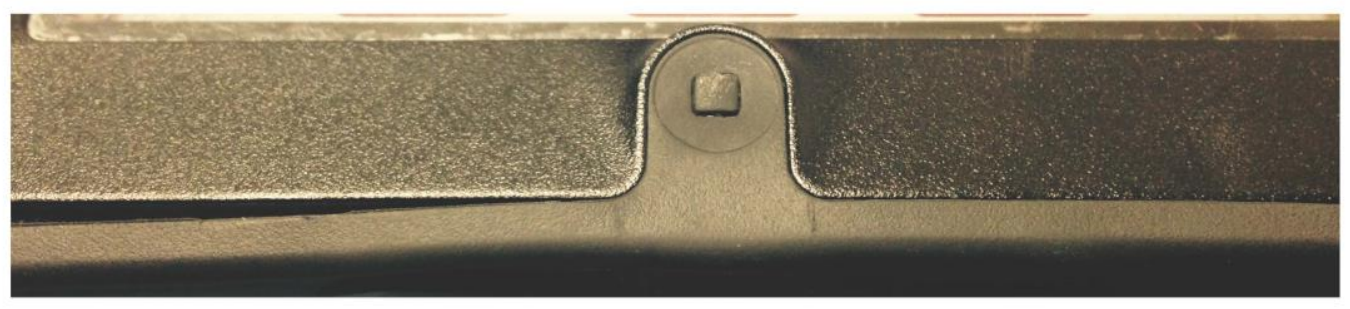




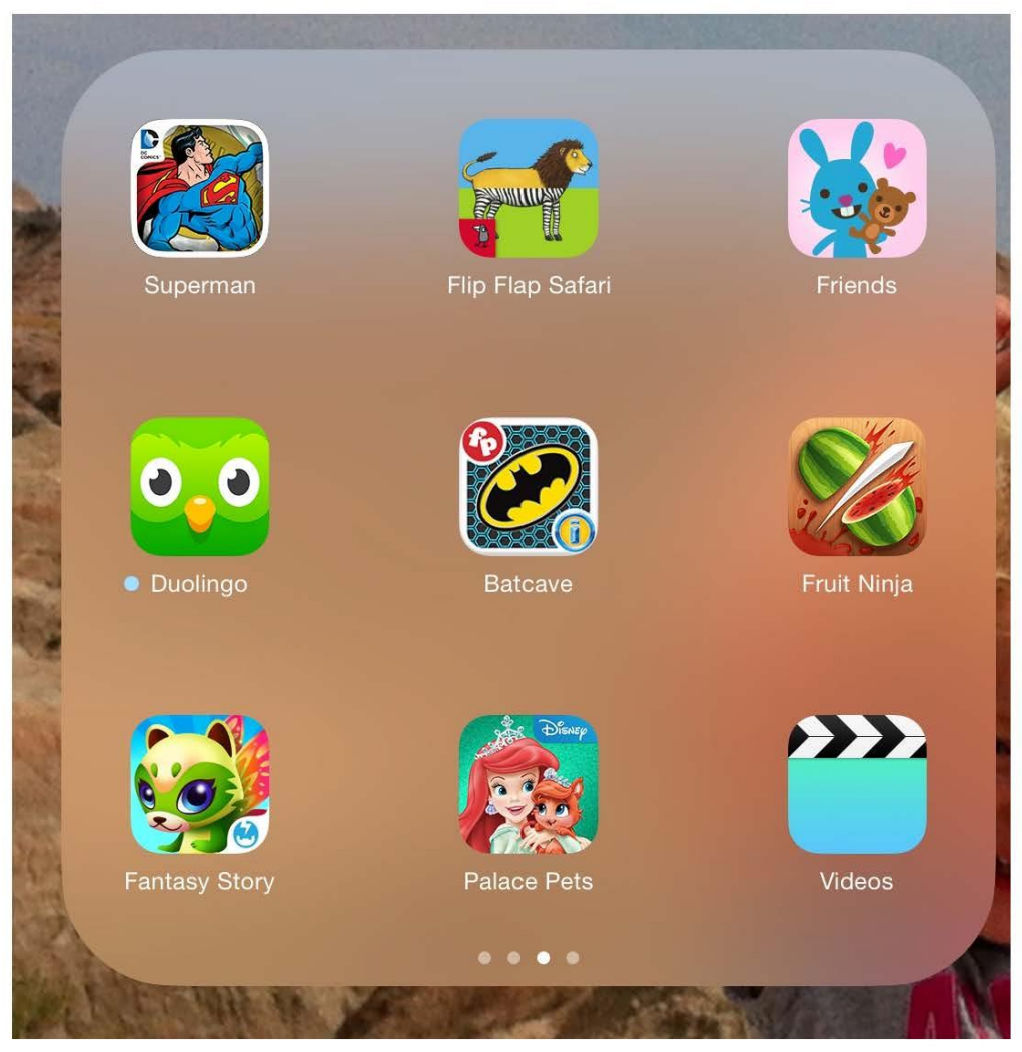




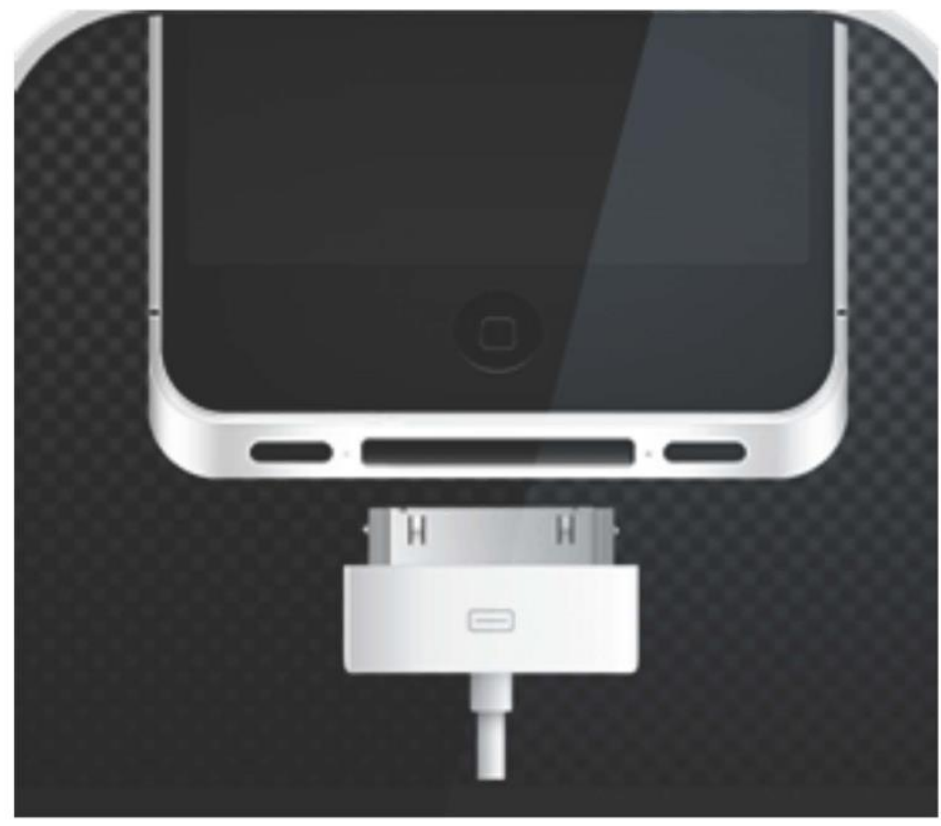




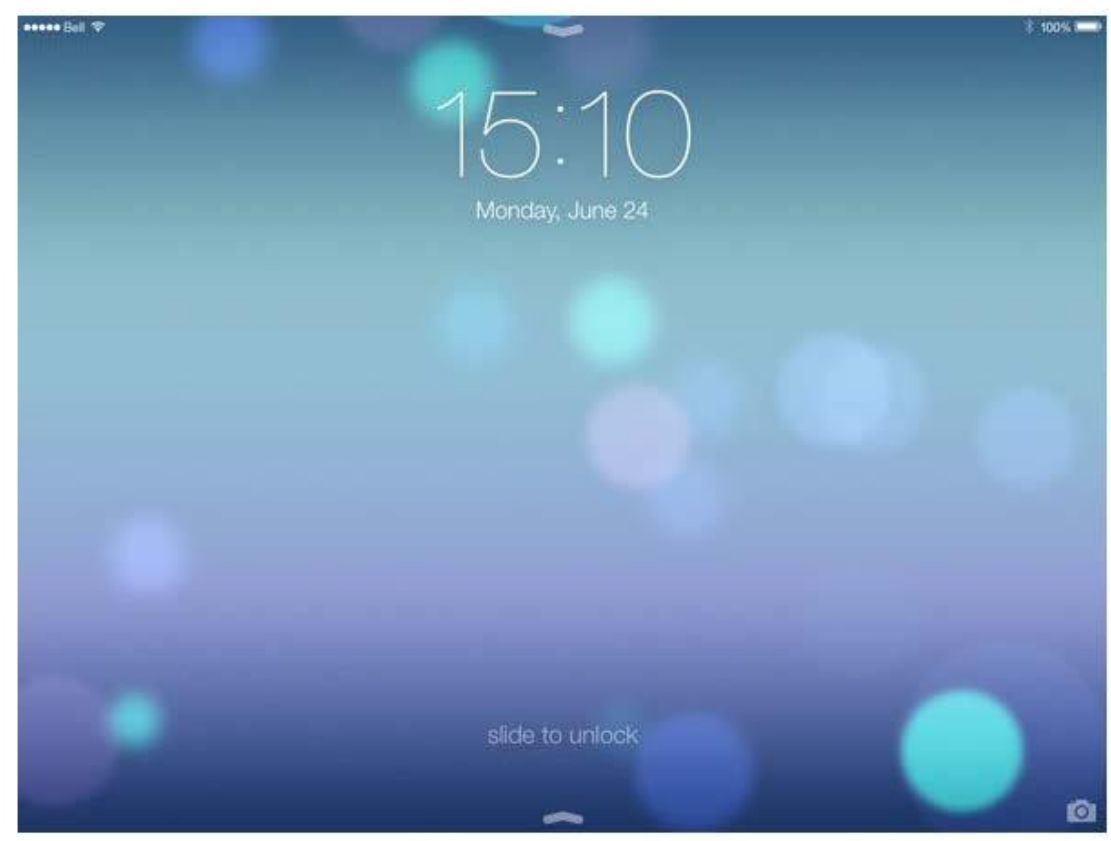




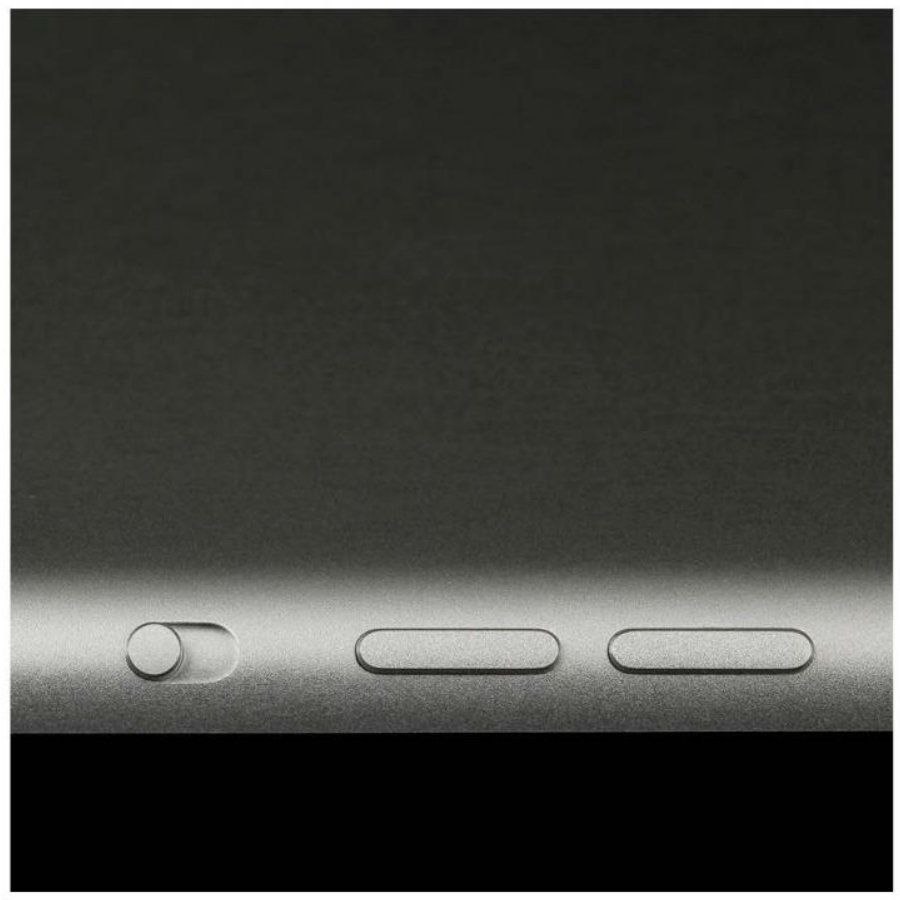




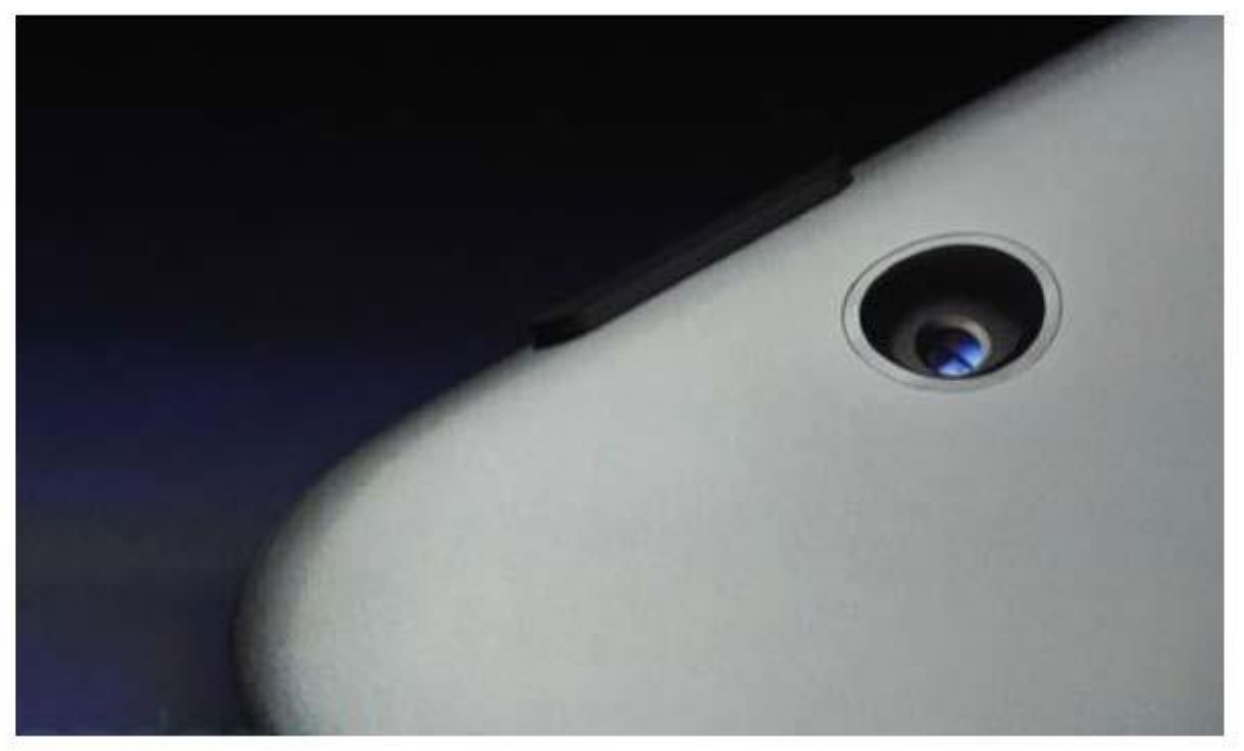


Child's Code:

Date:

Assessor:

\section{iPad Expressive Vocabulary Assessment}

Instructions: For each item, ask the stimulus question. You may repeat it only once. Allow about 10 seconds for a response to each item. If the child's response matches the correct response, circle the 1 in the score column. If the child says anything other than the correct response, write the child's exact word(s) in the 0ther column. Put a check mark in the DK column if the child fails to respond or does not know the answer. Add any other comments about the assessment situation or child's behaviors at the bottom.

\begin{tabular}{|c|c|c|c|c|c|}
\hline Score & Item & $\begin{array}{l}\text { Stimulus } \\
\text { Question }\end{array}$ & $\begin{array}{l}\text { Correct } \\
\text { Response }\end{array}$ & DK & Other \\
\hline $\begin{array}{lll}2 & 1 & 0\end{array}$ & 1 & What is this? & $\begin{array}{l}\text { iPad }=2 \\
\text { tablet }=1 \\
\text { DK or other }=0\end{array}$ & & \\
\hline 10 & 2 & $\begin{array}{l}\text { What part of the } \\
\text { iPad is this } \\
\text { (point)? }\end{array}$ & screen & & \\
\hline 10 & 3 & $\begin{array}{l}\text { What is he doing } \\
\text { with his finger? }\end{array}$ & swip[ing] & & \\
\hline
\end{tabular}

Write any comments on the back of this page 
Child's Code:

Date:

Assessor:

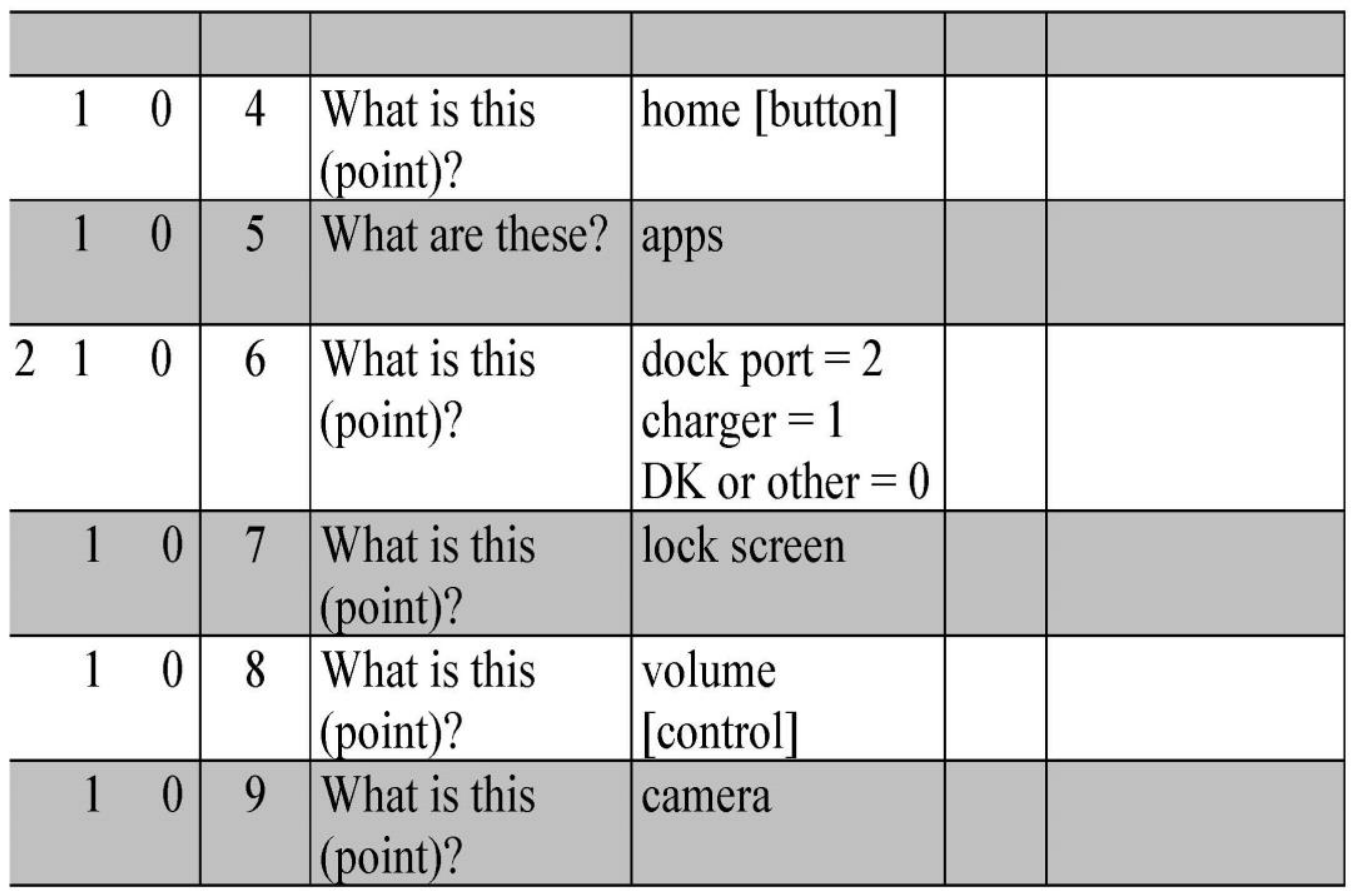

Write any comments on the back of this page 
APPENDIX F

ENGLISH FAMILY TECHNOLOGY OWNERSHIP AND USE SURVEY 


\section{Family Technology Ownership and Use Survey}

$$
\text { Angela Vatalaro }
$$

This survey is designed to find out the ways in which parents of Head Start children use mobile devices at home. Your responses will offer valuable insight. Your help is greatly appreciated. If you have any questions or concerns you can contact Angela at 321-432-2942 or Angela.Vatalaro $a$ ucf.edu

\section{Start Here}

For questions 1 and 2, please write your response.

1. Your Name:

2. Your Child's Name:

For questions 3-14, please mark an $X$ in the most appropriate box.

3. Relationship to Child :
$\square$ Mother
$\square$ Father
$\square$ Grandmother
$\square$ Grandfather
$\square$ Foster Parent
$\square$ Other: Please Specify

4. Was your child enrolled in school at this Head Start before this school year?

$\square$ Yes

$\square \quad$ No 
Rev. 1.19 .15

Page 2 of 6

5. Does your child receive any special services? Please mark all that apply:

$\square$ Occupational Therapy

$\square$ Speech Therapy

$\square \quad$ Play Therapy

$\square$ Behavior Therapy

$\square$ Other: Please Specify

$\square \quad$ My child does not receive any special services

6. My child's ethnic background is:

$\square$ Caucasian

$\square \quad$ African American

$\square$ Hispanic

$\square \quad$ Asian/Pacific Islander

$\square$ American Indian/Alaskan Native

$\square$ Other: Please Specify

7. What is the main language spoken in your home?

$\square$ Only English

$\square \quad$ Mainly English, but also some other language(s)

$\square \quad$ Mainly other language(s), but also some English

$\square \quad$ A non-English language Only

Please specify any language other than English spoken in your home: 


\section{Continue Here}

8. Which of the following mobile devices, if any, does your child have access to outside of school? This may be a device you use that your child plays with or a device specifically purchased for your child. Please mark all that apply:

$\square$ A smart phone (like an iPhone, Galaxy, or Droid)

$\square$ A handheld video game player (like a Gameboy, PSP, or Nintendo DS)

$\square \quad$ An e-reader (like a Kindle or Nook)

$\square \quad$ A video iPod (like an iTouch)

$\square \quad$ A tablet device (like an iPad, Kindle FIRE, Microsoft Surface, or Galaxy Tab)

$\square$ An educational game player (like LeapPad, Nabi, or VTech InnoTab)

$\square$ Other: Please Specify

$\square$ My child does not have access to a mobile device outside of school

If you own a mobile device, please complete the remainder of the survey.

9. Overall, approximately how many applications ("apps"), have you downloaded onto your mobile device?
$\square$ None
$\square$ Under 5 apps
$\square \quad 5-9$ apps
$\square \quad$ 10-19 apps
20-29 apps
$\square 30+$ apps

10. Of the apps downloaded onto your mobile device, how many does your child use?

$\square$ None

$\square$ Only a few

$\square$ Less than half of them

$\square$ About half of them

$\square$ Most of them

$\square$ All of them 


\section{Continue Here}

11. Approximately how many of the apps are educational apps?
$\square$ None
$\square$ Only a few
$\square$ Less than half of them
$\square$ About half of them
$\square$ Most of them
$\square \quad$ All of them

12. Approximately how often does your child participate in the following activities on a mobile device:

\begin{tabular}{|c|c|c|c|c|c|c|}
\hline & $\begin{array}{l}\text { Several } \\
\text { times a } \\
\text { day }\end{array}$ & Once a day & $\begin{array}{l}\text { Several } \\
\text { times a } \\
\text { week }\end{array}$ & $\begin{array}{l}\text { Once a } \\
\text { week }\end{array}$ & $\begin{array}{l}\text { Less than } \\
\text { once a } \\
\text { week }\end{array}$ & $\begin{array}{l}\text { Has never } \\
\text { done this }\end{array}$ \\
\hline Read Books & & 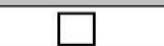 & $\square$ & & $\square$ & $\square$ \\
\hline $\begin{array}{l}\text { Listen to } \\
\text { music }\end{array}$ & & & & & & \\
\hline $\begin{array}{l}\text { Watch TV } \\
\text { shows, movies, } \\
\text { or videos }\end{array}$ & & & & & & \\
\hline $\begin{array}{l}\text { Play games on } \\
\text { a handheld } \\
\text { video game } \\
\text { player (like a } \\
\text { Gameboy, } \\
\text { PSP, or } \\
\text { Nintendo DS) }\end{array}$ & & & & & & \\
\hline $\begin{array}{l}\text { Use apps on a } \\
\text { mobile device }\end{array}$ & & & \begin{tabular}{|l} 
\\
\end{tabular} & & & $\square$ \\
\hline $\begin{array}{l}\text { Look at } \\
\text { photos taken } \\
\text { with the } \\
\text { device }\end{array}$ & & & L & 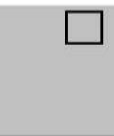 & $\square$ & $\square$ \\
\hline
\end{tabular}




\section{Continue Here}

13. Approximately how often does your child use the following types of apps:

\begin{tabular}{|c|c|c|c|c|c|c|}
\hline & $\begin{array}{l}\text { Several } \\
\text { times a } \\
\text { day }\end{array}$ & Once a day & $\begin{array}{l}\text { Several } \\
\text { times a } \\
\text { week }\end{array}$ & $\begin{array}{l}\text { Once a } \\
\text { week }\end{array}$ & $\begin{array}{l}\text { Less than } \\
\text { once a } \\
\text { week }\end{array}$ & $\begin{array}{l}\text { Has never } \\
\text { done this }\end{array}$ \\
\hline $\begin{array}{l}\text { Educational } \\
\text { games like } \\
\text { puzzles, } \\
\text { memory } \\
\text { games, math, } \\
\text { or reading }\end{array}$ & & & & & & \\
\hline $\begin{array}{l}\text { Games that } \\
\text { are just for } \\
\text { fun }\end{array}$ & & & & & & \\
\hline $\begin{array}{l}\text { Creative apps } \\
\text { for things like } \\
\text { drawing, } \\
\text { making music, } \\
\text { or creating } \\
\text { videos }\end{array}$ & & & & & & \\
\hline $\begin{array}{l}\text { Apps based on } \\
\text { a familiar } \\
\text { character } \\
\text { from a TV } \\
\text { show }\end{array}$ & & & & & & \\
\hline $\begin{array}{l}\text { Apps that play } \\
\text { music }\end{array}$ & & & & & & \\
\hline $\begin{array}{l}\text { Apps that } \\
\text { display photos }\end{array}$ & & & & & & \\
\hline $\begin{array}{l}\text { Other types of } \\
\text { apps }\end{array}$ & & & & & & \\
\hline
\end{tabular}

14. When your child uses a mobile device, how does your child primarily use the device? Please mark one choice.

$\square$ By his/herself, with no adult supervision

$\square$ By his/herself, with adult supervision

$\square$ With me (child's guardian)

$\square \quad$ With siblings or friends 


\section{Continue Here}

For questions 15 and 16, please write your response.

15. Which app or game does your child play most often on a mobile device? Please specify:

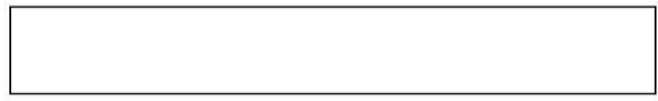

16. Other comments about mobile device or app use you would like to share:

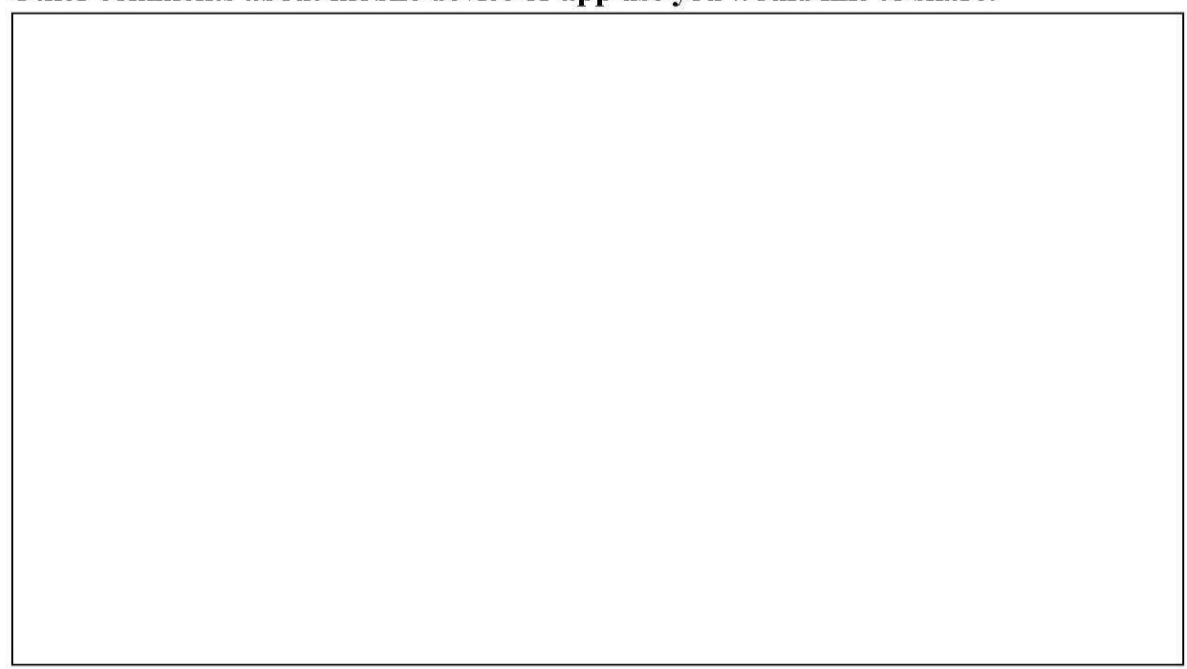


APPENDIX G

SPANISH FAMILY TECHNOLOGY OWNERSHIP AND USE SURVEY 


Encuesta Sobre la Tenencia y el Uso de Tecnología en la Familia
Angela Vatalaro
Esta encuesta está diseñada para estudiar de qué manera los padres de niños de Head
Start usan dispositivos móviles en el hogar. Sus respuestas nos ofrecerán información
valiosa para nuestra investigación. Agradecemos su colaboración y en caso de que
desee hacer alguna pregunta, por favor contáctese con Angela al número 321-432-2942
o a la dirección de e-mail Angela.Vatalaro@ucfedu

Comience Aquí

Para las preguntas 1 y 2, por favor escriba su respuesta.

1. Nombre:

2. Nombre de su niño/niña

Para las preguntas 3-14, por favor marque una cruz en el casillero más apropiado.

3. Relación con el niño/la niña:
$\square \quad$ Madre
$\square \quad$ Padre
$\square$ Abuela
$\square$ Abuelo
$\square$ Padre adoptive
$\square$ Otro: Por Favor Especifique

4. Estaba su niño/niña inscripto en una escuela en este Head Start antes de este año escolar?
$\square$ Si
$\square$ No 


\section{Continúe Aquí}

5. Recibe su niño/niña algún servicio especial? Por favor marque todo lo que corresponda:

$\square \quad$ Terapia ocupacional

$\square \quad$ Terapia del lenguaje oral

$\square \quad$ Terapia de juego

$\square \quad$ Terapia del comportamiento

$\square$ Otro: Por Favor Especifique

$\square \quad$ Mi niño/niña no recibe ningún servicio especial

6. Mi niño/niña corresponde al siguiente grupo étnico:

$\square$ Caucásico

$\square$ Afro-Americano

$\square$ Hispánico

$\square \quad$ Asiático/Isleño del Pacifico

$\square$ Indo-Americano/Nativo de Alaska

$\square$ Otro: Por Favor Especifique

7. Cuál es la principal lengua hablada en su hogar?

$\square \quad$ Solo inglés

$\square$ Principalmente Inglés, pero también alguna otra lengua/otras lenguas

$\square$ Principalmente otra lengua/otras lenguas, pero también algo de Inglés

$\square \quad$ A Solo una lengua que no es Inglés

Por favor especifique otra lengua que no sea Inglés que se hable en su hogar: 


\section{Continúe Aquí}

8. A cuál de los siguientes dispositivos móviles tiene su niño/niña acceso fuera de la escuela? Este puede ser un dispositivo usado por adultos y que el niño/la niña usa para jugar, o un dispositivo específicamente comprado para uso del niño/de la niña: Por favor, marque todo lo que corresponda:

$\square$ Un teléfono inteligente (como iPhone, Galaxy, or Droid)

$\square$ Juegos de video (como Gameboy, PSP, o Nintendo DS)

$\square \quad$ Un dispositivo de lectura (como Kindle o Nook)

$\square \quad$ Un iPod video (como un iTouch)

$\square$ Una tablet (como un iPad, Kindle FIRE, Microsoft Surface, o Galaxy Tab)

$\square$ Un juego educativo (como LeapPad, Nabi, o VTech InnoTab)

$\square$ Otro: Por Favor Especifique

$\square \mathrm{Mi}$ niño/niña no tiene acceso a dispositivos móviles fuera de la escuela

Si usted posee un dispositivo móvil, por favor complete el resto de la encuesta.

9. Cuántas aplicaciones o "apps" ha bajado a su dispositivo móvil?

$\square$ Ninguna

$\square$ Menos de 5 aplicaciones

$\square$ 5-9 aplicaciones

$\square$ 10-19 aplicaciones

$\square \quad 0-29$ aplicaciones

$\square \quad 30+$ aplicaciones

10. De las aplicaciones que usted ha bajado a su dispositivo móvil, cuántas usa su niño/niña?

$\square$ Ninguna

$\square$ Solo unas cuantas

$\square$ Menos de la mitad de ellas

$\square$ Alrededor de la mitad de ellas

$\square$ La mayoría de ellas

$\square$ Todas ellas 


\section{Continúe Aquí}

11. Cuántas de la aplicaciones son educativas?
$\square$ Ninguna
$\square$ Solo unas cuantas
$\square$ Menos de la mitad de ellas
$\square$ Alrededor de la mitad
$\square \quad$ La mayoría de ellas
$\square$ Todas ellas

12. Cuán a menudo participa su niño/niña en las siguientes actividades con un dispositivo móvil:

\begin{tabular}{|c|c|c|c|c|c|c|}
\hline & $\begin{array}{l}\text { Muchas } \\
\text { veces al } \\
\text { dia }\end{array}$ & $\begin{array}{l}\text { Una vez al } \\
\text { dia }\end{array}$ & $\begin{array}{l}\text { Muchas } \\
\text { veces por } \\
\text { semana }\end{array}$ & $\begin{array}{l}\text { Una } \\
\text { vez a la } \\
\text { semana }\end{array}$ & $\begin{array}{l}\text { Menoas } \\
\text { de una } \\
\text { vez por } \\
\text { semana }\end{array}$ & Nunca \\
\hline Leer libros & & & & & & \\
\hline $\begin{array}{l}\text { Escuchar } \\
\text { música }\end{array}$ & & & & & & \\
\hline $\begin{array}{l}\text { Mirar } \\
\text { televisión, } \\
\text { shows, } \\
\text { películas o } \\
\text { videos }\end{array}$ & & & & & & \\
\hline $\begin{array}{l}\text { Jugar juegos } \\
\text { de video } \\
\text { (como } \\
\text { Gameboy, } \\
\text { PSP, o } \\
\text { Nintendo DS) }\end{array}$ & & & & & & \\
\hline $\begin{array}{l}\text { Usar } \\
\text { aplicaciones } \\
\text { en un } \\
\text { dispositivo } \\
\text { móvil }\end{array}$ & & & & & & \\
\hline $\begin{array}{l}\text { Mirar fotos } \\
\text { tomadas con } \\
\text { el dispositivo }\end{array}$ & & & & & 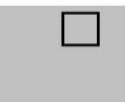 & 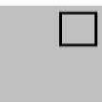 \\
\hline
\end{tabular}




\section{Continúe Aquí}

13. Cuán a menudo usa su niño/niña las siguientes aplicaciones:

\begin{tabular}{|l|c|c|c|c|c|c|}
\hline & $\begin{array}{l}\text { Muchas } \\
\text { veces al } \\
\text { dia }\end{array}$ & $\begin{array}{l}\text { Una vez al } \\
\text { dia }\end{array}$ & $\begin{array}{l}\text { Muchas } \\
\text { veces por } \\
\text { semana }\end{array}$ & $\begin{array}{l}\text { Una } \\
\text { vez a la } \\
\text { semana }\end{array}$ & $\begin{array}{l}\text { Menos de } \\
\text { una vez } \\
\text { por } \\
\text { semana }\end{array}$ & \begin{tabular}{c} 
Nunca \\
\hline $\begin{array}{l}\text { Juegos } \\
\text { educativos } \\
\text { (como } \\
\text { rompecabezas } \\
\text { juegos de } \\
\text { memoria, } \\
\text { matemáticas y } \\
\text { lectura) }\end{array}$
\end{tabular} \\
\hline $\begin{array}{l}\text { Juegos para } \\
\text { diversión }\end{array}$ & $\square$ & $\square$ & $\square$ & $\square$ & $\square$ & $\square$ \\
$\begin{array}{l}\text { Aplicaciones } \\
\text { creativas para } \\
\text { dibujo, música } \\
\text { o crear videos }\end{array}$ & $\square$ & $\square$ & $\square$ & $\square$ & $\square$ & $\square$ \\
$\begin{array}{l}\text { Aplicaciones } \\
\text { basadas en un } \\
\text { personaje de } \\
\text { un programa } \\
\text { de TV } \\
\begin{array}{l}\text { Aplicaciones } \\
\text { para música } \\
\text { Aplicaciones } \\
\text { que muestran } \\
\text { fotos } \\
\text { Otras } \\
\text { aplicaciones }\end{array}\end{array}$
\end{tabular}

14. Cómo usa su niño/niña el dispositivo móvil cuando lo hace? Por favor marque una opción.

$\square$ Solo/sola sin la supervisión de un adulto

$\square$ Solo/sola con la supervisión de un adulto

$\square$ Con su guardián

$\square$ Con hermanos y amigos 
Rev. 1.19 .15

Page 6 of 6

\section{Continúe Aquí}

Para las preguntas 15 y 16 por favor escriba su respuesta.

15. Cuál aplicación o juego juega su hijo más a menudo en un dispositivo móvil? Por favor especifique.

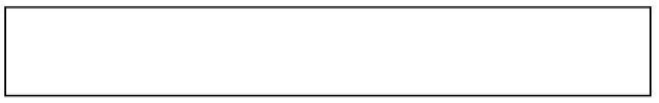

16. Otros comentarios sobre el uso de dispositivos móviles y aplicaciones que le gustaría compartir:

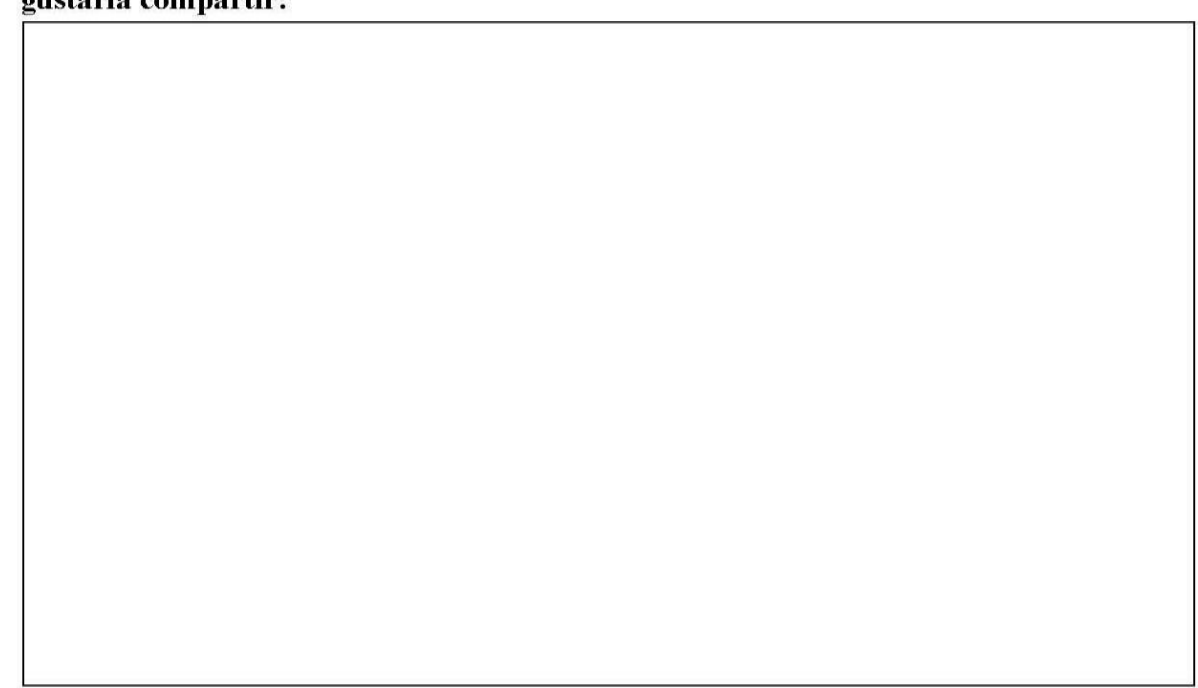

Gracias por completar esta encuesta. 
APPENDIX $\mathrm{H}$

TEACHER TECHNOLOGY PERCEPTION AND USE SURVEY 
Teacher Technology Perception and Use Survey Angela Vatalaro

This survey is designed to find out the ways in which Head Start teachers use mobile devices and applications ("apps") in the classroom. Your responses will offer valuable insight. Your help is greatly appreciated.

\section{Start Here}

For questions 1-4, please write your response.

1. Your Code:

2. Your age: $\square$ Years

3. Number of years you have been in the teaching profession:

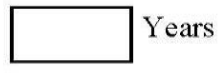

4. Number of years you have taught at a Head Start Center:

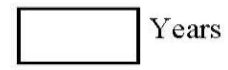

For questions 5-18, please mark an $X$ in the most appropriate box.

5. My ethnic background is:

$\square$ Caucasian

$\square$ African American

$\square$ Hispanic

$\square$ Asian/Pacific Islander

$\square$ American Indian/Alaskan Native

$\square$ Other: Please Specify

6. What type of early childhood professional preparation do you have?

$\square \quad$ No formal early childhood education preparation

$\square$ Some early childhood education coursework, but no degree

$\square$ Child Development Associate (CDA) credential

$\square \quad$ Associate's degree in early childhood education

$\square$ Bachelor's degree in early childhood education

$\square$ Graduate work in early childhood education, but no degree

$\square$ Graduate degree in early childhood education 


\section{Continue Here}

7. On a typical day, approximately how many minutes do you spend using mobile device (iPad) apps with the children in your classroom?

$\square$ Less than 10 minutes

$\square$ About 10 minutes

$\square$ About 20 minutes

$\square$ About 30 minutes

$\square$ About 40 minutes

$\square$ About 50 minutes

$\square$ About 60 minutes

$\square$ More than 60 minutes

Please specify how many minutes if more than 60

8. How confident are you at using mobile device apps with children in developmentally appropriate ways?

$\square$ Not confident at all

$\square$ Not very confident

$\square$ Neutral

$\square$ Somewhat confident

$\square$ Very confident

9. Please indicate the learning areas where you are integrating mobile device apps into your practice. Please check all that apply:

$\square$ Language and literacy

$\square$ Mathematical thinking and numeracy

$\square$ Scientific thinking

$\square$ Social studies

$\square$ Arts

$\square$ Health and well-being

$\square$ Social and emotional development

$\square$ Other: Please Specify 


\section{Continue Here}

10. How are mobile device apps used in your early childhood classroom?

All teacher directed/guided learning activities

$\square$ Mostly teacher directed/guided, with some time for child initiated learning activities

$\square$ About half teacher directed/guided and half child initiated learning activities

$\square$ Mostly child initiated, with some time for teacher directed/guided learning activities

$\square \quad$ All child initiated learning activities

11. What is the earliest age you think is appropriate to introduce child ren to mobile devices in an early childhood program?

$\square \quad 0-2$ years old

$\square$ 3-4 years old

$\square \quad 5-6$ years old

$\square \quad 7-8$ years old

$\square$ Not appropriate for early childhood classrooms/programs

12. What types of professional development/support have you received specifically in using mobile device apps in your classroom? Please check all that apply:

$\square$ Attended in-person workshop/trainings

$\square$ Engaged in online workshops/trainings

$\square$ Used computer-based self-paced tutorials

$\square$ Received help from a mentor or colleague

$\square$ Found help from online blogs or forums

$\square \quad$ I have not receive any professional development/support in using mobile device apps

$\square$ Other: Please Specify 


\section{Continue Here}

13. To what extent was the professional development/support useful or useless?

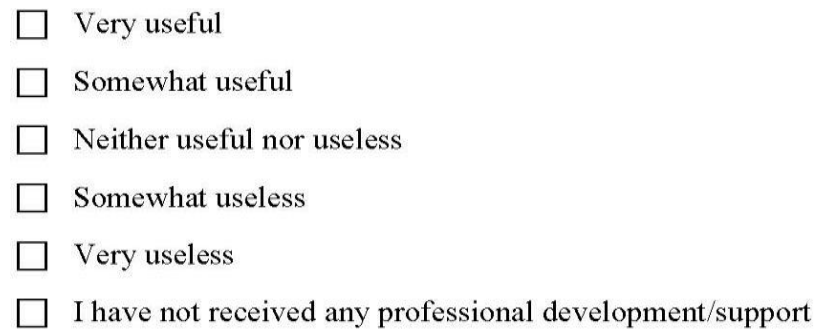

14. How desirable is professional development training to help you know how to use mobile device apps in your classroom?

$\square$ Very desirable

$\square$ Somewhat desirable

$\square$ Not at all desirable

15. In March 2012, the National Association for the Education of Young Child ren and the Fred Rogers Center for Early Learning and Children's Media at Saint Vincent College released a policy statement on the use of technology in early childhood education. Have you reviewed this statement?

$\square$ No

$\square$ Yes

If yes, please briefly describe if and how the position statement affects your practice:

16. How much do you agree or disagree with the following: Mobile media and apps are tools that can promote effective learning and development when they are used intentionally by early childhood educators, within the framework of developmentally appropriate practice, to support learning goals established for individual children.

$\square$ Strongly disagree

$\square$ Disagree

$\square$ Neither agree nor disagree

$\square$ Agree

$\square$ Strongly agree 


\section{Continue Here}

17. Please indicate how much you agree or disagree with the following statements in regards to your early childhood classroom:

\begin{tabular}{|c|c|c|c|c|c|}
\hline & $\begin{array}{l}\text { Strongly } \\
\text { Disagree }\end{array}$ & Disagree & $\begin{array}{c}\text { Neither } \\
\text { Agree } \\
\text { Nor } \\
\text { Disagree }\end{array}$ & Agree & $\begin{array}{c}\text { Strongly } \\
\text { Agree }\end{array}$ \\
\hline $\begin{array}{l}\text { Mobile device } \\
\text { apps can help } \\
\text { develop } \\
\text { children's } \\
\text { critical } \\
\text { thinking skills }\end{array}$ & & & & & \\
\hline $\begin{array}{l}\text { Mobile device } \\
\text { apps can } \\
\text { improve } \\
\text { individualized } \\
\text { learning }\end{array}$ & & & & & \\
\hline $\begin{array}{l}\text { Mobile device } \\
\text { apps are } \\
\text { useful for } \\
\text { social } \\
\text { interactions } \\
\text { among } \\
\text { children }\end{array}$ & & & & & \\
\hline $\begin{array}{l}\text { Mobile device } \\
\text { apps can help } \\
\text { to develop } \\
\text { children's } \\
\text { content } \\
\text { knowledge }\end{array}$ & & & & & \\
\hline $\begin{array}{l}\text { Mobile device } \\
\text { apps can } \\
\text { improve } \\
\text { documentation } \\
\text { of children's } \\
\text { learning }\end{array}$ & & & & & \\
\hline $\begin{array}{l}\text { Other ways } \\
\text { mobile device } \\
\text { apps can be } \\
\text { useful: Please } \\
\text { specify }\end{array}$ & & & & & \\
\hline
\end{tabular}




\section{Continue Here}

18. Please indicate how much you agree or disagree with the following statements:

\begin{tabular}{|c|c|c|c|c|c|}
\hline & $\begin{array}{l}\text { Strongly } \\
\text { Disagree }\end{array}$ & Disagree & $\begin{array}{l}\text { Neither } \\
\text { Agree } \\
\text { Nor } \\
\text { Disagree }\end{array}$ & Agree & $\begin{array}{c}\text { Strongly } \\
\text { Agree }\end{array}$ \\
\hline $\begin{array}{l}\text { Mobile device } \\
\text { app use is } \\
\text { limited by } \\
\text { insufficient or } \\
\text { lack of } \\
\text { funding }\end{array}$ & & & & & \\
\hline $\begin{array}{l}\text { Mobile device } \\
\text { app use is } \\
\text { limited by my } \\
\text { lack of time to } \\
\text { use technology } \\
\text { in my } \\
\text { classroom }\end{array}$ & & & & & \\
\hline $\begin{array}{l}\text { Mobile device } \\
\text { app use is } \\
\text { limited } \\
\text { because I am } \\
\text { unsure how to } \\
\text { make } \\
\text { technology } \\
\text { relevant to } \\
\text { subject areas }\end{array}$ & & & & & \\
\hline $\begin{array}{l}\text { Mobile device } \\
\text { app use is } \\
\text { limited by my } \\
\text { lack of } \\
\text { comfort with } \\
\text { technology }\end{array}$ & & & & & \\
\hline $\begin{array}{l}\text { Mobile device } \\
\text { app use is } \\
\text { limited by } \\
\text { children's } \\
\text { inability to } \\
\text { appropriately } \\
\text { use technology }\end{array}$ & & & & & \\
\hline $\begin{array}{l}\text { Other ways } \\
\text { mobile device } \\
\text { app use is } \\
\text { limited: Please } \\
\text { specify }\end{array}$ & & & & & \\
\hline
\end{tabular}


Continue Here

For question 19, please write your response.

19. Other comments about mobile device or app use in your early childhood classroom that you would like to share:

Thank you for completing this survey. 
APPENDIX I

TEACHER SELF-REPORT AND OBSERVATION CHECKLIST 
Classroom \#

Form for App Use in the Classroom

Date

Name of Person Completing This Form

1. At what time(s) of day were apps used (mark all that apply)?

$\square \quad$ Morning Journal Writing

$\square$ Music \& Movement

$\square$ Morning Circle Time

$\square$ End of Day Circle Time

$\square$ Morning Small Group

$\square \quad$ Morning Work Time

$\square$ Story Time

$\square \quad$ Clean up/Transition

$\square \quad$ Afternoon Journal Writing

$\square \quad$ Afternoon Work Time

$\square \quad$ Afternoon Small Group

$\square$ Outside Time

$\square \quad$ Other (please specify):

Apps were not used today

2. To what degree did app use support children's learning?

$\square \quad$ Very
$\square \quad$ Somewhat
$\square \quad$ Not At All

3. To what degree did app use encourage children to be actively involved in their learning?

$\square$ Very

$\square$ Somewhat

$\square$ Not At All

4. To what degree did app use encourage children to be creative?

$\square$ Very

$\square$ Somewhat

$\square$ Not At All

5. To what degree did app use support daily classroom themes and activities?

$\square$ Very

$\square$ Somewhat

Not At All

6. To what degree did app use encourage children to collaborate with one another?

$\begin{array}{ll}\square & \text { Very } \\ \square & \text { Somewhat } \\ \square \quad \text { Not At All }\end{array}$

7. Which app or apps were used? If children used independently, press the "Home" button twice to see which apps were used.

\begin{tabular}{|c|c|}
\hline Apps used on the iPad Air & Apps used on the iPad Mini \\
\hline & \\
\hline
\end{tabular}

8. Other observations, ideas, or struggles that arose from app use: 


\section{REFERENCES}

Administration for Children \& Families. (2014). Fact sheet: New steps by the Administration to help parents "bridge the word gap". Administration for Children \& Families. Retrieved from https://www.whitehouse.gov/sites/default/files/microsites/ostp/federal_word_gap_ fact_sheet_final.pdf

Alessi, N. E., \& Alessi, V. A. (2008). New media and an ethics analysis model for child and adolescent psychiatry. Child and Adolescent Psychiatric Clinics of North America, 17(1), 67-92. doi:10.1016/j.chc.2007.08.002

American Academy of Pediatrics Committee on Public Education. (1999). Media education. Pediatrics, 104(2), 341-343. doi:10.1542/peds.2010-1636

American Academy of Pediatrics Council on Communications and Media. (2011). Media use by children younger than 2 years. Pediatrics, 128(5), 1040-1045. doi:10.1542/peds.2011-1753

Beschorner, B., \& Hutchison, A. (2013). iPads as a literacy teaching tool in early childhood. International Journal of Education in Mathematics, Science and Technology, 1(1), 16-24. Retrieved from ERIC database. (ED543276)

Blackwell, C. K., Lauricella, A. R., \& Wartella, E. (2014). Technology in early childhood. Retrieved from http://web5.soc.northwestern.edu/cmhd/wpcontent/uploads/2013/06/Final-NAEYC-Survey-2.pdf

Bloom, L. (1991). Language development from two to three. New York: Cambridge University Press. 
Bloom, P. (2000). How children learn the meanings of words. Cambridge, MA: The MIT Press.

Bochner, S., \& Jones, J. (2003). Child language development: Learning to talk (2nd ed.). London: Whurr.

Boeglin-Quintana, B., \& Donovan, L. (2013). Storytime using iPods: Using technology to reach all learners. TechTrends, 57(6), 49-56. doi:10.1007/s11528-013-0701-x

Bredekamp, S. (Ed.). (1987). Developmentally appropriate practice in early childhood programs serving children from birth through age 8, Washington, DC: National Association for the Education of Young Children.

Camilli, G., Vargas, S., Ryan, S., \& Barnett, W. S. (2010). Meta-analysis of the effects of early education interventions on cognitive and social development. Teachers College Record, 112(3), 579-620. Retrieved from http://www.tcrecord.org/library

Cardon, T. A. (2012). Teaching caregivers to implement video modeling imitation training via iPad for their children with autism. Research in Autism Spectrum Disorders, 6, 1389-1400. doi:10.1016/j.rasd.2012.06.002

Cartmill, E. A., Armstrong, B. F., Gleitman, L. R., Goldin-Meadow, S., Medina, T. N., \& Trueswell, J. C. (2013). Quality of early parent input predicts child vocabulary 3 years later. Proceedings of the National Academy of Sciences of the United States of America, 110(28), 11278-11283. doi:10.1073/pnas.1309518110

Chai, Z., Vail, C. O., \& Ayres, K. M. (2015). Using an iPad application to promote early literacy development in young children with disabilities. The Journal of Special Education, 48(4), 268-278. doi:10.1177/0022466913517554 
Chang, Y. M., Mullen, L., \& Stuve, M. (2005). Are PDAs pedagogically feasible for young children? Examining the age-appropriateness of handhelds in a kindergarten classroom. T.H.E. Journal, 32(8), 40-43. Retrieved from ERIC database. (EJ711538)

Charlton, T., Panting, C., \& Hannan, A. (2002). Mobile telephone ownership and usage among 10- and 11-year-olds. Emotional and Behavioural Difficulties, 7(3), 152163. doi:10.1080/13632750200507013

Christakis, D. A. (2014). Interactive media use at younger than the age of 2 years: Time to rethink the American Academy of Pediatrics guideline? JAMA Pediatrics, E1E2. doi:10.1001/jamapediatrics.2013.5081

Ciampa, K., \& Gallagher, T. L. (2013). Professional learning to support elementary teachers' use of the iPod Touch in the classroom. Professional Development in Education, 39(2), 201-221. doi:10.1080/19415257.2012.749802

Clements, D. (1998). Young children and technology. Paper presented at the Forum on Early Childhood Science, Mathematics, and Technology Education. Washington, DC. Retrieved from ERIC database. (ED416991)

Cohen, J. (1988). Statistical power analysis for the behavioral sciences (2nd ed.). Hillsdale, NJ: Erlbaum.

Common Sense Media. (2013). Zero to eight: Children's media use in America 2013. Retrieved from https://www.commonsensemedia.org/sites/default/files/research/zero-to-eight2013.pdf 
Couse, L. J., \& Chen, D. W. (2010). A tablet computer for young children? Exploring its viability for early childhood education. Journal of Research on Technology in Education, 43(1), 75-98. doi:10.1080/15391523.2010.10782562

Cubelic, C. C., \& Larwin, K. H. (2014). The use of iPad technology in the kindergarten classroom: A quasi-experimental investigation of the impact on early literacy skills. Comprehensive Journal of Educational Research, 2(4), 47-59.

Dawson, C., \& Rakes, G. C. (2003). The influence of principals' technology training on the integration of technology into schools. Journal of Research on Technology in Education, 36(1), 29-49. doi:10.1080/15391523.2003.10782401

Dunn, L. M., \& Dunn, D. M. (2007). Peabody picture vocabulary test (4th ed.). Bloomington, MN: Pearson.

Falloon, G. (2014). What's going on behind the screens? Researching young students' learning pathways using iPads. Journal of Computer Assisted Learning, 30, 318336. doi:10.1111/jcal.12044

Falloon, G. (2015). What's the difference? Learning collaboratively using iPads in conventional classrooms. Computers \& Education, 84, 62-77. doi:10.1016/j.compedu.2015.01.010

Faul, F., Erdfelder, E., Lang, A. G., \& Buchner, A. (2007). G*Power: Statistical Power Analyses for Windows and Mac (Version 3.1.9.2) [Software]. Available from http://www.gpower.hhu.de/en.html 
Fillmore, L. W., \& Snow, C. E. (2000). What teachers need to know about language. Washington, D.C.: Center for Applied Linguistics. Retrieved from ERIC database. (ED444379)

Fritz, M. L. (2005). Students using handheld computers to learn collaboratively in a first grade classroom (Doctoral dissertation). Retrieved from ERIC database. (ED498656)

Gall, M. D., Gall, J. P., \& Borg, W. R. (2007). Educational research: An introduction (8th ed.). Boston, MA: Allyn and Bacon.

Geist, E. A. (2012). A qualitative examination of two year-olds interaction with tablet based interactive technology. Journal of Instructional Psychology, 39(1), 26-35. Retrieved from ERIC database. (EJ979005)

Gulchak, D. J. (2008). Using a mobile handheld computer to teach a student with an emotional and behavioral disorder to self-monitor attention. Education and Treatment of Children, 31(4), 567-581. doi:10.1353/etc.0.0028

Hammerstrøm, K., Wade, A., \& Jørgensen, A. K. (2010, Supplement 1). Searching for studies: A guide to information retrieval for Campbell Systematic Reviews. Campbell Systematic Reviews. Retrieved from http://www.campbellcollaboration.org/lib/download/969/

Harms, T., Clifford, R, M., \& Cryer, D. (2005). Early childhood environment rating scale-revised (ECERS-R). New York: Teachers College Press.

Hart, B., \& Risley, T. R. (1995). Meaningful differences in the everyday experience of young American children. Baltimore, MD: Paul H. Brookes. 
Hart, B., \& Risley, T. R. (2003). The early catastrophe: The 30 million word gap by age 3. American Educator, 27(1), 4-9. Retrieved from http://www.campbellcollaboration.org/lib/download/969/http://www.aft.org/pdfs/ americaneducator/spring2003/TheEarlyCatastrophe.pdf

Head Start Act, as amended 2007, 42 USC $§ 9801$. Retrieved from http://eclkc.ohs.acf.hhs.gov/hslc/standards/law/HS_Act_2007.pdf

Hoffman, J. L., \& Paciga, K. A. (2014). Click, swipe, and read: Sharing e-Books with toddlers and preschoolers. Early Childhood Education Journal, 42(6), 379-388. doi:10.1007/s10643-013-0622-5

Hsu, I., \& Geist, E. A. (2012). A qualitative examination of social interaction during cooperative computer activities. Education, 133(2), 383-390. Retrieved from ERIC database. (EJ992032)

Hylén, J. (2015). Mobile learning and social media in adult learning. European Commission: Vocational Training and Adult Education. Retrieved from http://www.janhylen.se/wp-content/uploads/2015/04/Mobile-Learning-andSocial-Media-in-Adult-Learning.pdf International Society for Technology Education (ISTE). (2007). ISTE standards $\bullet$. Retrieved from http://www.iste.org/docs/pdfs/20-14_ISTE_Standards-S_PDF.pdf International Society for Technology Education (ISTE). (2008). ISTE standards $\bullet$. Retrieved from http://www.iste.org/docs/pdfs/20-14_ISTE_Standards-T_PDF.pdf International Society for Technology Education (ISTE). (2009). ISTE standards $\bullet$. Retrieved from http://www.iste.org/docs/pdfs/20-14_ISTE_Standards-A_PDF.pdf 
Kuhlman, W. D., Danielson, K. E., Campbell, E. J., \& Topp, N. W. (2005). Implementing handheld computers as tools for first-grade writers. Computers in the Schools: Interdisciplinary Journal of Practice, Theory, and Applied Research, 22(3-4), 173-185. doi:10.1300/J025v22n03_14

Lan, Y., Sung, Y., \& Chang, K. (2007). A mobile-device-supported peer-assisted learning system for collaborative early EFL reading. Language Learning \& Technology, 11(3), 130-151. Retrieved from ERIC database. (EJ805453)

LeapFrog Enterprises. (2014). LeapPad ${ }^{\mathrm{TM}}$ Ultra: The ultimate kids' learning tablet. Retrieved from http://www.leapfrog.com/en-us/store/p/leappad-ultra/_/A$\operatorname{prod} 33200$

Leung, L., \& Wei, R. (1999). Who are the mobile phone have-nots? New Media and Society 1(2), 209-226. doi:10.1177/1461444899001002003

Levin, D. E. (2013). Beyond remote-controlled childhood: Teaching young children in the media age. Washington, DC: National Association for the Education of Young Children.

Lomax, R. G., \& Hahs-Vaughn, D. L. (2012). An introduction to statistical concepts (3rd ed.). New York: Routledge.

Lorah, E. R., \& Parnell, A. (2014). The acquisition of letter writing using a portable multi-media player in young children with developmental disabilities. Journal of Developmental \& Physical Disabilities, 26(6), 655-666. doi:10.1007/s10882-0149386-0 
Magagna-McBee, C. A. (2010). The use of handheld devices for improved phonemic awareness in a traditional kindergarten classroom (Doctoral dissertation). Available from ProQuest Dissertations and Theses database. (UMI No. 3404418)

Margolis, J. L., Nussbaum, M., Rodriguez, P., \& Rosas, R. (2006). Methodology for evaluating a novel education technology: A case study of handheld video games in Chile. Computers and Education, 46(2), 174-191. doi:10.1016/j.compedu.2004.07.007

Marklund, L. (2015). Preschool teachers' informal online professional development in relation to educational use of tablets in Swedish preschools. Professional Development in Education, 41(2), 236-253. doi:10.1080/19415257.2014.999380 Masoumi, D. (2015). Preschool teachers' use of ICTs: Towards a typology of practice. Contemporary Issues in Early Childhood, 16(1), 5-17. doi:10.1177/1463949114566753

Miller, P. H. (2011). Theories of developmental psychology (5th ed.). New York: Worth. Muller, A. A., \& Perlmutter, M. (1985). Preschool children’s problem-solving interactions at computers and jigsaw puzzles. Journal of Applied Developmental Psychology, 6, 173-186. Retrieved from http://deepblue.lib.umich.edu/bitstream/handle/2027.42/25718/0000? sequence=1 National Association for the Education of Young Children (NAEYC) and the Fred Rogers Center for Early Learning and Children's Media at Saint Vincent College. (2012). Technology and interactive media as tools in early childhood programs 
serving children from birth through age 8. Retrieved from http://www.naeyc.org/files/naeyc/PS_technology_WEB.pdf

Neumann, M. M. (2014). An examination of touch screen tablets and emergent literacy in Australian pre-school children. Australian Journal of Education, 58(2), 109-122. doi: $10.1177 / 0004944114523368$

Nuttall, J., Edwards, S., Mantilla, A., Grieshaber, S., Wood, E. (2015). The role of motive objects in early childhood teacher development concerning children's digital play and play-based learning in early childhood curricula. Professional Development in Education, 41(2), 222-235. doi:10.1080/19415257.2014.990579

O'Mara, J., \& Laidlaw, L. (2011). Living in the iWorld: Two literacy researchers reflect on the changing texts and literacy practices of childhood. English Teaching: Practice and Critique, 10(4), 149-159.

Partnership for $21^{\text {st }}$ Century Skills. (2011). P21 common core toolkit: A guide to aligning the common core state standards with the framework for $21^{\text {st }}$ century skills. Retrieved from http://www.p21.org/storage/documents/P21CommonCoreToolkit.pdf

Piaget, J. (1977). The essential Piaget. H. E. Gruber, \& J. J. Vonèche. (Eds.). London: Routledge \& Kegan Paul.

Plowman, L., \& Stevenson, O. (2012). Using mobile phone diaries to explore children's everyday lives. Childhood: A Global Journal of Child Research, 19(4), 539-553. doi:10.1177/0907568212440014 
Puerling, B. (2012). Teaching in the digital age: Smart tools for age 3 to grade 3. St. Paul, MN: Red Leaf Press.

Radesky, J. S., Schumacher, J., \& Zuckerman, B. (2015). Mobile and interactive media use by young children: The good, the bad, and the unknown. Pediatrics, 135(1), 1-3. doi:10.1542/peds.2014-2251

Rice, M. L., Huston, A. C., Truglio, R., \& Wright, J. (1990). Words from "Sesame Street”: Learning vocabulary while viewing. Developmental Psychology, 26(3), 421-428. doi:10.1037/0012-1649.26.3.421

Rideout, V. (2014). Learning at home: Families' educational media use in America. New York: The Joan Ganz Cooney Center at Sesame Workshop. Retrieved from http://www.joanganzcooneycenter.org/wpcontent/uploads/2014/01/jgcc_learningathome.pdf

Sang, G., Valcke, M., van Braak, J., \& Tondeur, J. (2010). Student teachers' thinking processes and ICT integration: Predictors of prospective teaching behaviors with educational technology. Computers \& Education, 54, 103-112. doi:10.1016/j.compedu.2009.07.010

Simon, F., \& Nemeth, K. (2012). Digital decisions: Choosing the right technology tools for early childhood education. Lewisville, NC: Gryphon House.

Snow, C. E., \& Tabors, P. O. (1993). Language skills that relate to literacy development. In B. Spodek, \& O. N. Saracho (Eds.), Language and literacy in early childhood education (pp. 1-20). New York: Teachers College Press. 
Sweetser, P., Johnson, D., Ozdowska, A., \& Wyeth, P. (2012). Active versus passive screen time for young children. Australasian Journal of Early Childhood, 37(4), 94-98.

Tamim, R. M., Bernard, R. M., Borokhovski, E., Abrami, P. C., \& Schmid, R. F. (2011). What forty years of research says about the impact of technology on learning: A second-order meta-analysis and validation study. Review of Educational Research, 81(1), 4-28. doi:10.3102/0034654310393361

Tangible Play, Inc. (2014). Osmo. Retrieved from https://www.playosmo.com/

Tarasuik, J. C., Galligan, R., \& Kaufman, J. (2011). Almost being there: Video communication with young children. PLoS One, 6(2), 1-8. doi:10.1371/journal.pone.0017129

Teichert, L., \& Anderson, A. (2014). 'I don't even know what blogging is': The role of digital media in a five-year-old girl's life. Early Child Development and Care, 184(11), 1677-1691. doi:10.1080/03004430.2013.875540

U.S. Department of Education. (2010). Transforming American education: Learning powered by technology. Retrieved from http://www.ed.gov/sites/default/files/NETP-2010-final-report.pdf

U.S. Department of Health and Human Services. (2014). 2014 poverty guidelines. Retrieved from http://aspe.hhs.gov/poverty/14poverty.cfm Vatalaro, A. (2015a). iPad receptive vocabulary assessment. Unpublished assessment. Vatalaro, A. (2015b). iPad expressive vocabulary assessment. Unpublished assessment. 
Vygotsky, L. S. (1978). Mind in society: The development of higher psychological processes. M. Cole, V. John-Steiner, S. Scribner, \& E. Souberman (Eds.). Cambridge, MA: Harvard University Press.

Williams, K. T. (2007). Expressive vocabulary test (2nd ed.). Bloomington, MN: Pearson.

Wohlwend, K. E. (2009). Early adopters: Playing new literacies and pretending new technologies in print-centric classrooms. Journal of Early Childhood Literacy, 9(2), 117-140. doi:10.1177/1468798409105583

Yelland, N. (1999). Technology as play. Early Childhood Education Journal, 26(4), 217 220. doi:10.1023/A:1022907505087

Zurita, G., \& Nussbaum, M. (2004). A constructivist mobile learning environment supported by a wireless handheld network. Journal of Computer Assisted Learning, 20(4), 235-243. doi:10.1111/j.1365-2729.2004.00089.x 